NBSIR 86-3443

\section{Rail Straightness Metrology at the David W. Taylor Model Basin}

W. Tyler Estler

Bruce R. Borchardt

Charles J. Fronczek

Ralph C. Veale

U.S. DEPARTMENT OF COMMERCE

National Bureau of Standards

National Engineering Laboratory

Center for Manufacturing Engineering

Precision Engineering Division

Gaithersburg, MD 20899

October 1986

Work Performed for:

- QC - artment of the Navy

100 id W. Taylor Naval Ship R \& D Center

.456

hesda, MD 20084 
NATIONAL INSTITUTE OF STANDARDS \& TECHNOLOGY

Research Information Center

Gaithersburg, $\mathrm{MD} 20899$ 


\title{
RAIL STRAIGHTNESS METROLOGY AT THE DAVID W. TAYLOR MODEL BASIS
}

\author{
W. Tyler Estler \\ Bruce R. Borchardt \\ Charles J. Fronczek \\ Ralph C. Veale
}

U.S. DEPARTMENT OF COMMERCE

National Bureau of Standards

National Engineering Laboratory

Center for Manufacturing Engineering

Precision Engineering Division

Gaithersburg, MD 20899

October 1986

Work Performed for:

Department of the Navy

David W. Taylor Naval Ship R \& D Center

Bethesda, MD 20084

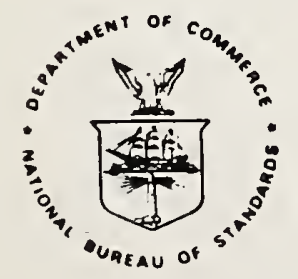

U.S. DEPARTMENT OF COMMERCE, Malcolm Baldrige, Secretary NATIONAL BUREAU OF STANDARDS, Ernest Ambler, Director 

We present results of field measurements of the horizontal and vertical straightness errors of three drive rails at the David Taylor Naval Ship Research and Development Center. The three measured rails are the main rails of Basin No. 1 (1008 feet) and Basin No. 2 (1296 feet), and the South rail of the High-speed Basin (2640 feet). In addition to the straightness measurements, we also conducted a brief series of local flatness measurements near the scarf joints on Basins 1 and 2. These joints show a very systematic pattern of wear. 

The David $W$. Taylor Naval Ship Research and Development Center (DTNSRDC) contains the primary U.S. Navy facilities for the testing of model hulls as well as nautical propulsion and steering components. These facilities include three towing basins together with associated towing carriages. The design, construction, and early trials in one of the basins are described in great detail in a series of papers by Cpt. H. E. Saunders [1].

In this report we present the results of field measurements of the horizontal and vertical straightness errors of the main rails * of the two low-speed basins and of the south rail of the high-speed basin. These measurements were made during December 1985 through March 1986 by a team from the Precision Engineering Division of the National Bureau of Standards (NBS). In addition to the straightness errors we also conducted a brief series of measurements to examine the nature of the systematic pattern of wear which has occurred at the 45-degree scarf joints between rail sections on the low-speed basins. These measurements are discussed in the last section of this report.

II. DESIGN SPECIFICATIONS

The specifications for the shape and alignment of the towing basin rails are given by Saunders. Following the convention used at NBS we refer to transverse deviations in the rails from an ideal line in space as straightness errors. In particular, we are concerned with horizontal straightness errors, which are errors perpendicular to a vertical plane through the center of the basins, and vertical straightness errors which are parallel to this vertical plane at right angles to the horizontal errors.

In most applications, such as straightness measurements on precision machines, the ideal line with respect to which straightness errors are measured is a straight line in space. At DTNSRDC the vertical alignment of the rails was accomplished using the water surface in the basins as a datum surface while a long stretched wire served as the horizontal reference. Thus the top surface of the rails is designed to be level rather than flat and the ideal line is an arc of a circle with a radius equal to the radius of the Earth. It is not clear from Saunders' descriptions whether the design specifications for the main rail alignments apply to the combined length of the two low-speed basins (Carriages Nos. 1 and 2) or to each basin individually. Since in practice the shallow-and deep-water basins are used individually, each with

* The main rails serve the dual purpose of guiding the carriages and providing bearing surfaces for the drive wheels. 
its own carriage, we have treated the rail straightness measurements as separate problems with the same alignment tolerances. According to saunders, these tolerances are:

(a) Horizontal straightness. "The sides of the main rail heads shall be parallel to each other and shall lie parallel to a straight vertical plane through the center of the basin, with a maximum variation of not more that 0.005 inch in either direction throughout their length. This maximum variation shall not occur within any one length of 50 feet." [2].

(b) VERTICAL STRAIGHTNESS. "The tops of the finished rails shall lie concentric with the still-water surface in the adjacent basins, with a maximum variation of plus and minus 0.005 inch throughout their length. This maximum variation shall not occur within any one length of 50 feet." [2].

Saunders makes no reference to the rails on the high-speed basin, which was not in use at the time of his papers.

\section{NBS STRAIGHTNESS MEASUREMENT SYSTEM}

Rather than attempt to duplicate the rather elaborate alignment techniques used during the basin construction, we employed an alignment laser and solid-state optical position detector. A schematic diagram of the setup is shown in Fig. (1). The reference line for the measurement of straightness errors was the output beam of a low-power (lmW) Helium-Neon laser fitted with a beam expanding collimator. Beam diameter at the collimator was approximately 0.25 inches $(6 \mathrm{~mm})$ with a beam divergence of 0.1 milliradians. The laser was mounted to the rail to be measured with a specially-designed fixture which included micrometer adjustments for transverse position and beam direction (tilt). For each straightness setup the beam was adjusted to be roughly collinear with the rail using a small alignment target constructed for the purpose. Because such an adjustment is never perfect, each set of straightness data was least-squares fit to a straight line in order to remove the linear component in both horizontal and vertical directions.

At each measured position on the rail, the position of the centroid of the laser beam was measured with a commercial 2axis lateral effect photodiode position detector and associated electronics. When placed normal to a collimated beam of light, changes in the two outputs of this device correspond to changes in the position of the centroid of the incident beam along two perpendicular axes in the plane of the detector. The ultimate resolution of this device is approximately 10 microinches $(0.25$ micrometers) which is much higher than 
necessary for the rail straightness measurements. At DTNSRDC we used a less sensitive scale which yielded an effective position resolution of 0.0001 inches ( 2.5 micrometers).

For large ( $>0.05$ inches) beam excursions away from the center of the detector the outputs become non-linear. For this reason the detector was calibrated at NBS using a precision coordinate measuring machine. This procedure yielded an error map of the detector which was subsequently used to correct the straightness data in the analysis software. During the calibration the angular position of the detector around its roll axis was also adjusted so as to align the two measurement axes with the mounting fixture and eliminate axis crosstalk.

The position detector was mounted on the rails using a kinematically-designed fixture. The fixture contacted the top rail surface at three points consisting of a triangular pattern of 1/4-inch diameter tungsten carbide ball bearings epoxied into conical seats. An additional two ball bearings on one side of the fixture provided lateral contact with the South side of the rail approximately 0.25 inches $(6 \mathrm{~mm})$ below the top surface in an area free of wear. Tests with this fixture demonstrated that it could be repeatedly positioned on the rail to within 0.0002 inches in both axes. It should be noted that because of the design of this fixture all horizontal straightness errors refer to the location of points on the south side of the basin rails.

The straightness measuring instrumentation was integrated with a small computer system to provide automated data collection and storage. All components except the laser and the detector head were mounted on a cart which was rolled along beside the rail as the measured points were sampled.

Because of laser beam divergence, atmospheric refraction, and air turbulence it is not possible with this technique to measure a single line along a rail 1000 feet ( 300 meters) or more in length. Turbulence noise is particularly troublesome for large path lengths and since it is essentially random it can only be reduced by repeated sampling and data averaging. After a period of experimentation along the main rail of the Carriage No. 2 basin we judged that a maximum line length of 96 feet $(29 \mathrm{~m})$ provided an acceptable compromise between turbulence noise and sampling rate.

The three basin rails were thus measured in sections 96 feet in length. Each section was measured at 8 foot intervals, with each point sampled twice. After a particular section was measured, the laser source was moved 48 feet in the direction of travel, re-mounted on the rail, and a new 96 foot section measured. In this way we stepped our way along the entire measured length of each rail, working always from East to West. Because of the overlap of sequential measured rail sections, adjoining laser lines shared a common section of 
straightness data 48 feet in length. These sets of common data were used in mathematical algorithm to tie sequentially measured lines together. In this way we synthesized a laser line with length equal to the entire measured rail. of course there is the possibility of an accumulation of error in this process; we shall return to this point in the next section.

The mathematical joining of measured line segments is illustrated by Figs. (2-4). Figure (2) shows the measured horizontal straightness along a 96-foot section of the main rail of the Carriage No. 1 basin, beginning at the 96-foot mark.* The solid line connects points sampled with the detector stepped away from the laser and the dashed line connects points sampled on the return. The lack of exact bi-directional repeatability is due to air turbulence and this data is fairly representative of the noise on the horizontal data along the main rails in the two low-speed basins. Figure (3) shows that next section, measured after the laser was moved to the 48foot mark. A comparison with Figure (2) reveals the distinctive feature near the 32-foot position which is common to the two sets of data. The analysis then proceeds by first averaging the data for both lines. Then, the differences between the seven data points in the overlap region of each line were fit to a straight line using a 2-parameter leastsquares routine and the straight line subtracted from the data of the line being joined - in this case, the line starting at 48 feet. The composite line is then adjusted so that the end points lie at zero. The results of this process are shown in Fig. (4) where the common region of the two lines is clearly seen. The joining procedure is completed by averaging the straightness data in the region of overlap. As each new section of rail is measured it is then added to the composite line, extending the latter by 48 feet.

IV. HORIZONTAL STRAIGHTNESS RESULTS

In this section we present the results of our measurements of the horizontal straightness errors on the three measured basin rails. Horizontal misalignment is probably the most important error because of the way in which the carriages are guided during towing experiments. We chose to report the results in 144-foot pieces, as well as the complete shape of the measured rail. This enables the staff of DTNSRDC to see in sufficient detail the local shape of rails and the nature of the fit of adjacent 96-foot sections indicates the quality of the data. In all cases a positive error denotes rail displacement towards the respective basin-i.e towards the NORTH.

IV.1. HORIZONTAL STRAIGHTNESS - CARRIAGE NO. 2 BASIN

The main rail of the Carriage No. 2 basin was measured over 1296 feet of its length, from the 2280 foot mark to the 984

* Position marks in this report refer to numbered light markers on the walls adjacent to the basins. 
foot mark. The results are shown in Figs. (5-17). Because the two sets of guide wheels on Carriage No. 2 are about 60 feet apart, the primary concern is with sizable deviations from straightness which occur over distances of 60 feet or less. There are several such regions along the Carriage No. 2 main rail - for example, near 2232 feet, 2040 feet, 1944 feet, and 1576 feet. In general our measured errors far exceed the design tolerance stated by Saunders (see Sec. II), although there are a few sections (e.g. 1416-1262 feet) which are remarkably straight.

The overall shape of the Carriage No. 2 main rail, obtained after mathematically joining the 26 measured sections, is shown in Fig. (18). The most obvious feature is the systematic bow or curvature toward the basin of more than 0.3 inches.

IV.2. HORIZONTAL STRAIGHTNESS - CARRIAGE NO.I BASIN

The main rail of the Carriage No. I basin was measured over 1008 feet of its length, from the 720 foot mark to the -288 foot mark. The results are shown, in 144-foot pieces, in Figs. (19-28). A particulary large horizontal alignment error is evident near 624 feet. The overall shape is shown in Fig. (29) and displays a systematic curvature away from the basin of approximately 0.2 inches.

IV.3. HORIZONTAL STRAIGHTNESS - HIGH-SPEED BASIN, SOUTH RAIL

The South rail of the high-speed basin was measured over 2640 feet $(0.5 \mathrm{miles})$ of its length, from the 2676 foot mark to the 36 foot mark. The results, in 144-foot pieces, are shown in Figs. (30-58). This rail is locally much straighter than those in the low-speed basins and most of the data is presented with a finer vertical scale. A few sections with relatively large local straightness errors may be identified, among them those near 1172,484 , and 260 feet.

The overall shape of the rail is shown in Fig. (59) and displays an interesting, nearly sinusoidal, systematic straightness error with an amplitude of approximately 0.25 inches. It should be noted that no measurements of the straightness errors of the North rail of the high-speed basin were made by NBS.

IV.4 . THEODOLITE MEASUREMENTS

As a guard against the accumulation of unknown systematic errors and to test the line synthesis algorithm, several sections of the low-speed basins were checked for alignment by a different technique. The alignment laser was replaced with a high-precision digital theodolite and the photodiode detector was replaced with an illuminated target using the same kinematic fixture. The theodolite, commonly used in surveying and mapping work, is basically a high-quality 
telescope mounted on two orthogonal axes which are fitted with accurate high-resolution angle encoders. The purpose of the device is the determination of angular separation between points in the horizontal (azimuth) and vertical (altitude) directions. The instrument used for these measurements has an angular resolution of 0.1 arc-seconds ( 0.5 microradians).

The setup for theodolite validation is shown schematically in Fig. (60), which is meant to be a view from above. The horizontal angle is zeroed with the target at the end of the measured section. As the target is moved to another location any lateral deviation $X$ in its position can be calculated from the measured angle $A$, according to

$$
\mathrm{X}=\mathrm{D} \tan \mathrm{A}
$$

where D is the theodolite - target separation.

Figure (61) shows a 288-foot section of horizontal straightness data from the main rail of the Carriage No. 2 basin, between the 2280 and 1992 foot marks. The solid line is laser data derived by joining five consecutive 96-foot sections. The discrete points are theodolite measurements taken on this section, with the theodolite station located at the 2290 foot mark (to the left of the origin). The error bars represent a 1 arc-second one-sigma angular pointing uncertainty, derived from the measurement data. [ Note: the theodolite errors are averages of 10 observations per point by a single observer. When using multiple observers, errors are somewhat larger due to target bias.] There is a reasonable agreement between the two straightness measurements and no obvious sign of hidden systematic errors in the laser metrology.

Figure (62) compares the overall shape of the Carriage No. 2 main rail, as measured with the laser system, with two points taken by theodolite. Each theodolite data point is averaged over four observers taking eight repetitive sights and the error bars reflect a one sigma error of about 1.5 arc-seconds. The systematic 0.3 inch bow of this rail appears to be a real feature.

V. VERTICAL STRAIGHTNESS RESULTS

High-accuracy measurement of vertical straightness errors using an alignment laser is generally more difficult than horizontal measurement due to refractive index gradients along the beam path. In addition to the systematic errors caused by such gradients, convective circulation of the air within the towing basin building caused the turbulence noise in the vertical direction to be nearly twice as large as in the horizontal direction. For these reasons, the accuracy of our results in these measurements is somewhat degraded. On the other hand, however, all measured rails are noticeably freer 
of large local straightness errors in the vertical direction than in the horizontal.

\section{V.1. CORRECTION FOR EARTH'S CURVATURE}

All vertical straightness data was corrected for the curvature of the Earth. As the detector moves away from the laser along an ideal (level) rail surface, the curvature of the rail causes the detector to fall below the nominally horizontal laser line by an amount proportional to the square of the detector position along the rail. This curvature is small but significant, amounting to about 0.003 inches in 100 feet of travel. In order to measure the vertical rail deviations from the ideal circular arc, the curvature error was computed at each position and added to the measured error.

\section{V.2. CORRECTION FOR REFRACTIVE INDEX GRADIENTS}

Air near the surface of the Earth generally has a vertical density variation caused by pressure and temperature gradients. This causes a light beam to be bent (refracted) towards regions of greater density and is responsible for the existence of mirages. Since the refractive index of air is a well-known function of density (determined primarily by temperature and pressure) $[3,4]$ the effect of density gradients on alignment metrology can be corrected to the extent that temperature and pressure gradients can be measured along the optical path. Such corrections are routinely applied in surveying and mapping work and in the precision metrology of large structures [5].

The pressure gradient near the Earth's surface is approximately $0.03 \mathrm{~mm} \mathrm{Hg} /$ foot and maybe taken to be sensibly constant. The effect of this gradient is to cause a horizontal light beam to be refracted downward by an amount proportional to the square of the horizontal displacement. The deviation from horizontal is 0.0006 inches in 100 feet of travel. A vertical temperature gradient presents a bigger problem since it must be measured, may not be constant, and can produce large errors. For example, a vertical temperature gradient of $0.1 \mathrm{deg} C /$ foot will cause an error of nearly 0.006 inches in 100 feet of travel. The direction of the error depends upon the sign of the temperature gradient - typically in an indoor environment the temperature increases with height which results in downward refraction. Like the errors due to Earth's curvature and atmospheric pressure gradient, this error is quadratic in distance. Table I summarizes the vertical straightness systematic errors.

Using a pair of precision calibrated thermistors, the vertical temperature gradient was measured on several occasions during the field measurements and was found to vary somewhat erratically between 0.2 and 0.4 deg C/foot, with the temperature increasing with vertical position. Because of 
this large variation we made no attempt to determine the overall vertical curvature of the measured rails and present only the local data, in 144-foot pieces.

\section{V.3. VERTICAL STRAIGHTNESS RESULTS}

The vertical straightness errors of the Carriage No. 1 basin are shown in Figs. (63-71). The results for the Carriage No.2 basin and the high-speed basin are shown in Figs. (72-83) and Figs. (84-110), respectively. Because of the increased turbulence noise, the fits of the adjacent measured lines are not as good as for the horizontal measurements.

VI. WEAR OF RAIL JOINTS

The main rails of basins No.l and No.2 are joined by 45-degree scarf joints. In the course of many years of heavy use, these joints have developed a systematic pattern of wear which causes objectionable noise when the joints are traversed by the steel drive wheels of the carriages. During our field work, we undertook an examination of this wear. The local deviation from flatness was measured at each joint using a dial indicator mounted on a flat steel parallel.

Figures (111) and (112) show the average results of these measurements for the scarf joints in the carriage No.l and Carriage No.2 basins respectively. The numbers are local deviations in thousandths of an inch and should be interpreted as typical data illustrating the general pattern of wear. The locations of the measured points can be estimated by noting that the width of the rail head is 3.5 inches.

VII. REFERENCES

1. Saunders, H. E., "The David W. Taylor Model Basin, Parts 1, 2, and 3", SNAME Transactions Vols. 46,48 , and 49 (1938, 1940, and 1941).

2. Ibid., Part 2, p. 176 .

3. Edlen, B., "The Refractive Index of Air", Metrologia 2 , $71(1966)$.

4. Jones, F., "The Refractivity of Air", J. Res. NBS 86, 27 (1981).

5. Puttick, M. J., "Large-Scale Metrology", Annals of the CIRP 27, 351 (1978). 
Vertical Straightness Measurement Systematic Errors

Error Source $\underline{\text { Error at } 100 \mathrm{ft} . \text { (mils) }}$

Earth's Curvature 2.8

Pressure Gradient

0.6

Temperature Gradient $55 *(\mathrm{dT} / \mathrm{dZ})$

where $\mathrm{dT} / \mathrm{dZ}=\mathrm{T}$-gradient in $\operatorname{deg} \mathrm{C} / \mathrm{ft}$.

NOTE: All errors are quadratic in distance 


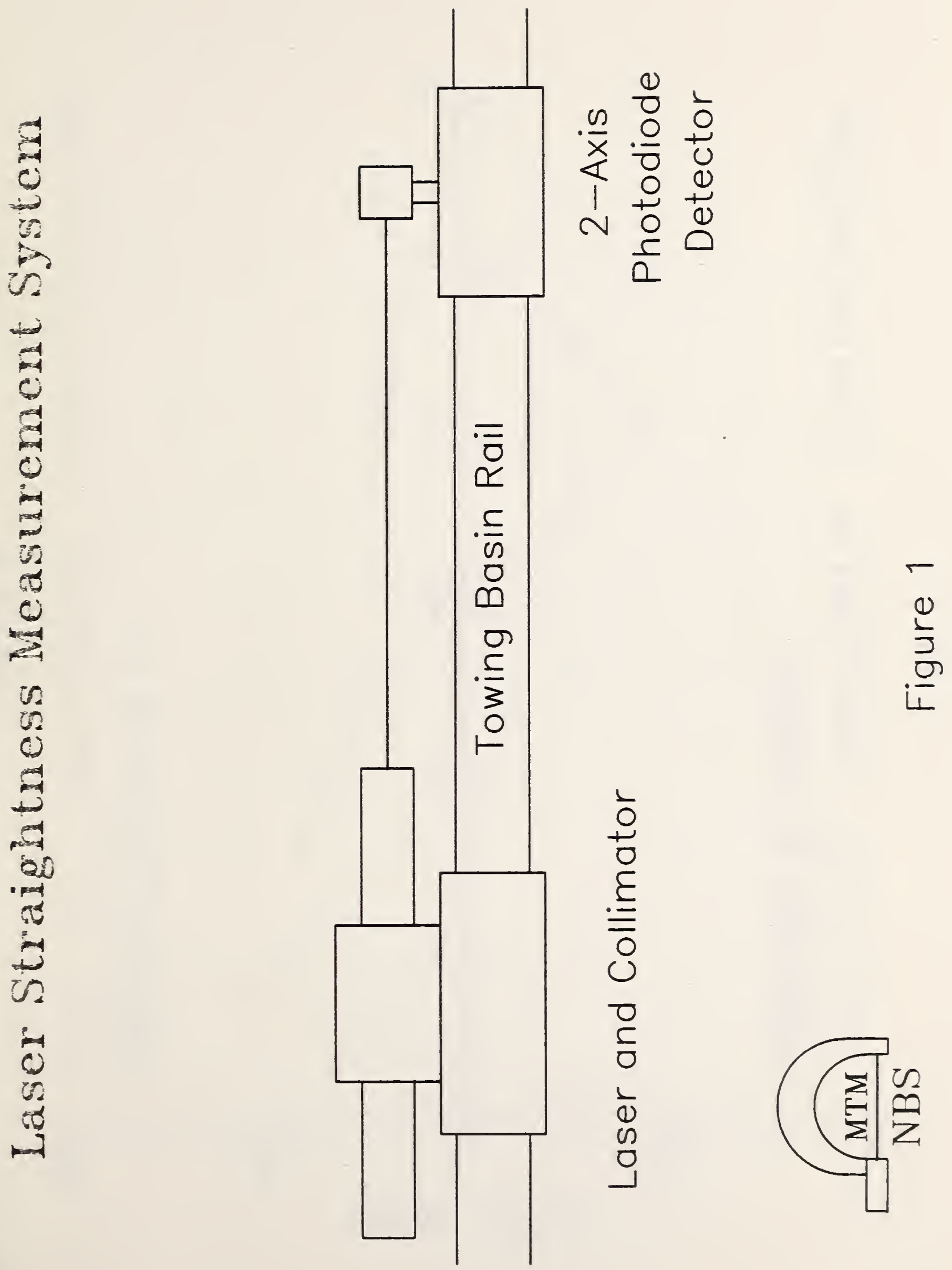
$U$
$U$
$\frac{1}{5}$
$\frac{1}{0}$
$\frac{1}{\alpha}$
$\frac{1}{5}$

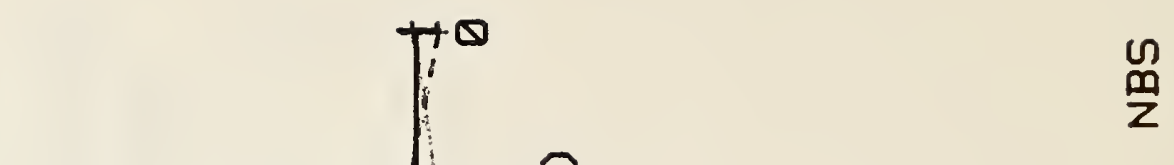

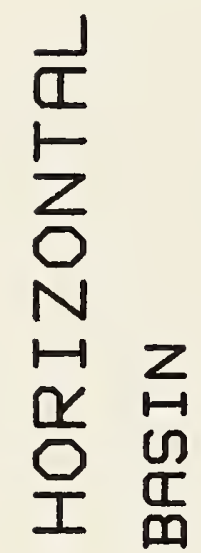

$\vec{\square} \#$

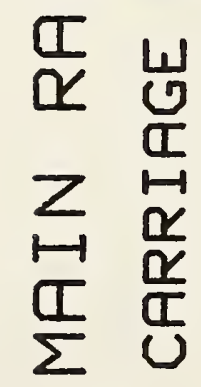

点

ต

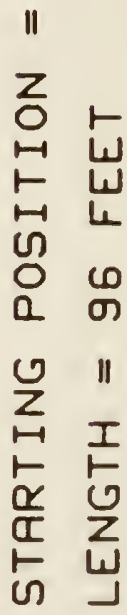

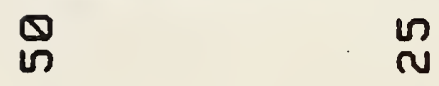

(s!m) 미키 


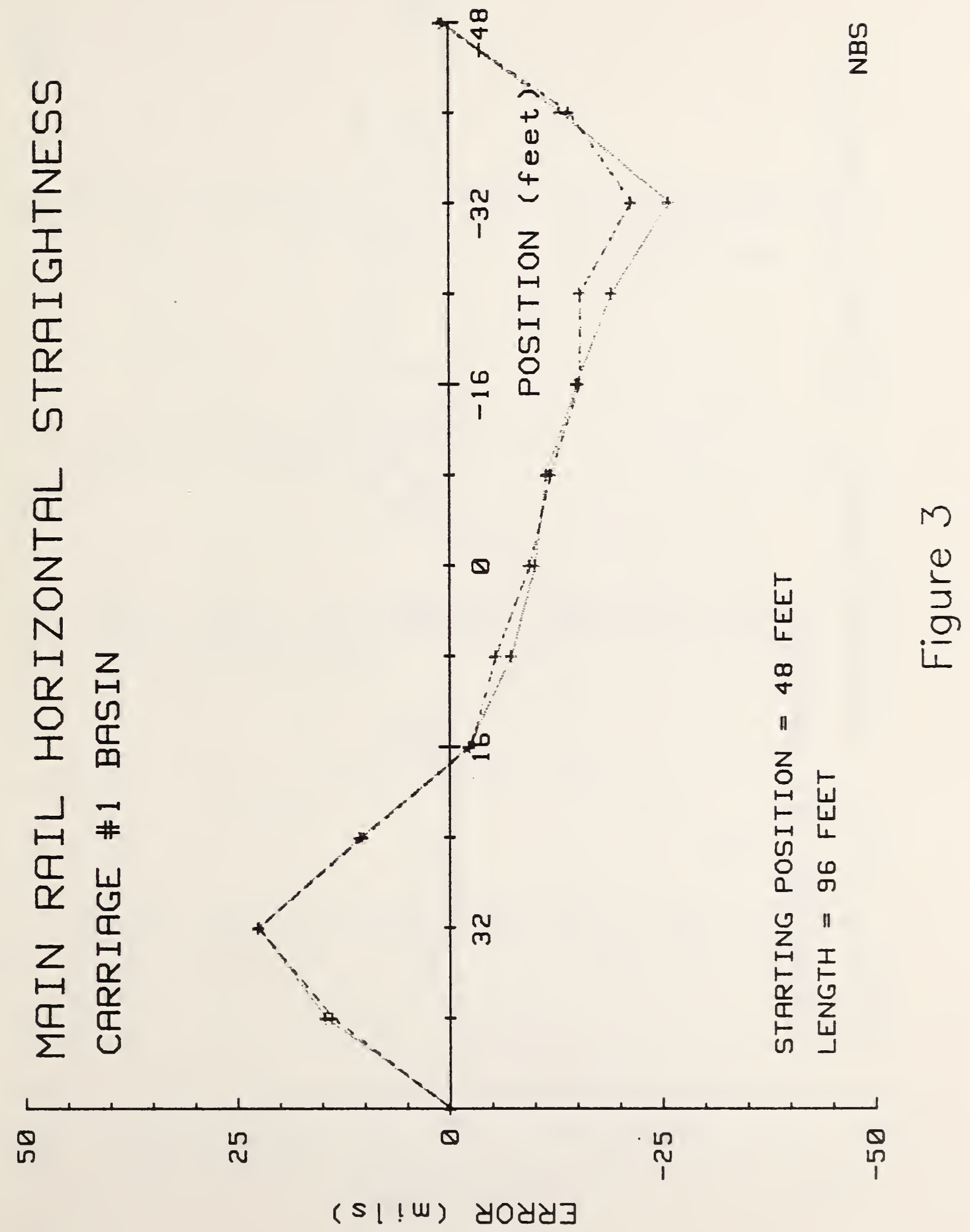




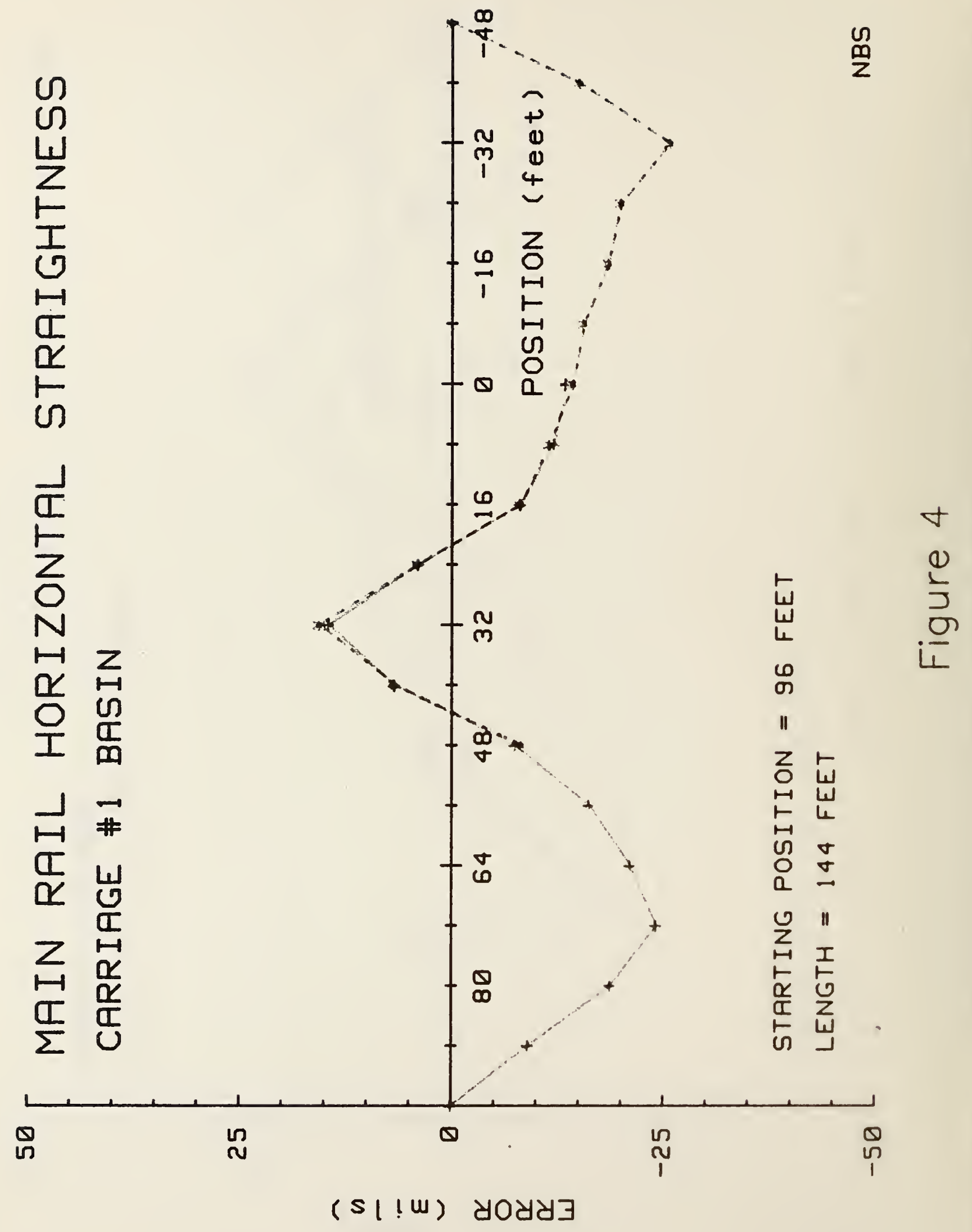



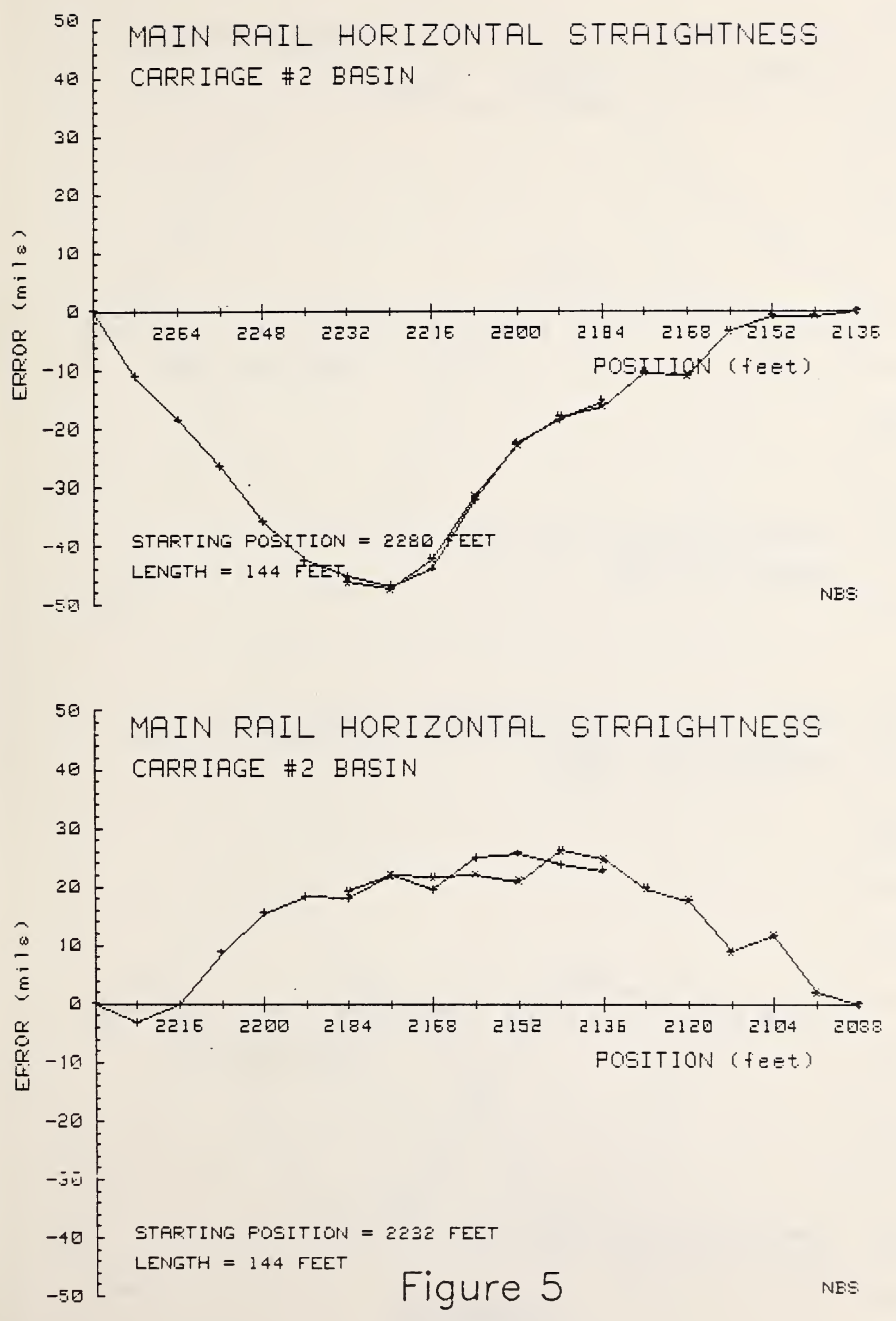

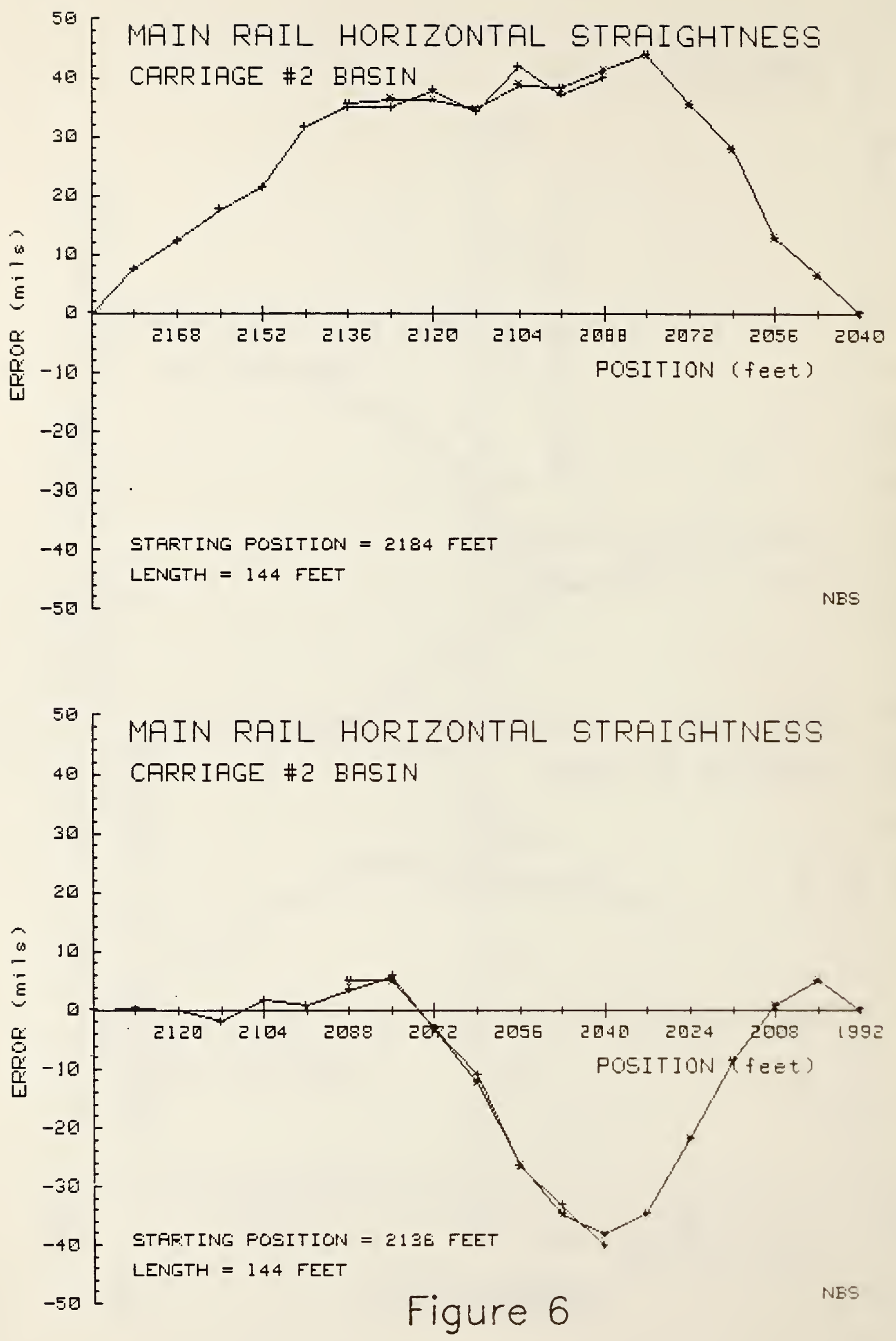

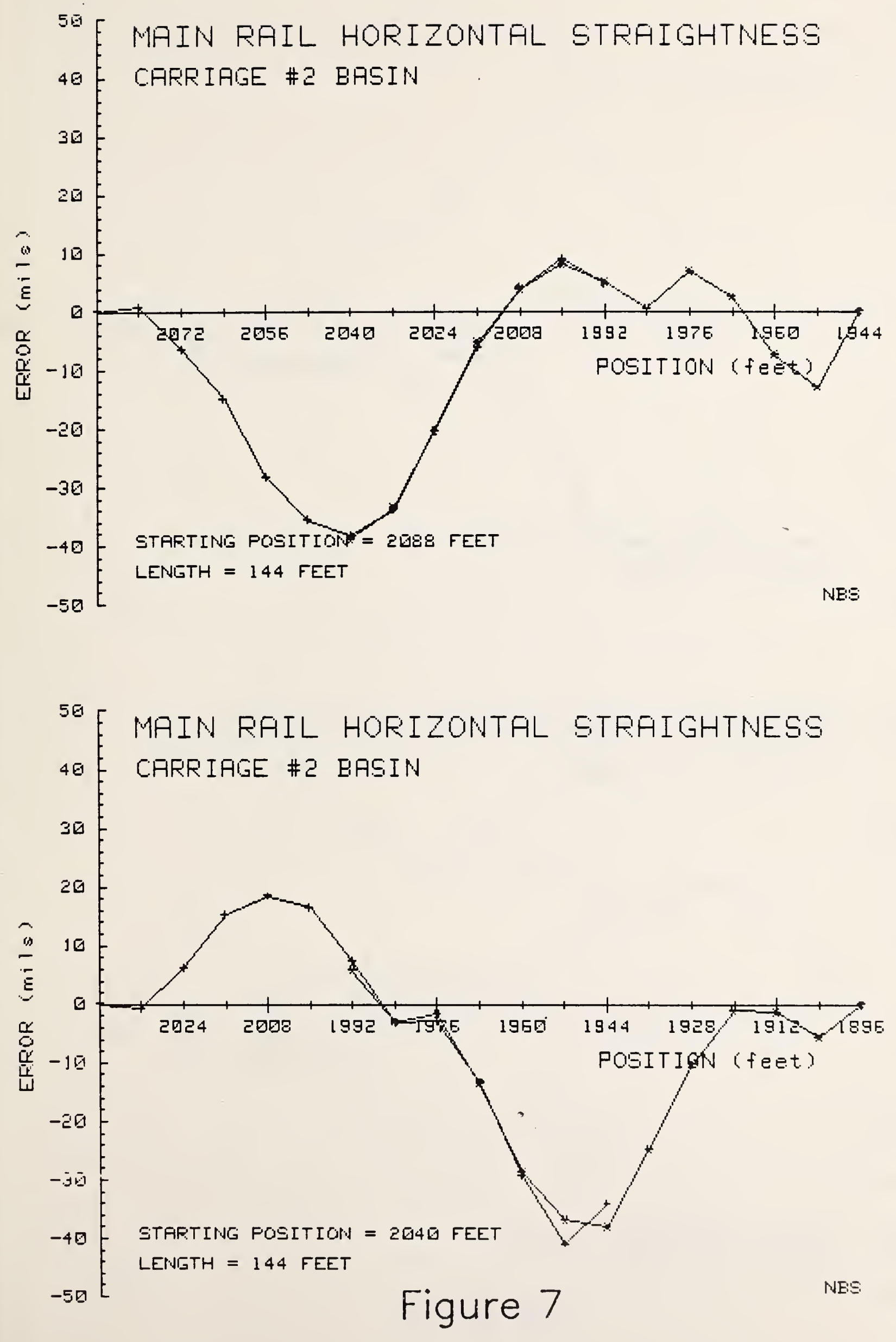

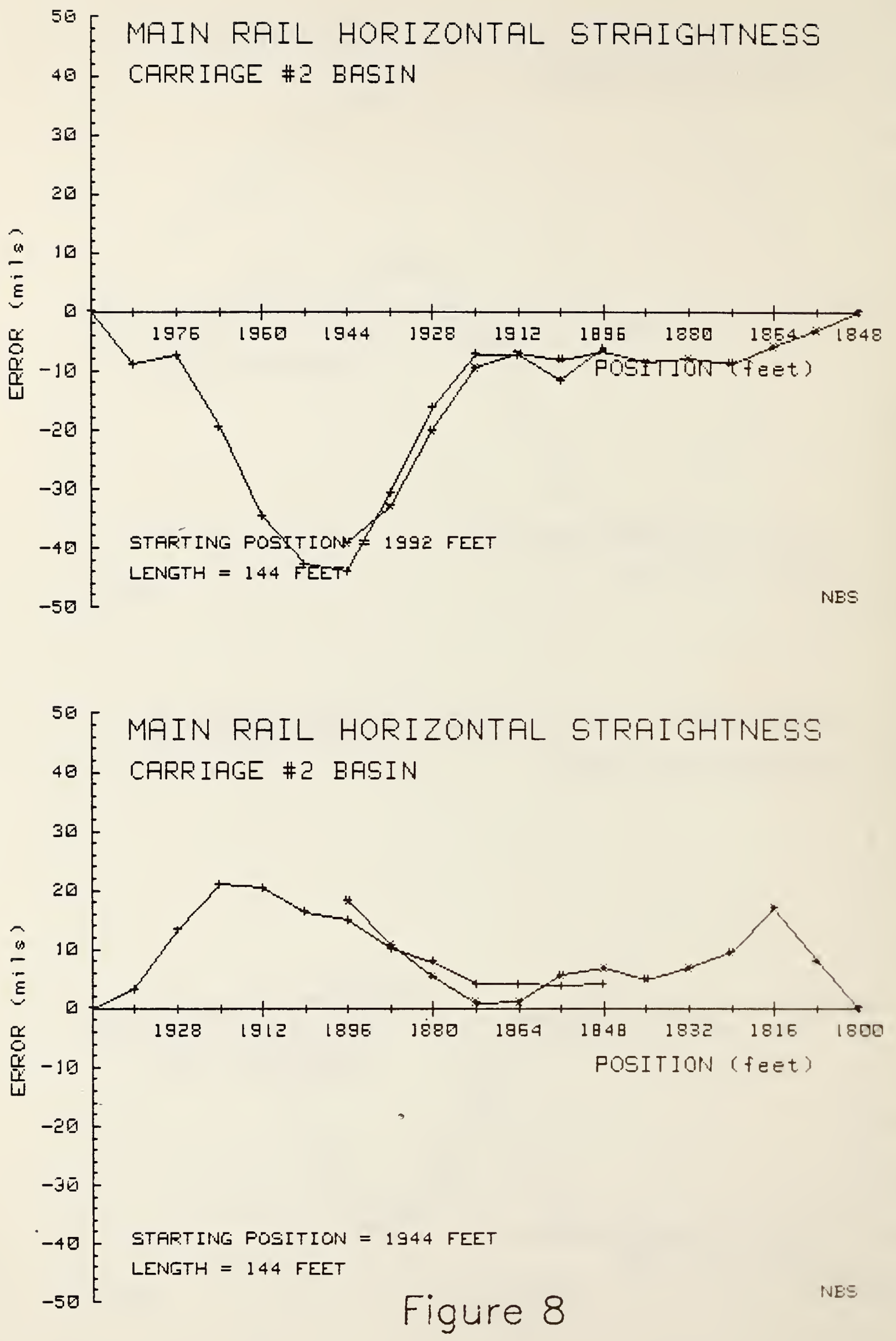

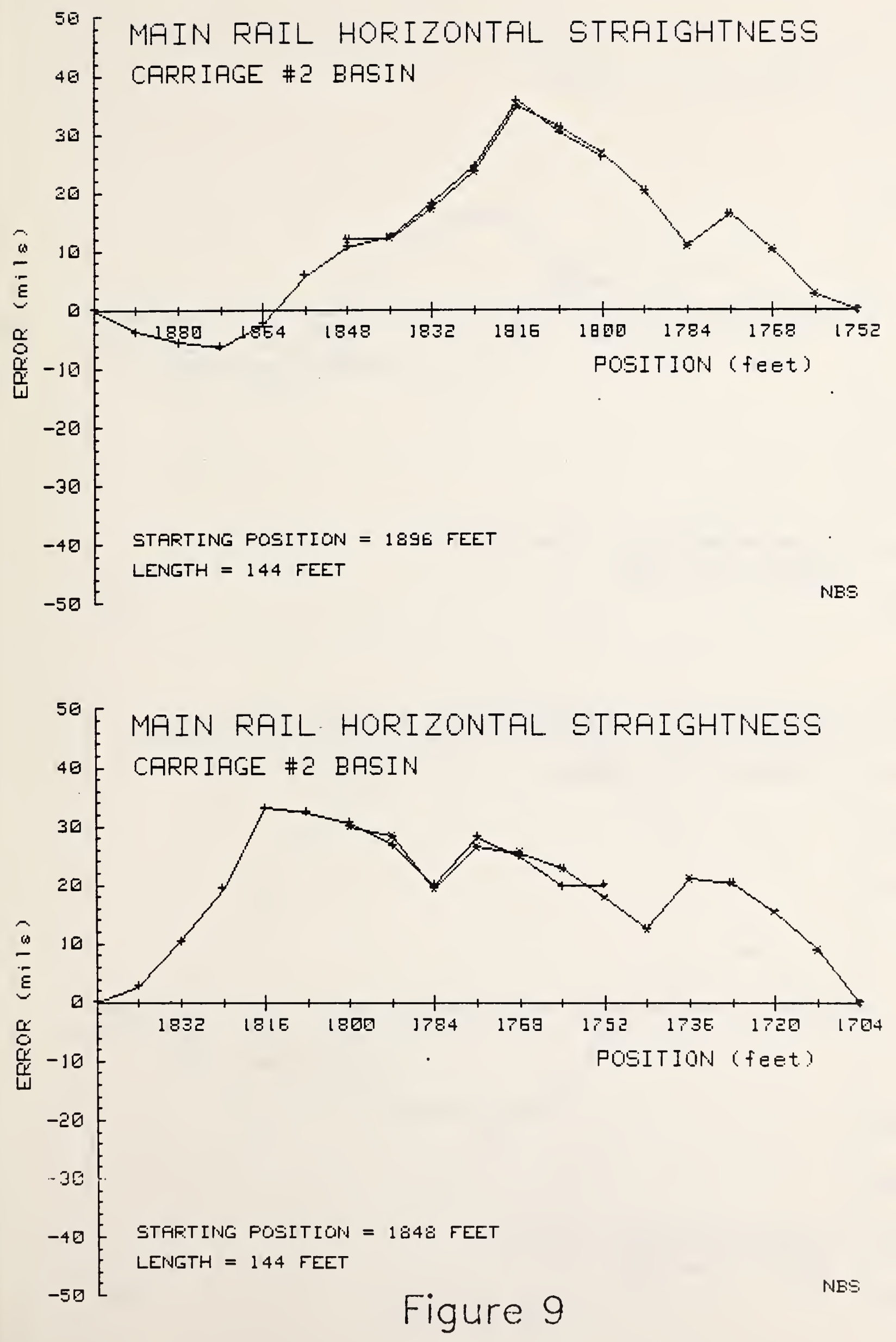

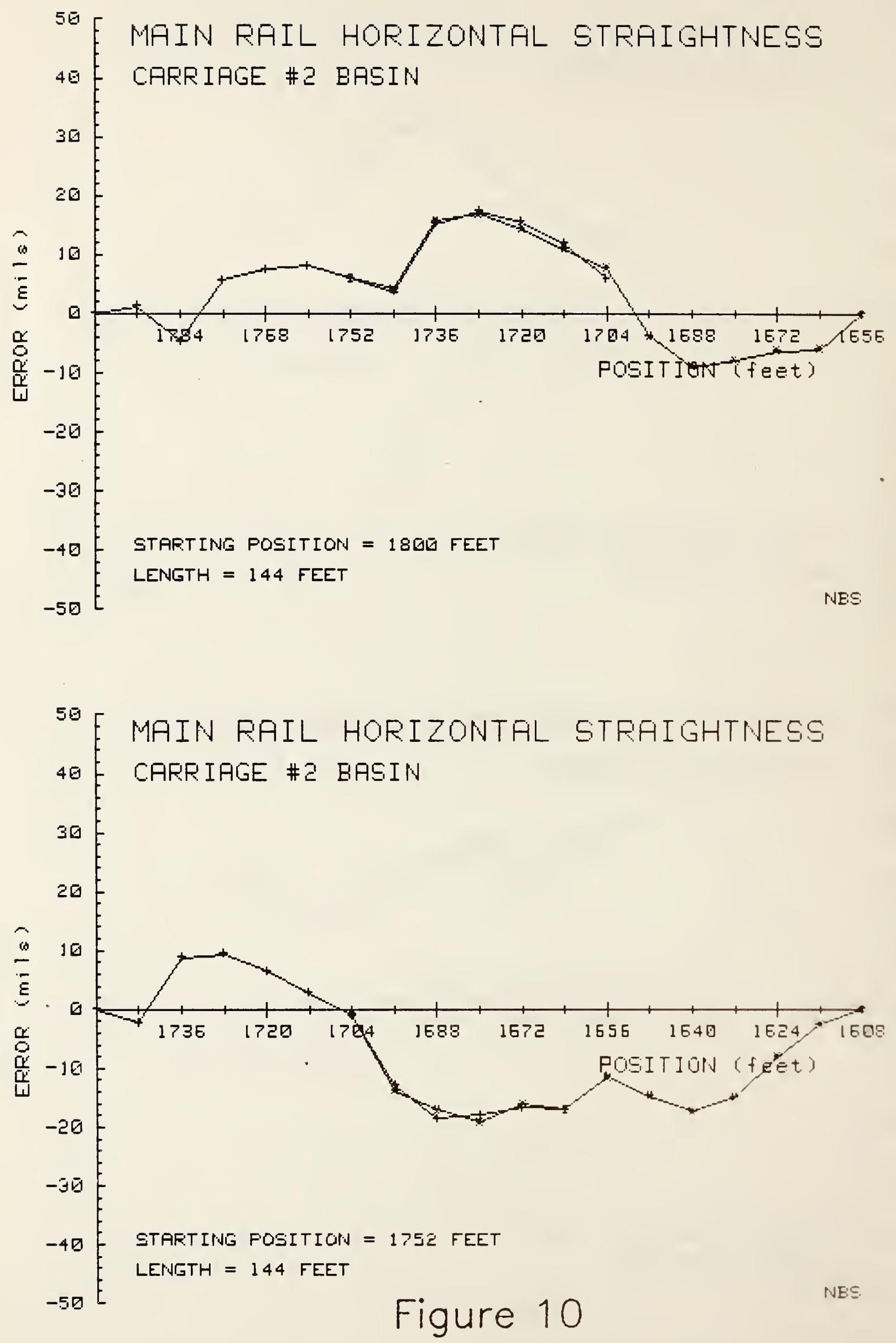

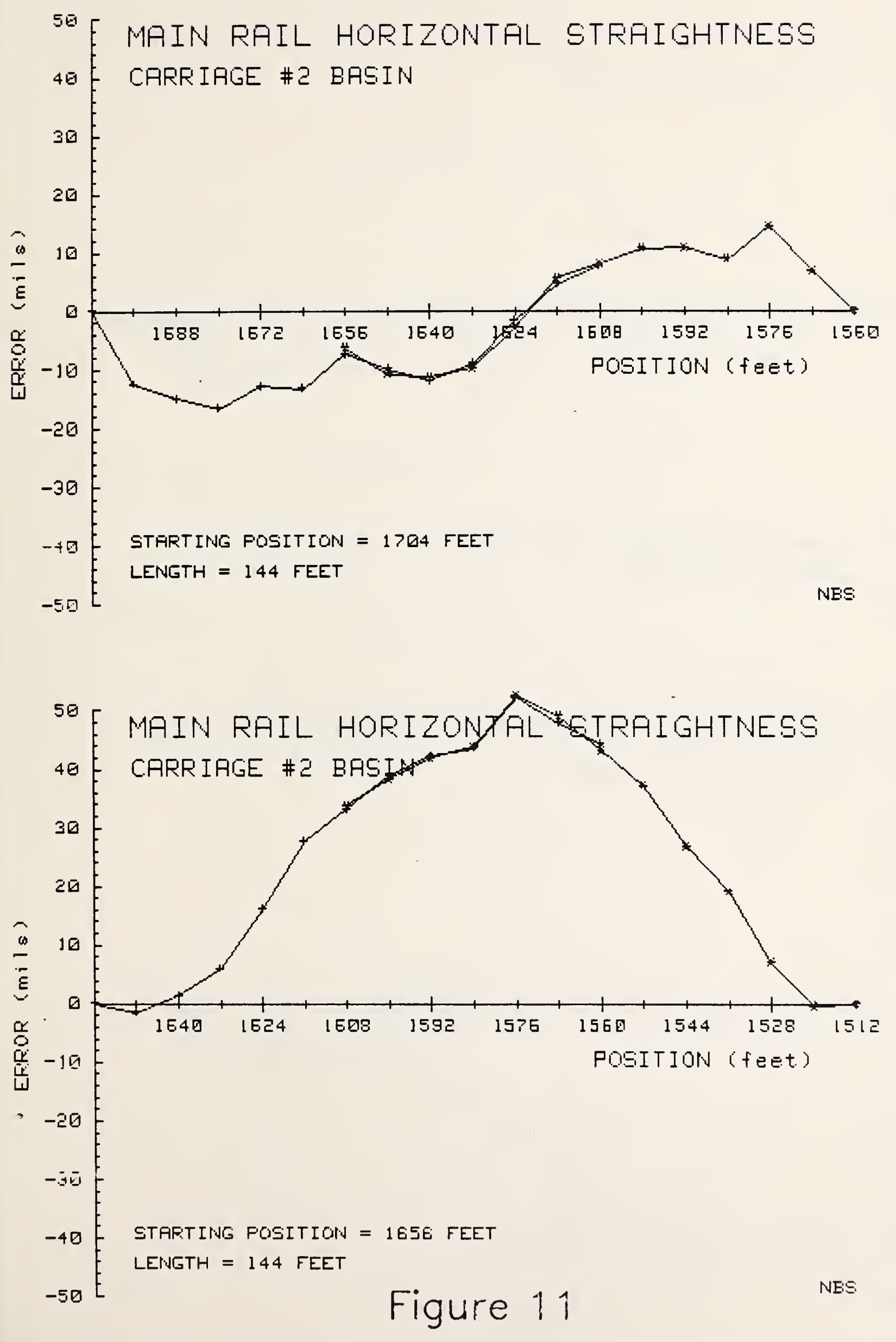

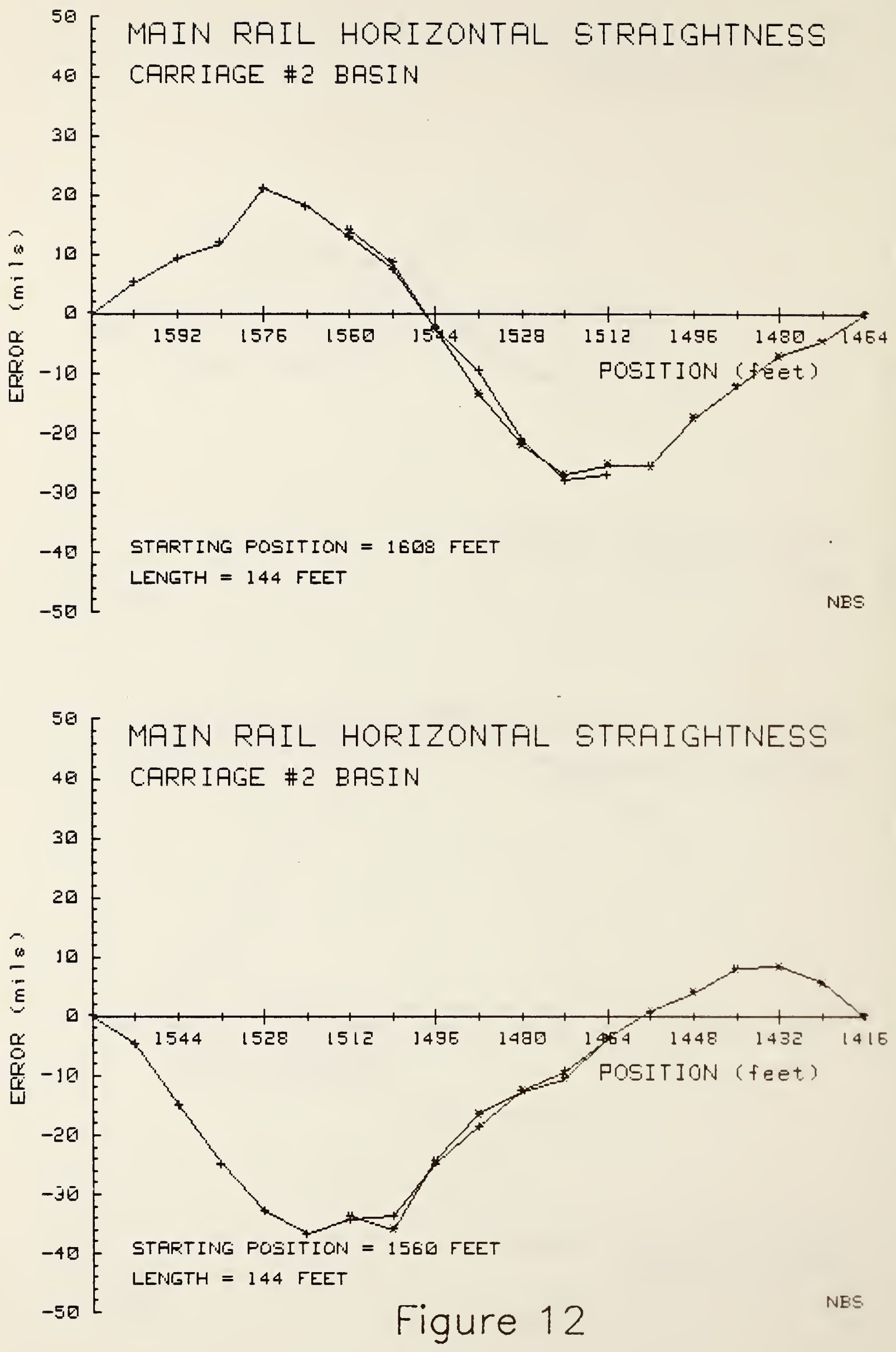

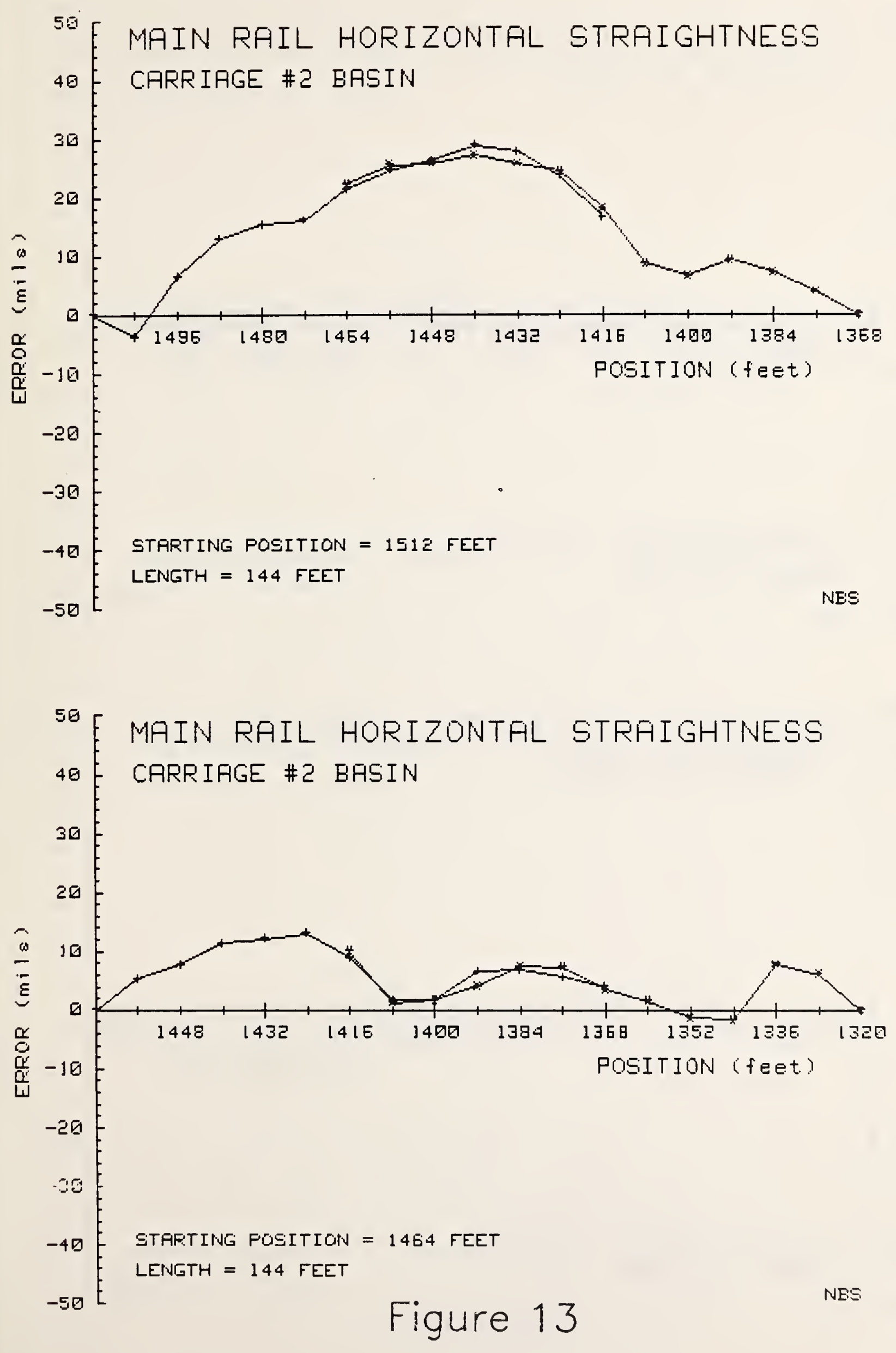

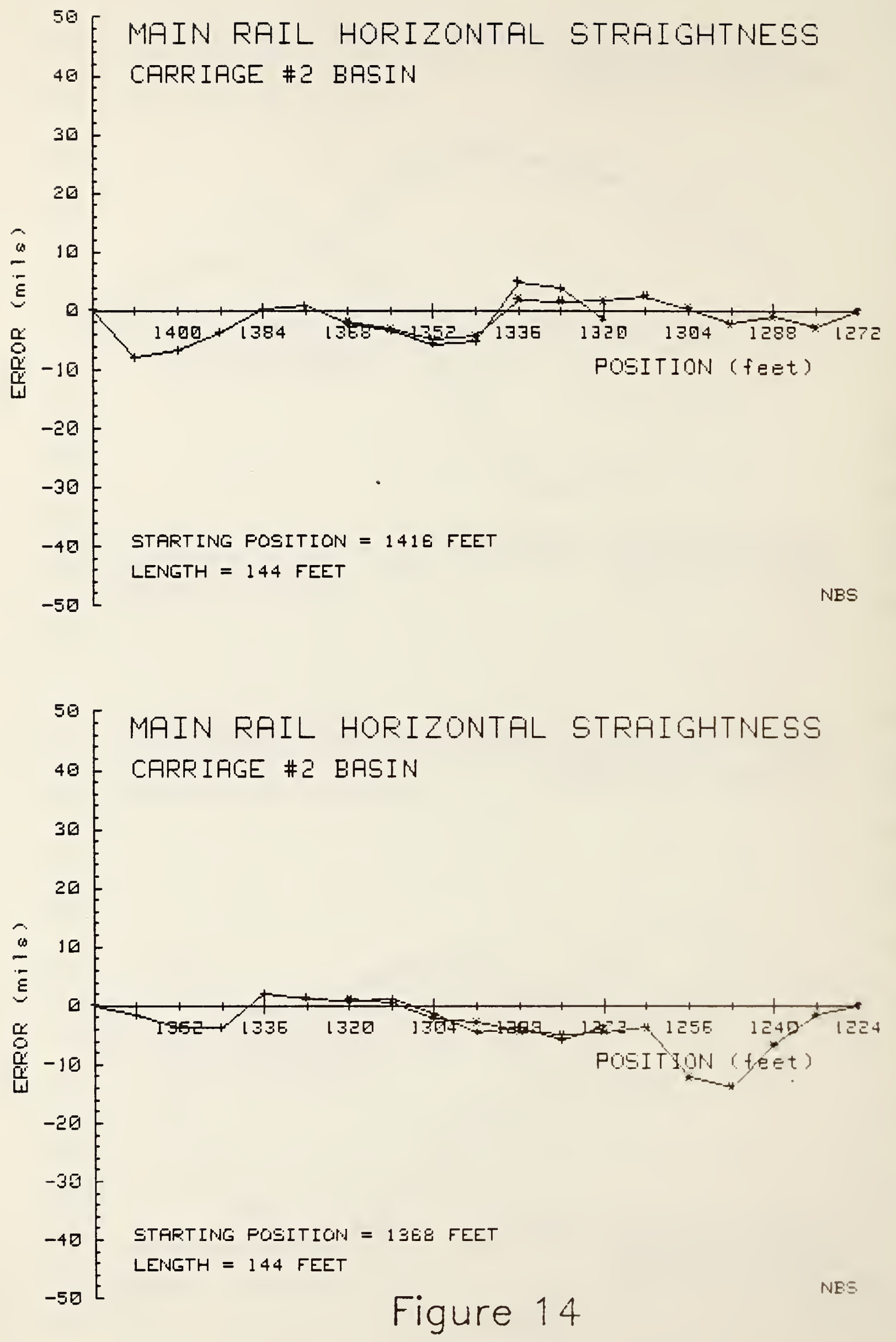

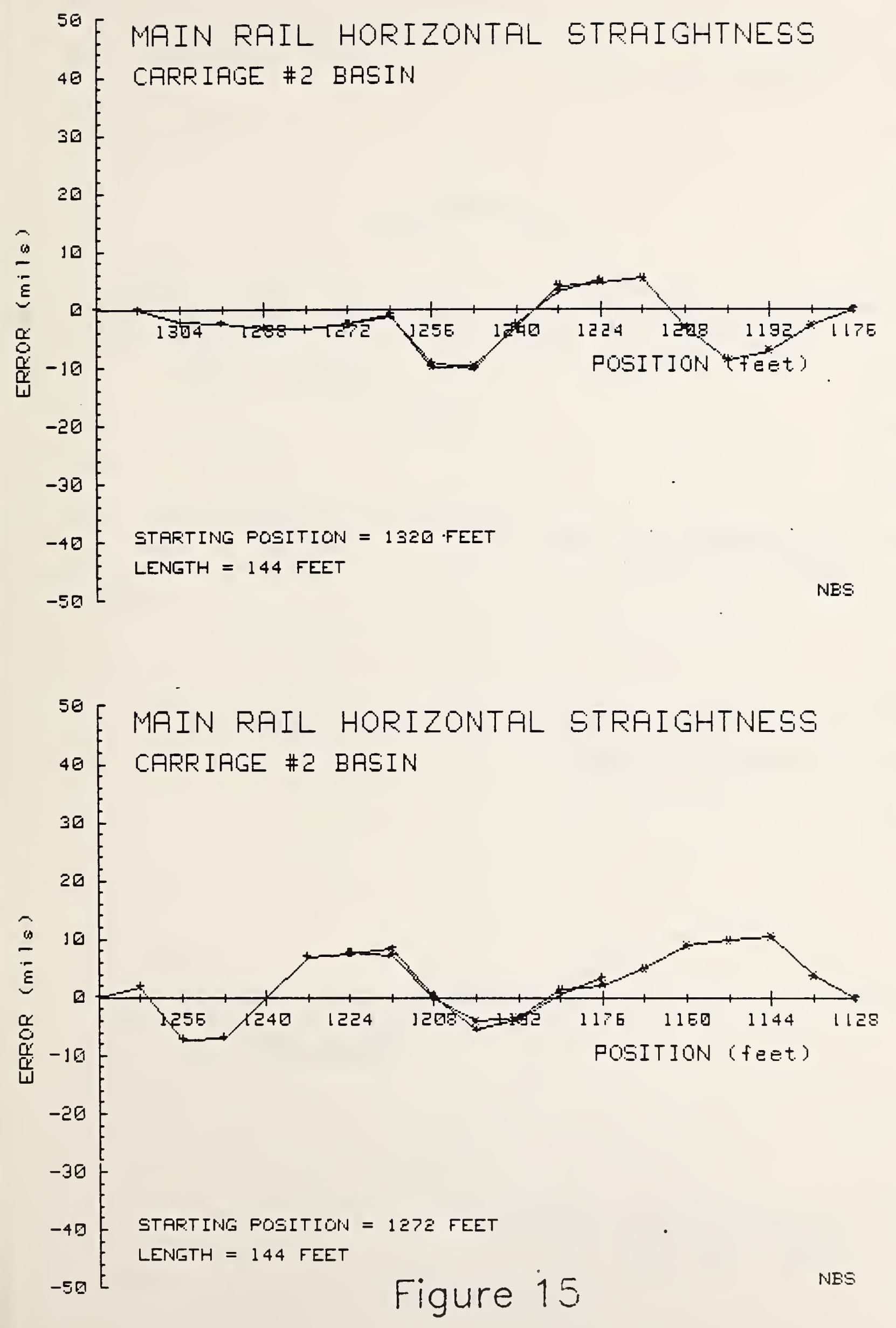

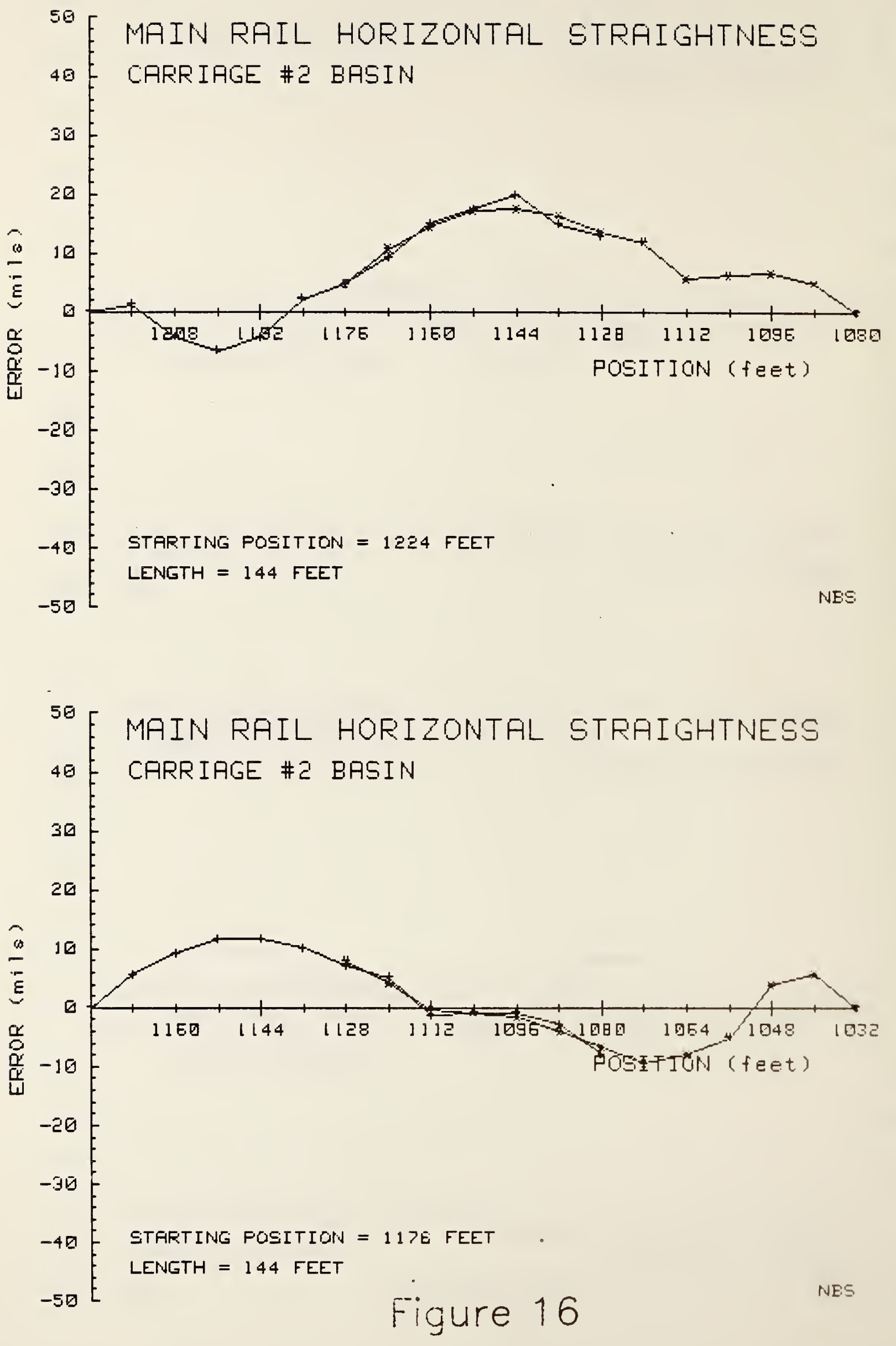


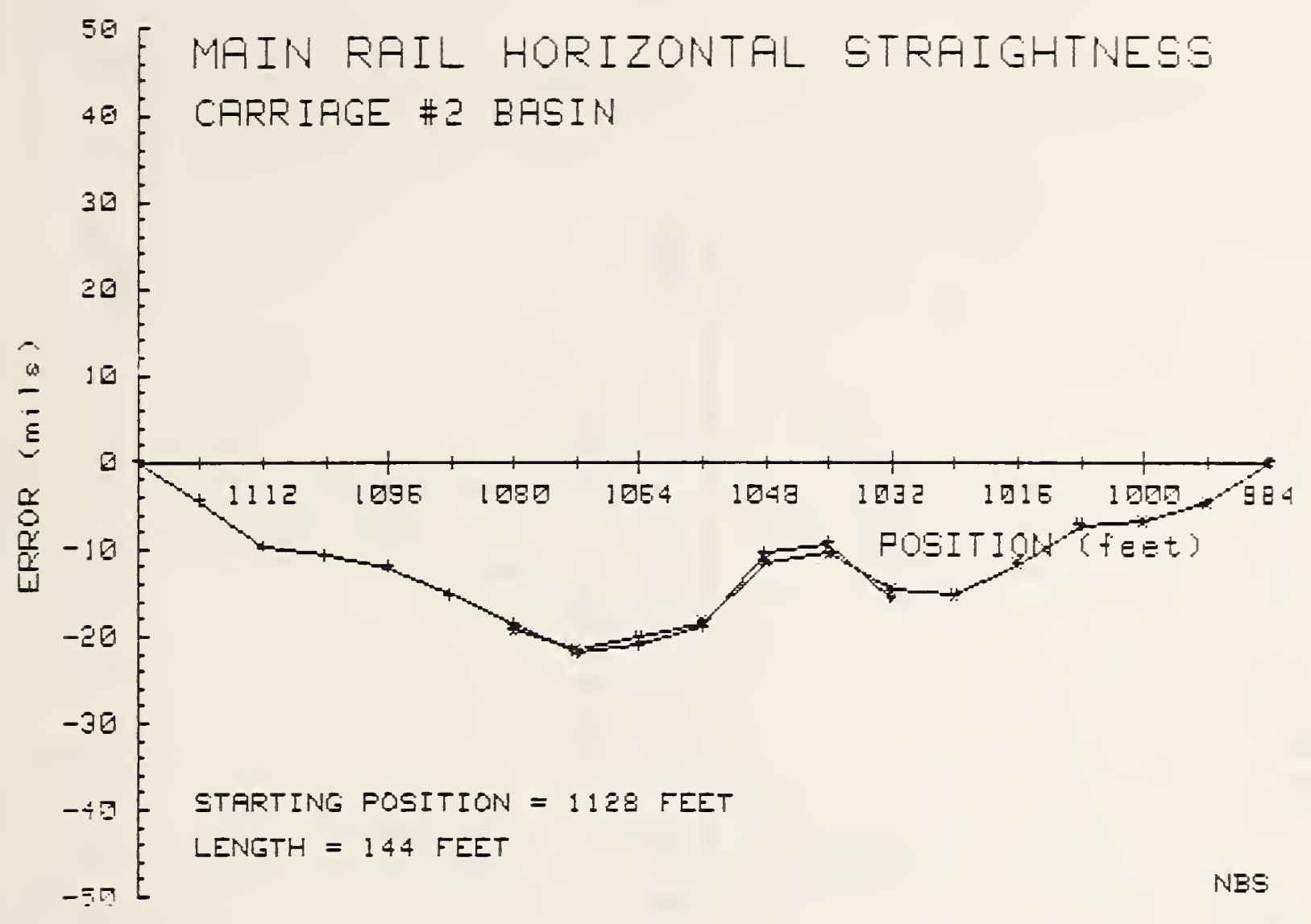

Figure 17 


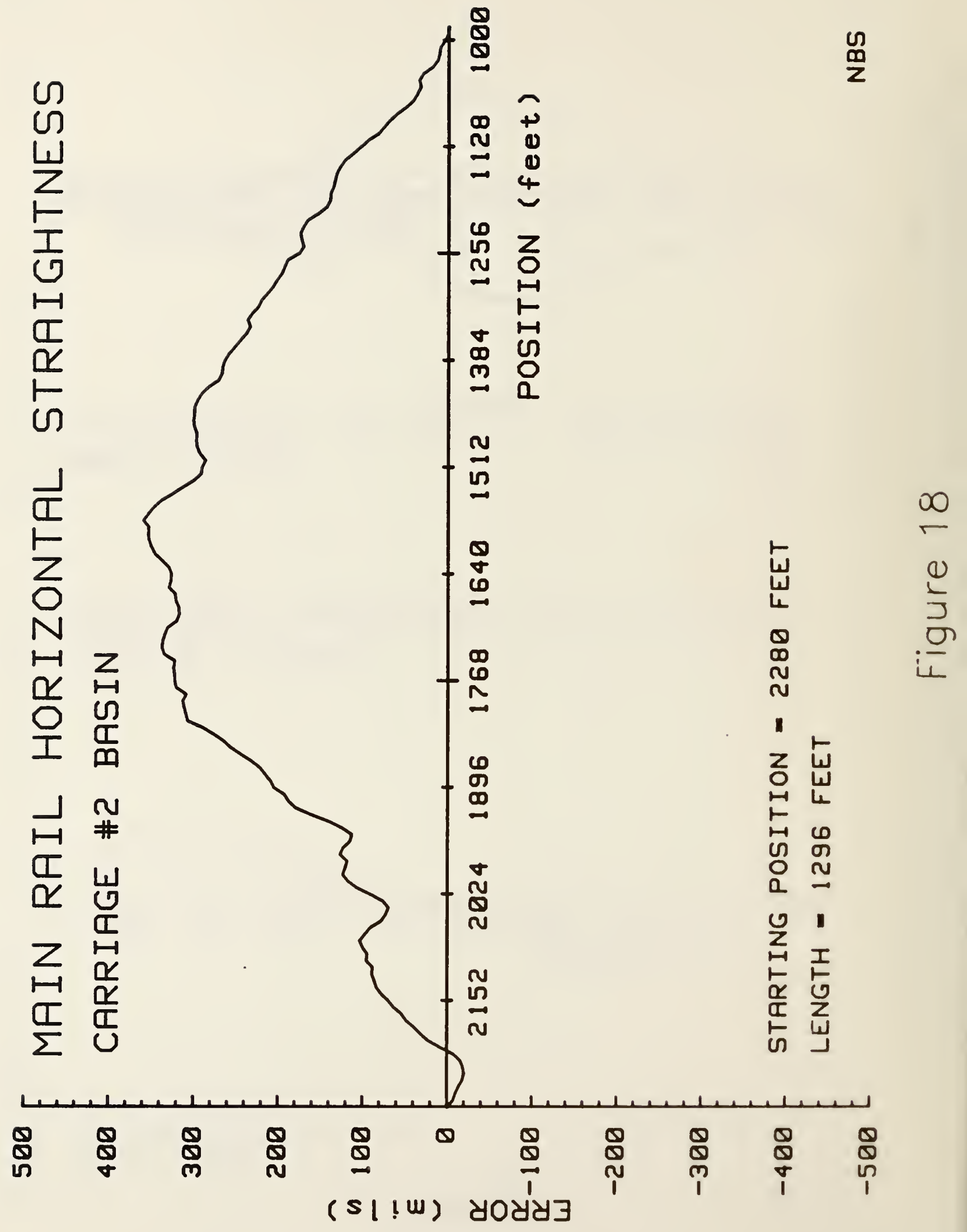



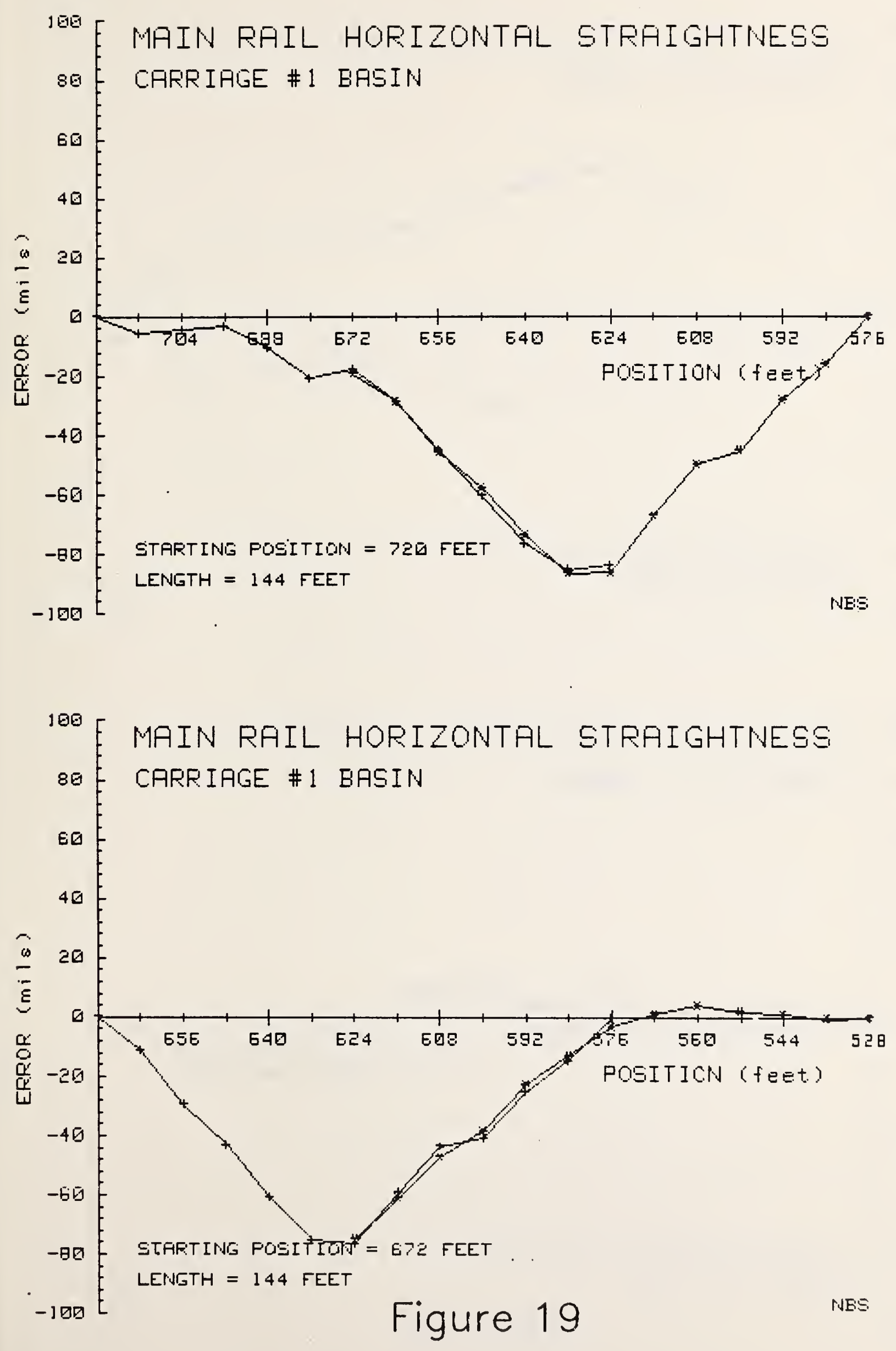

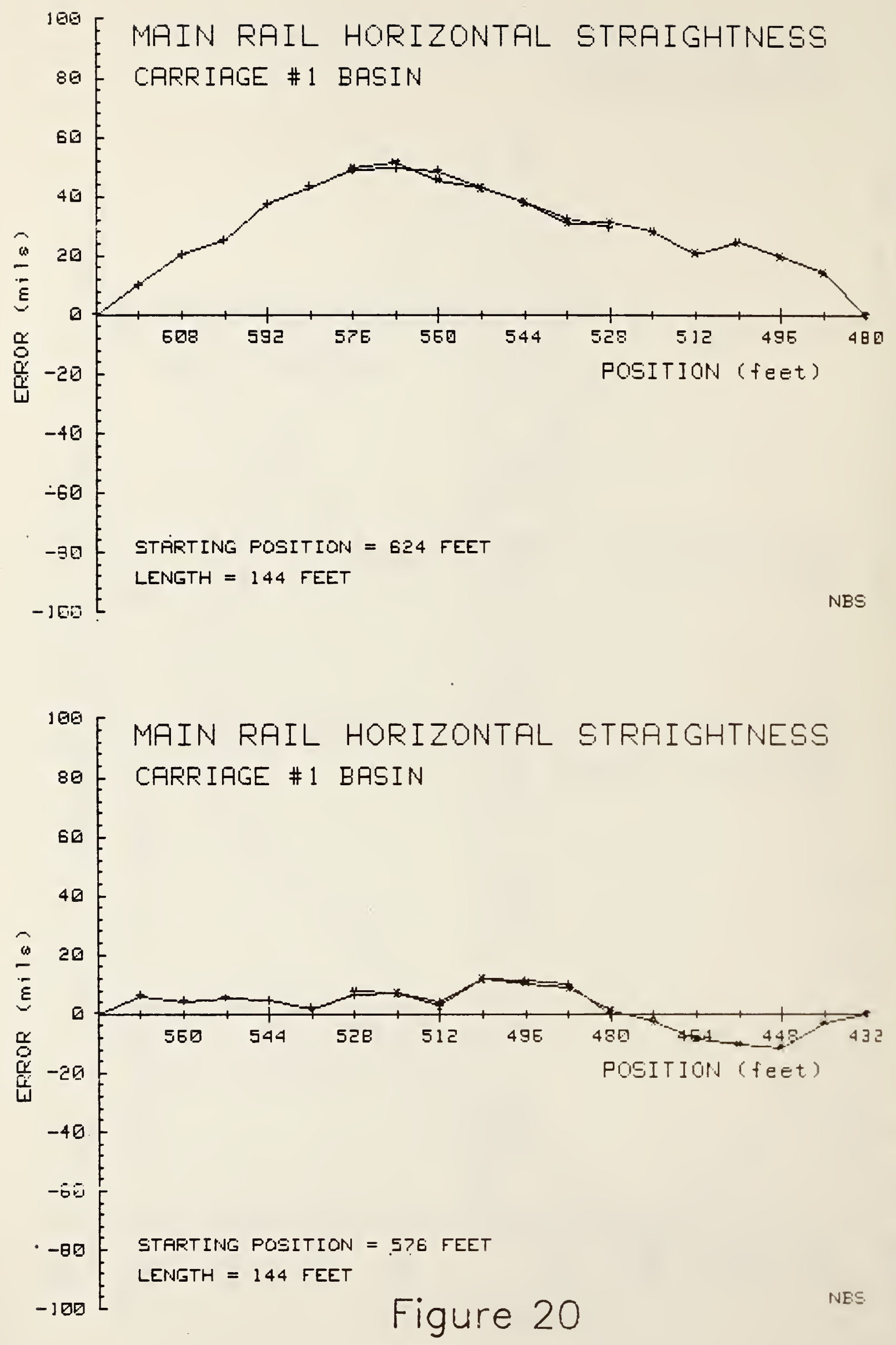

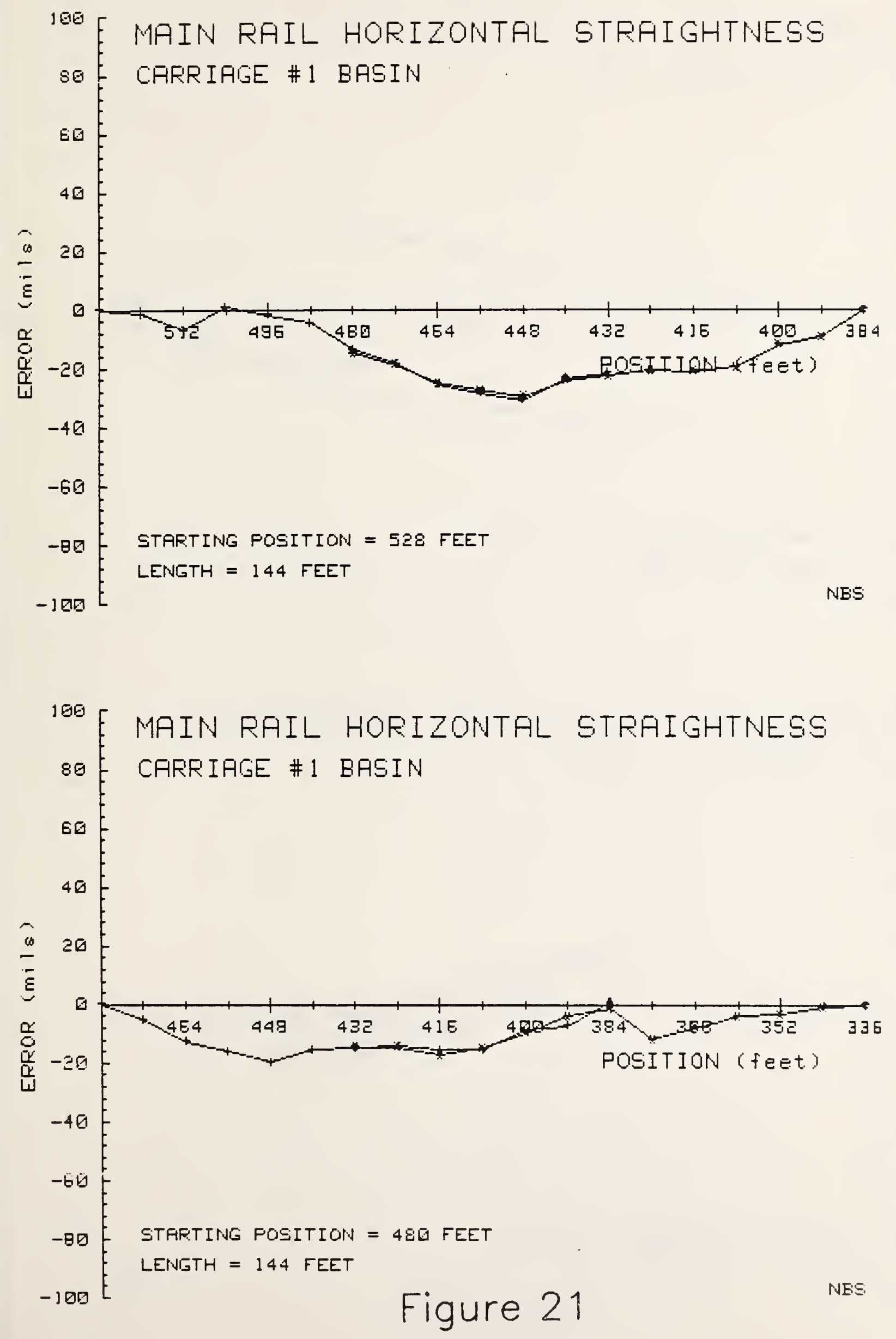

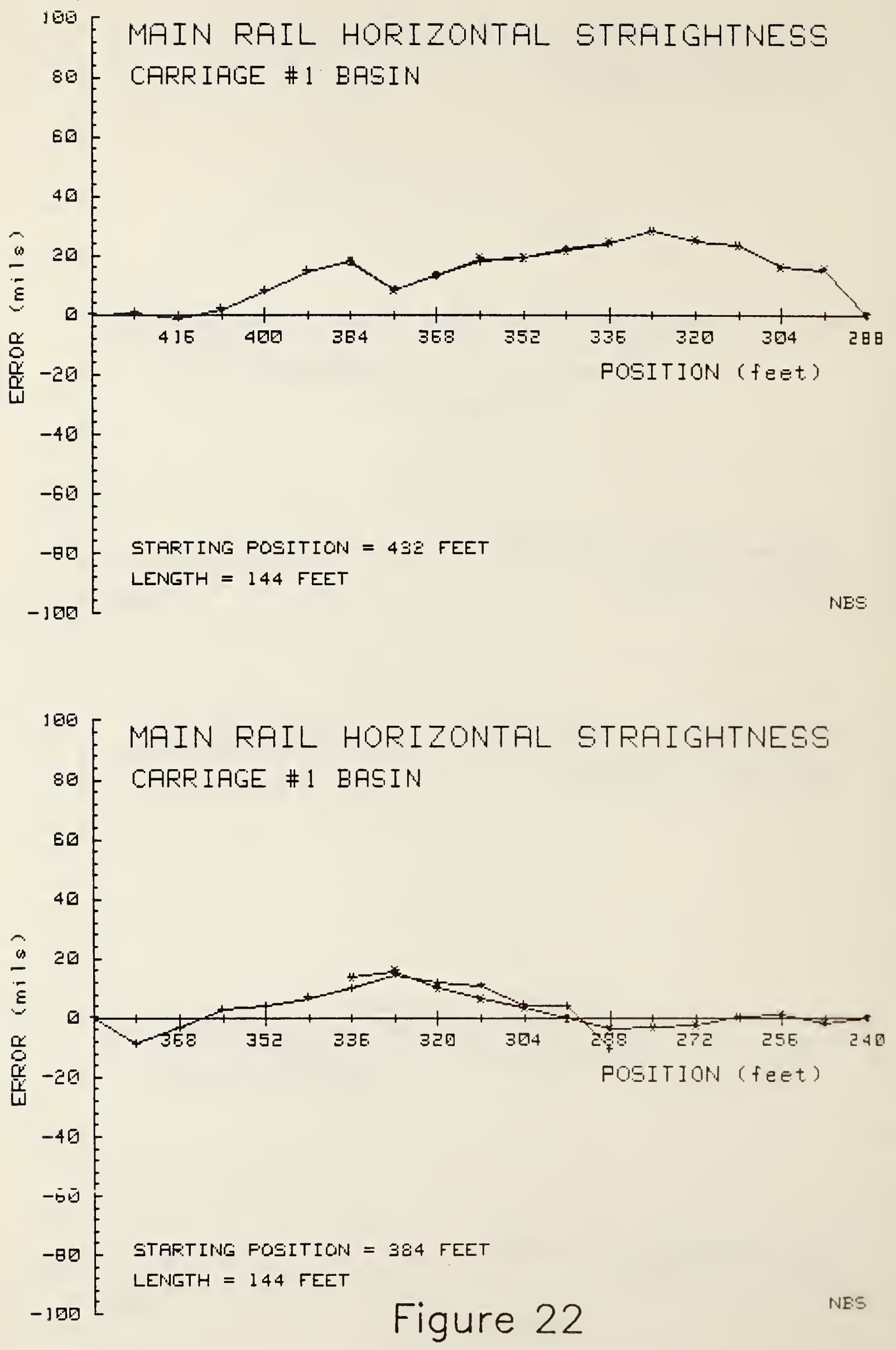

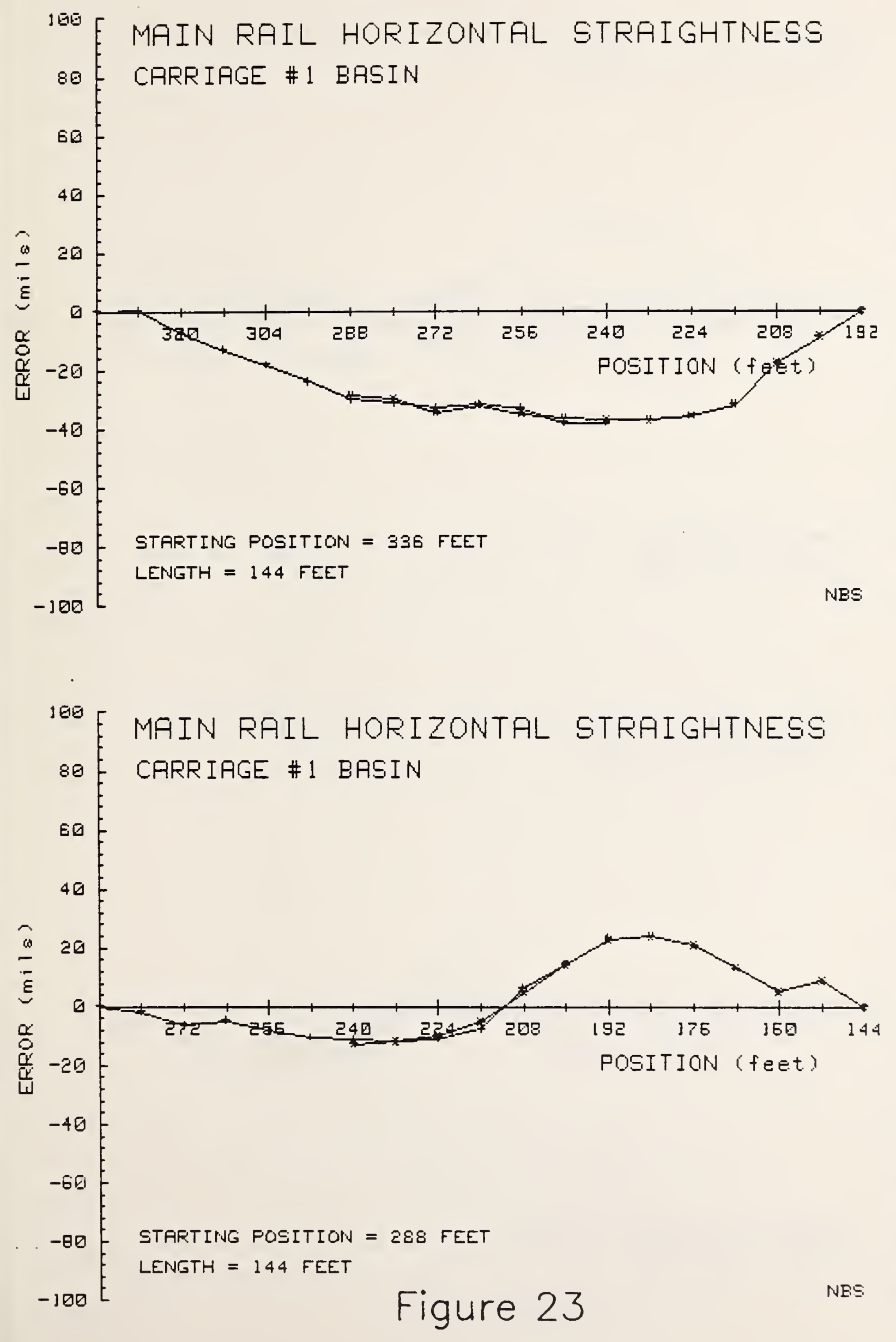

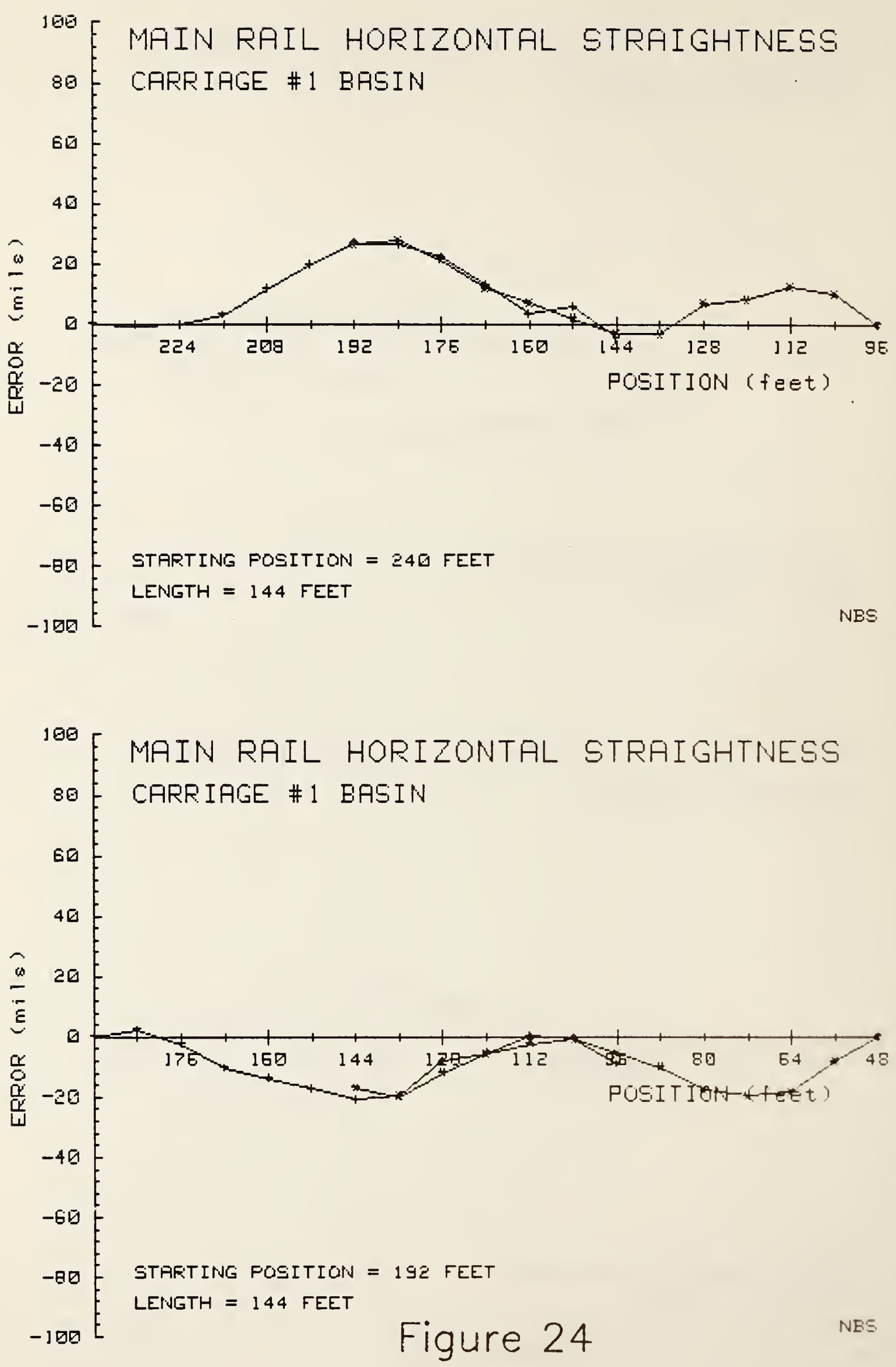

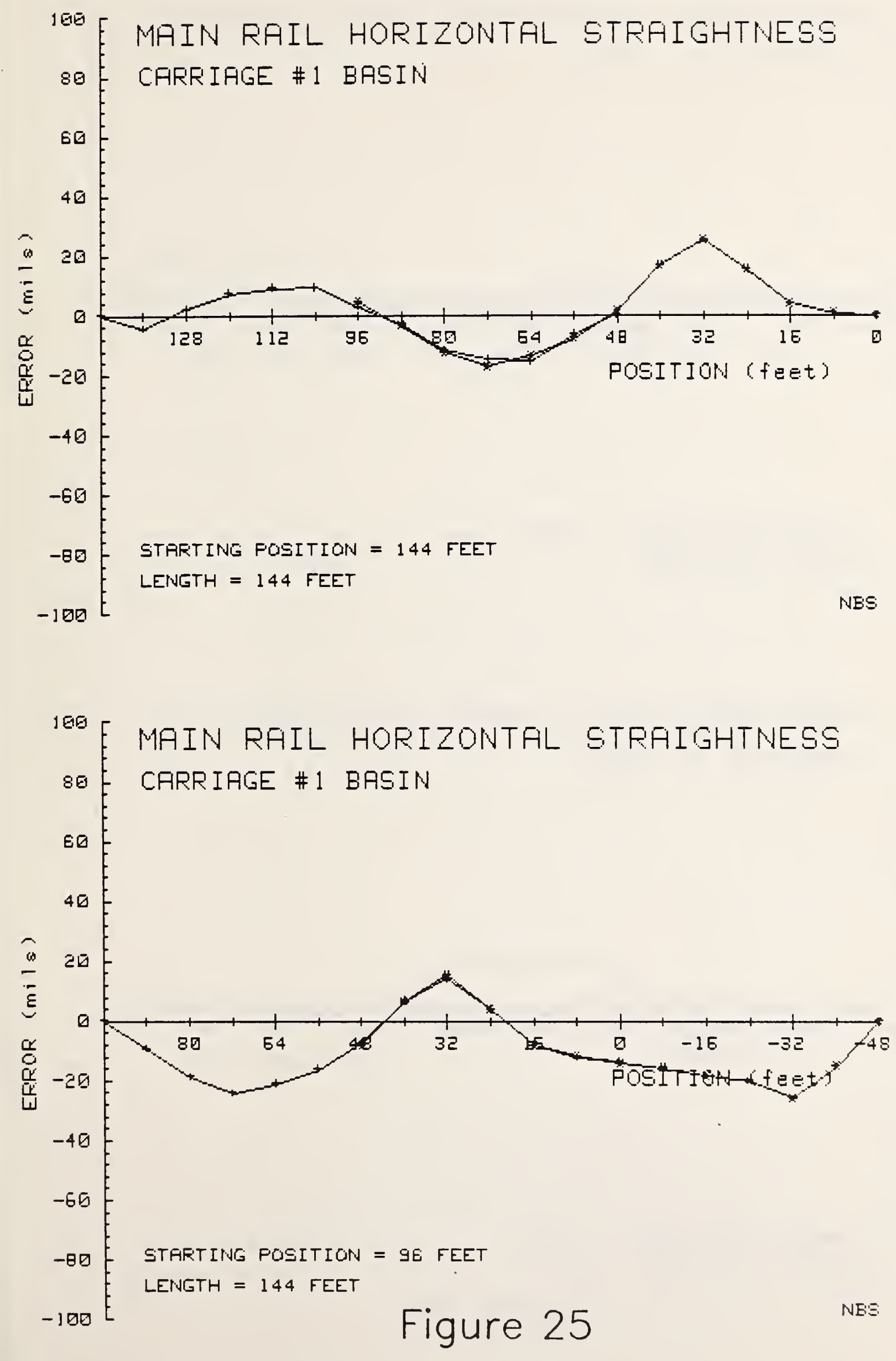

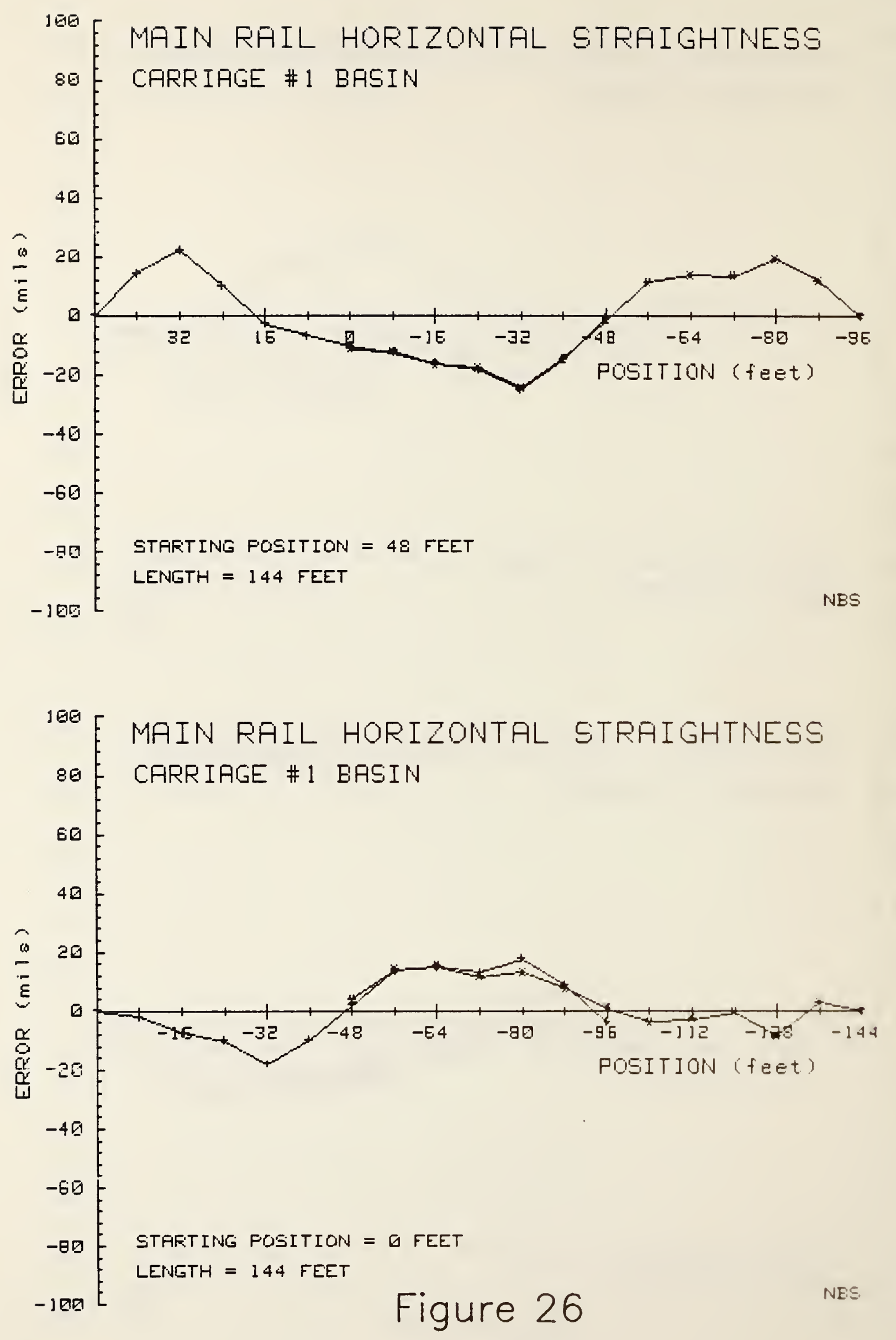

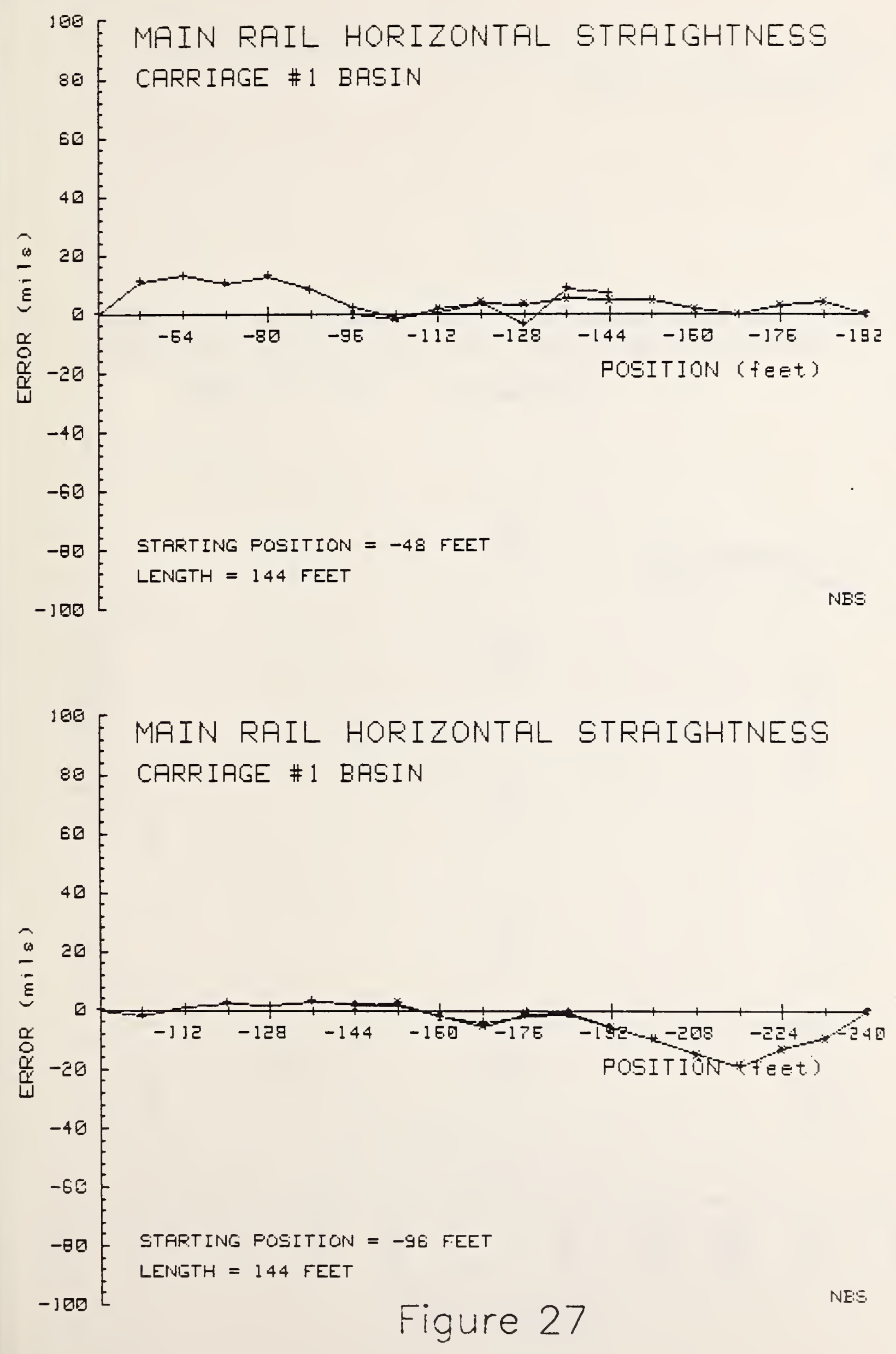


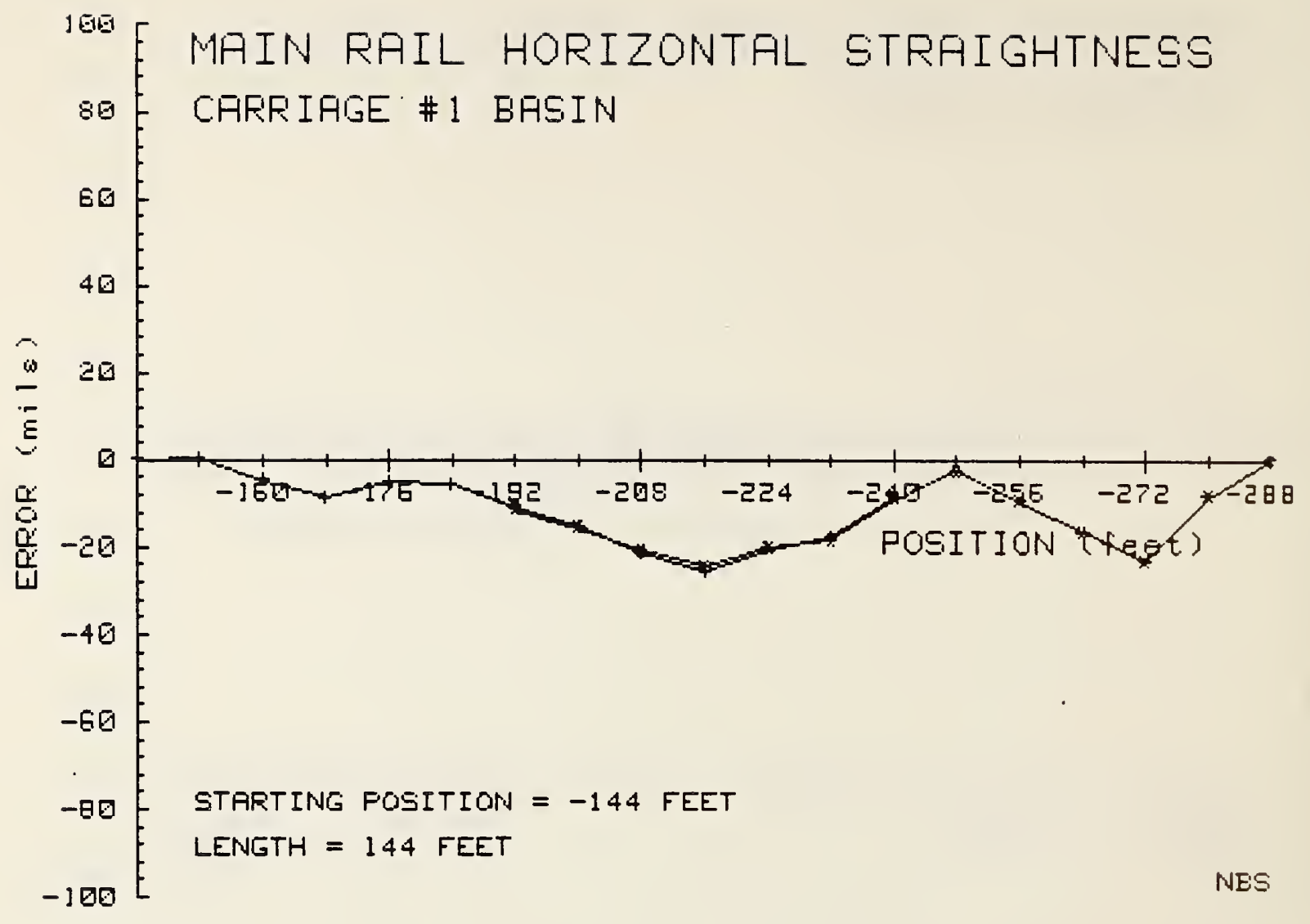

Figure 28 


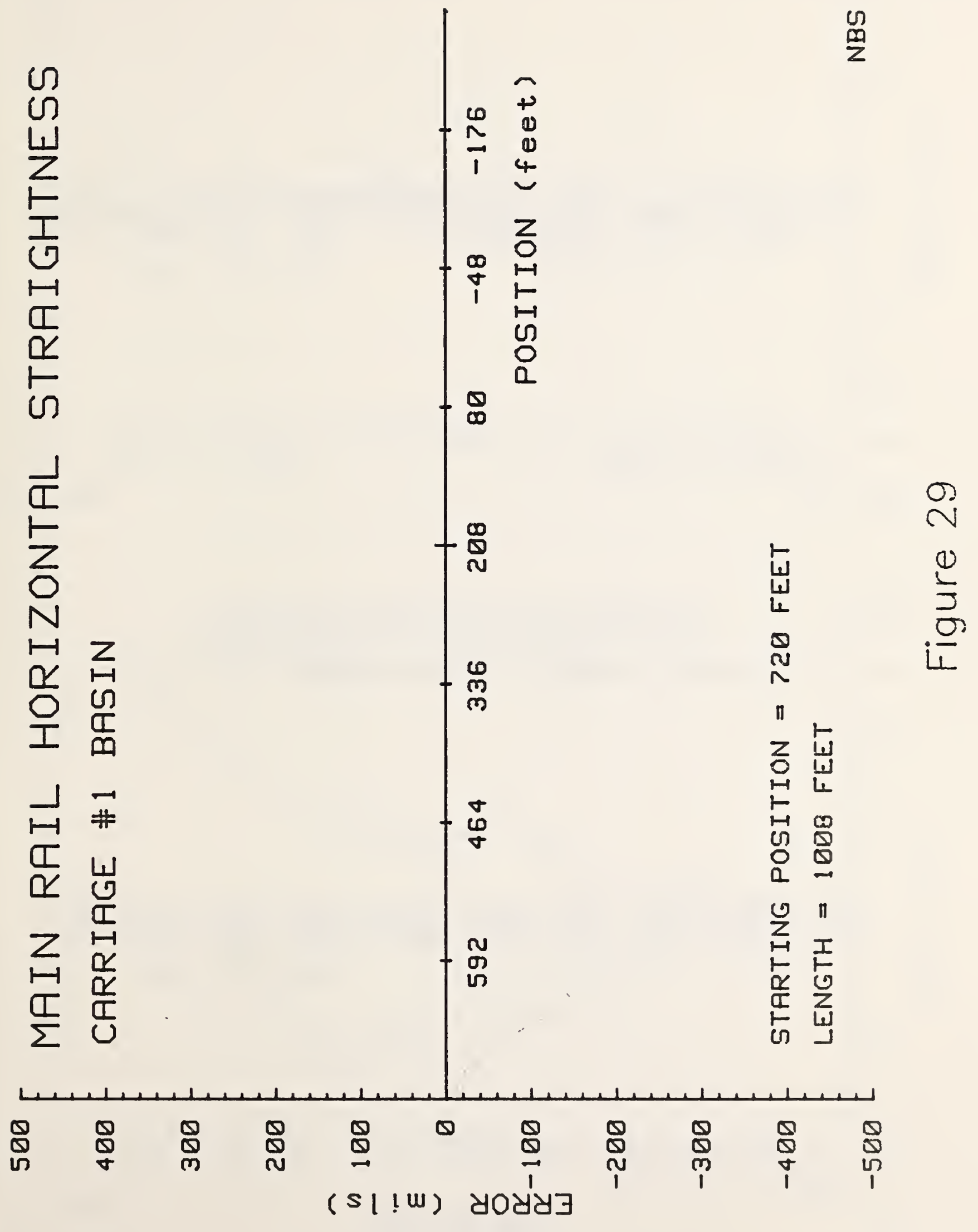



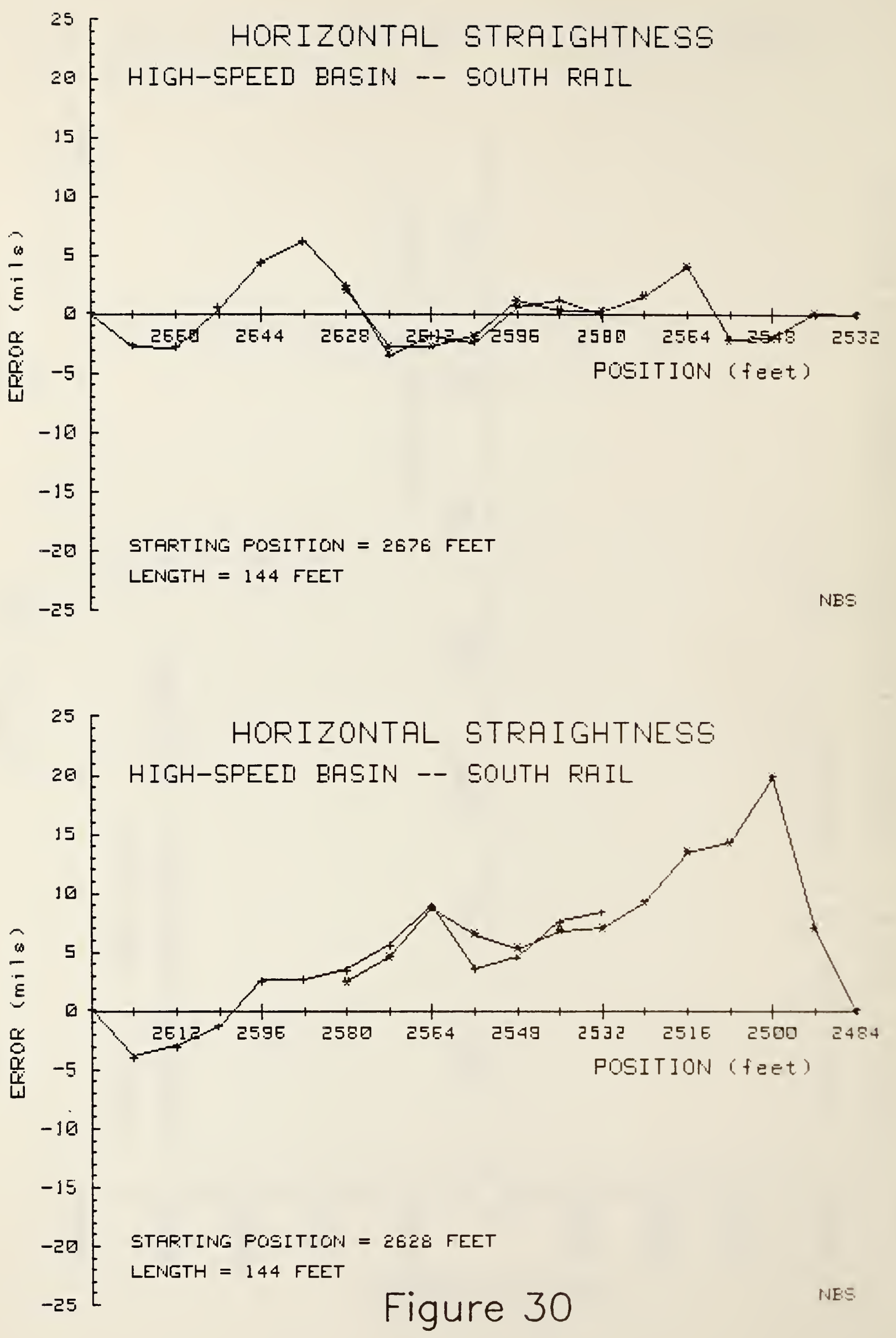

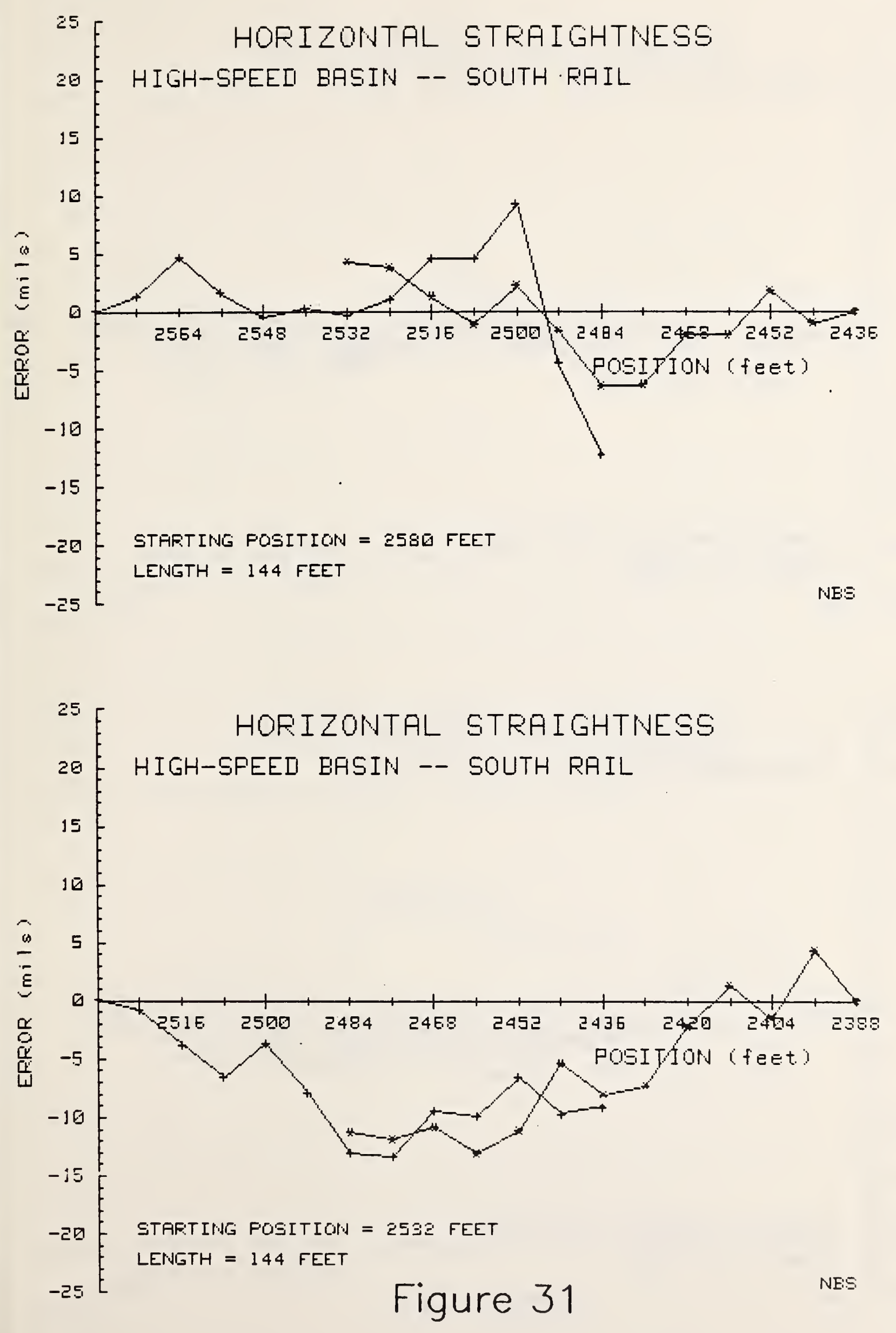

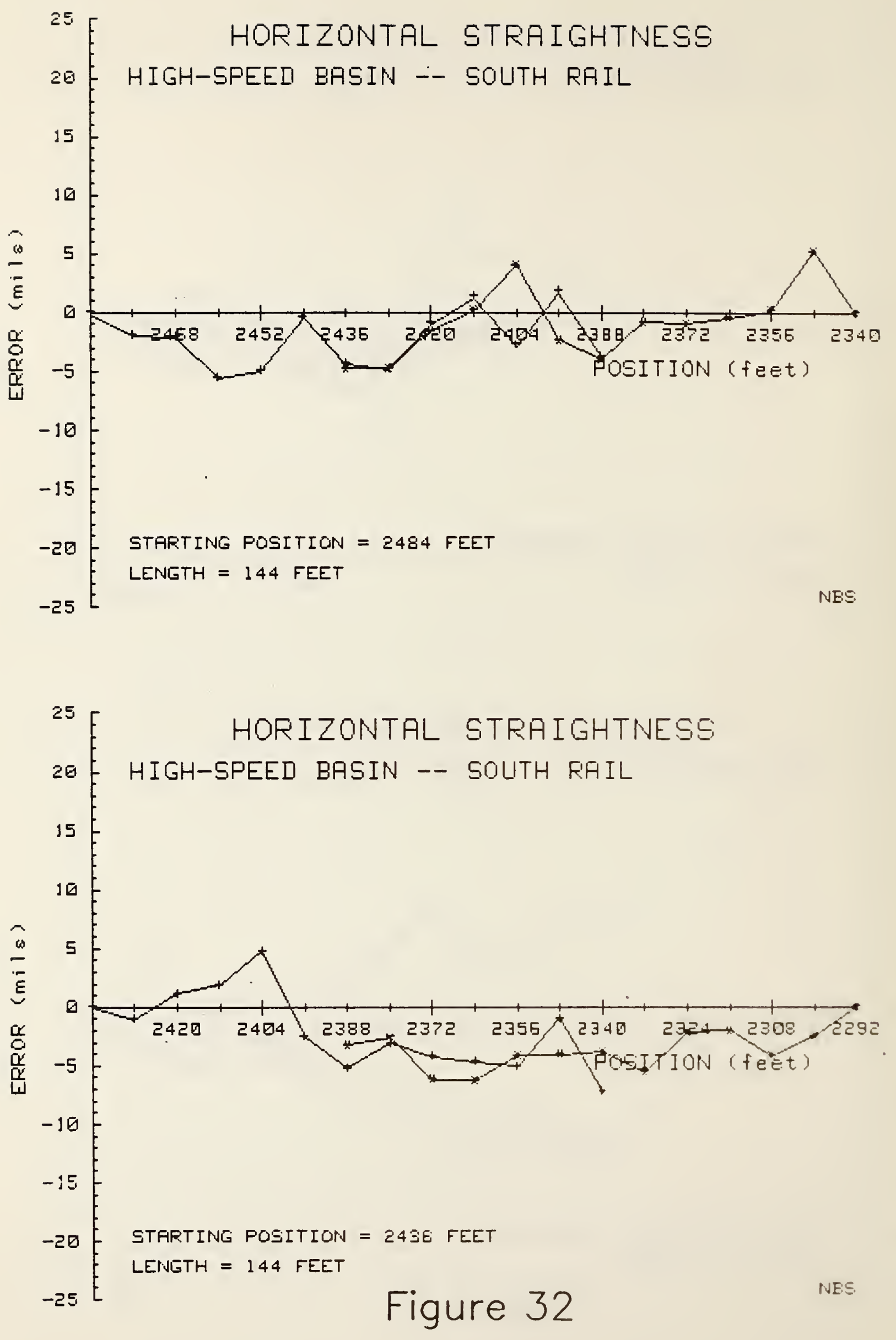

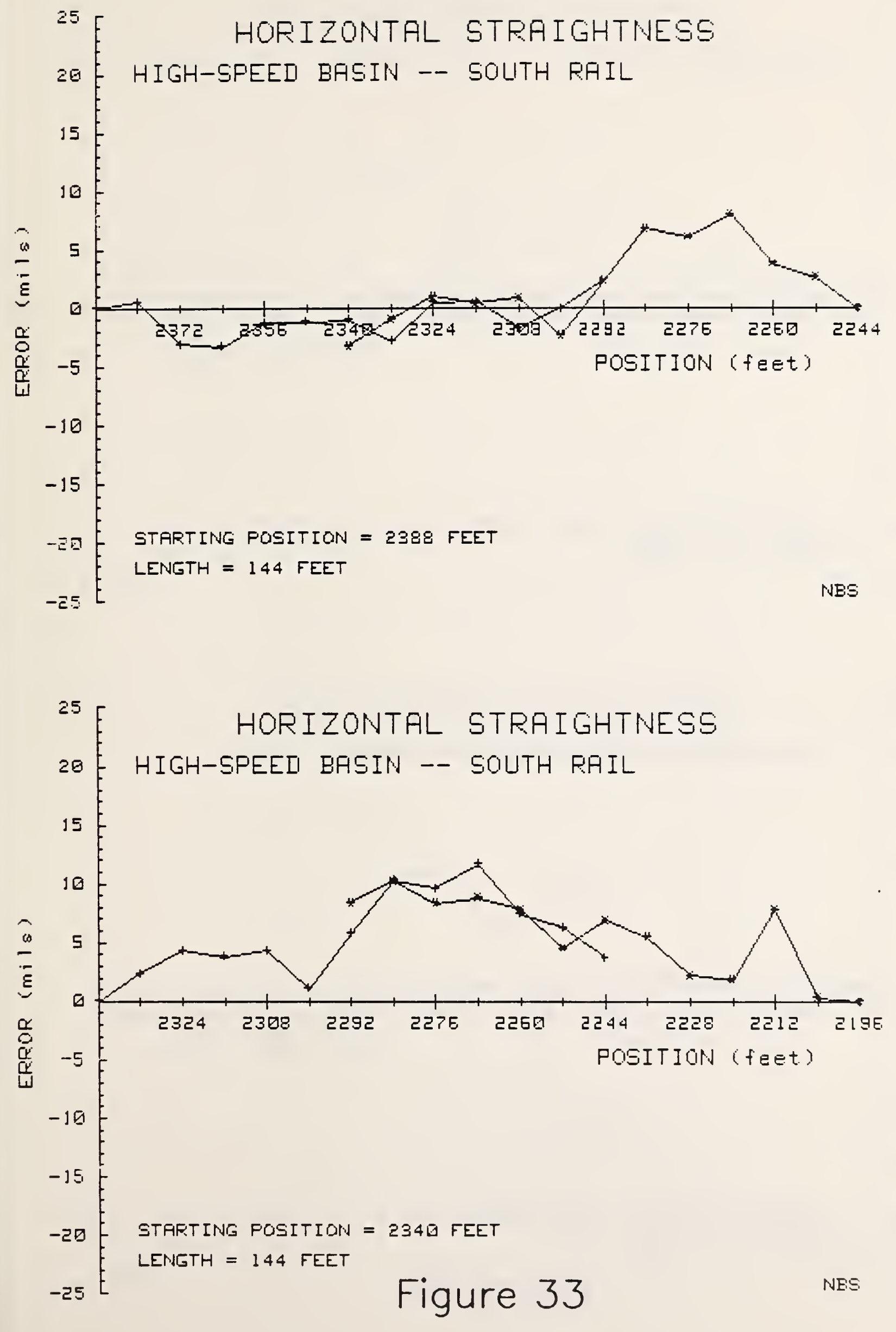

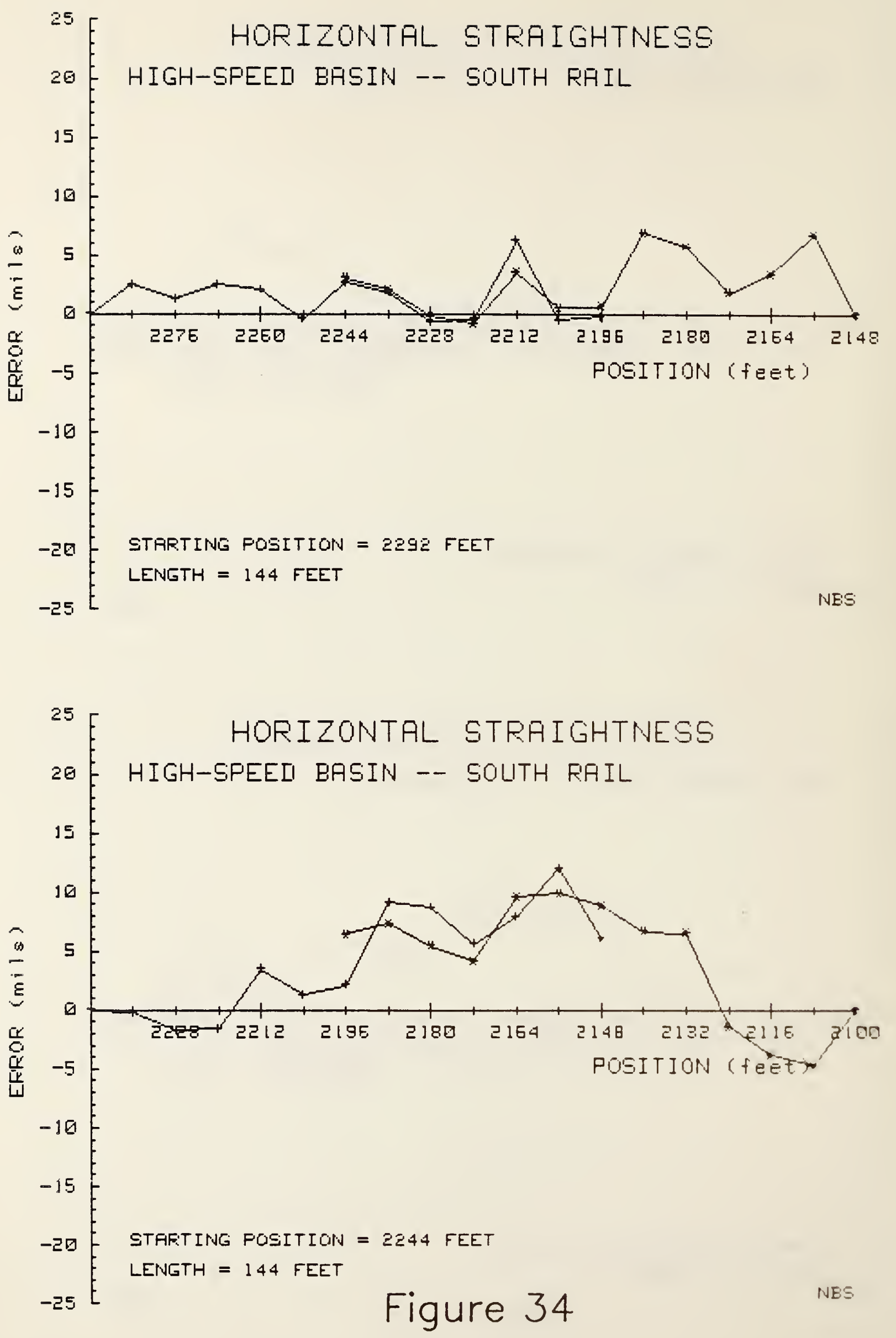

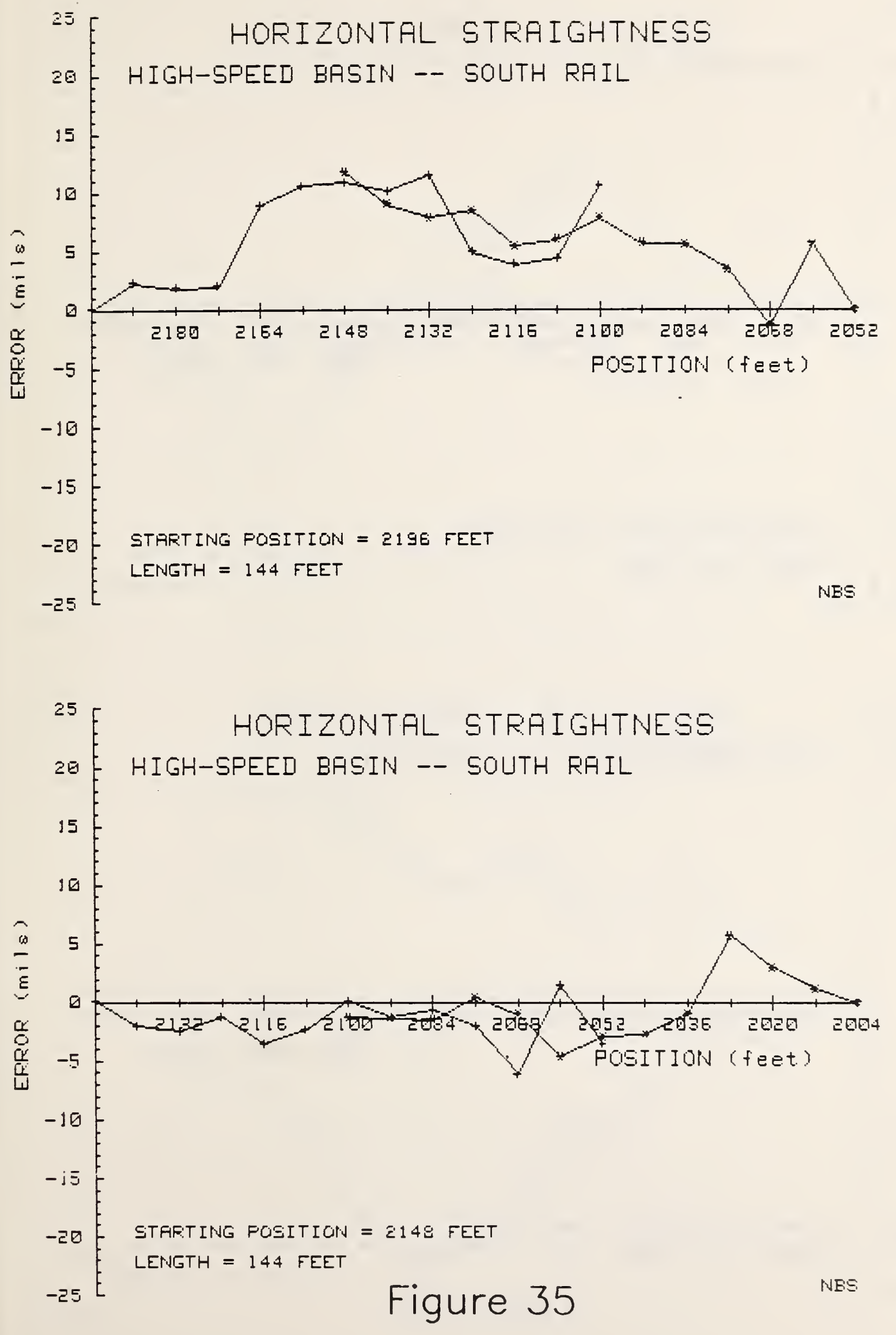

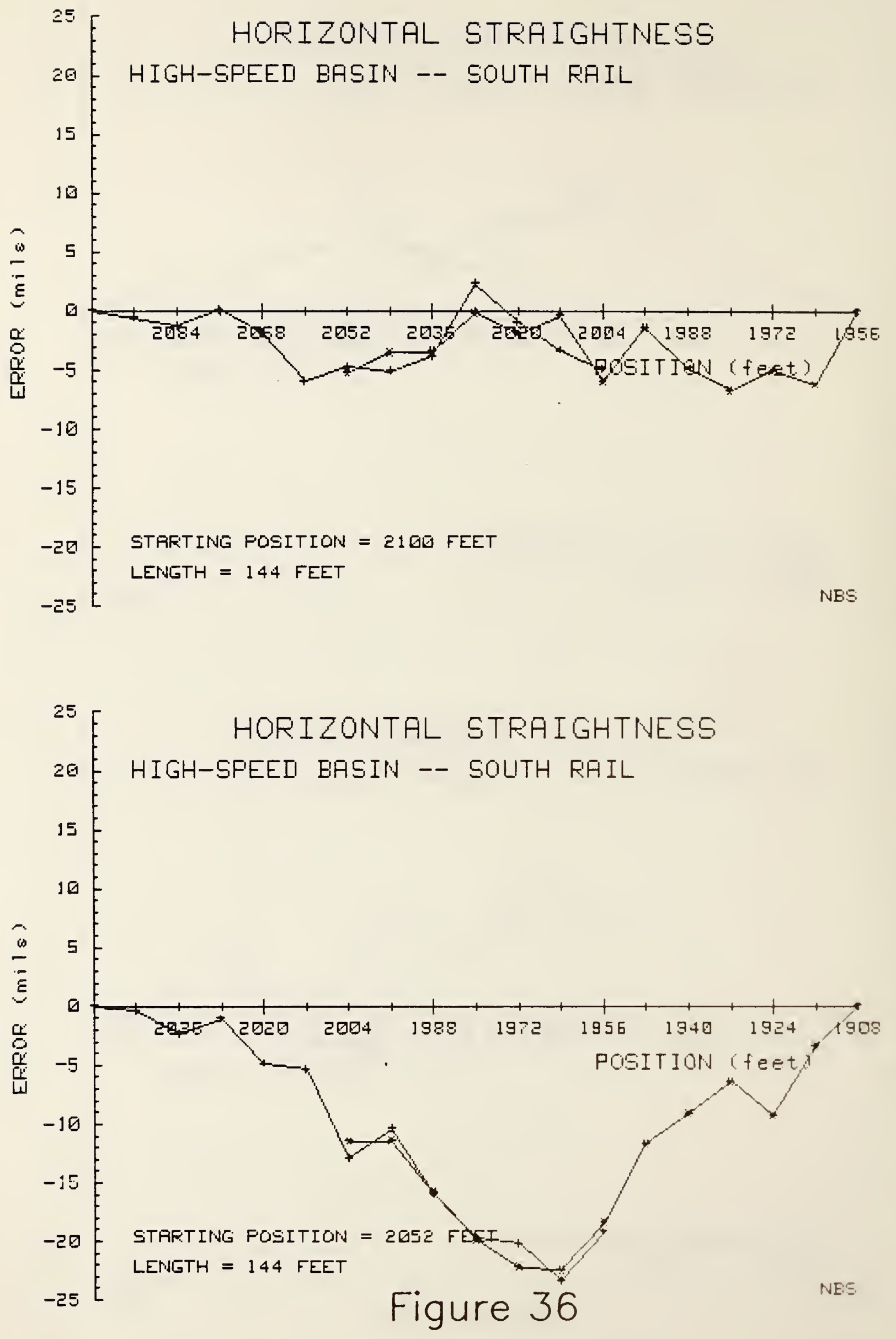

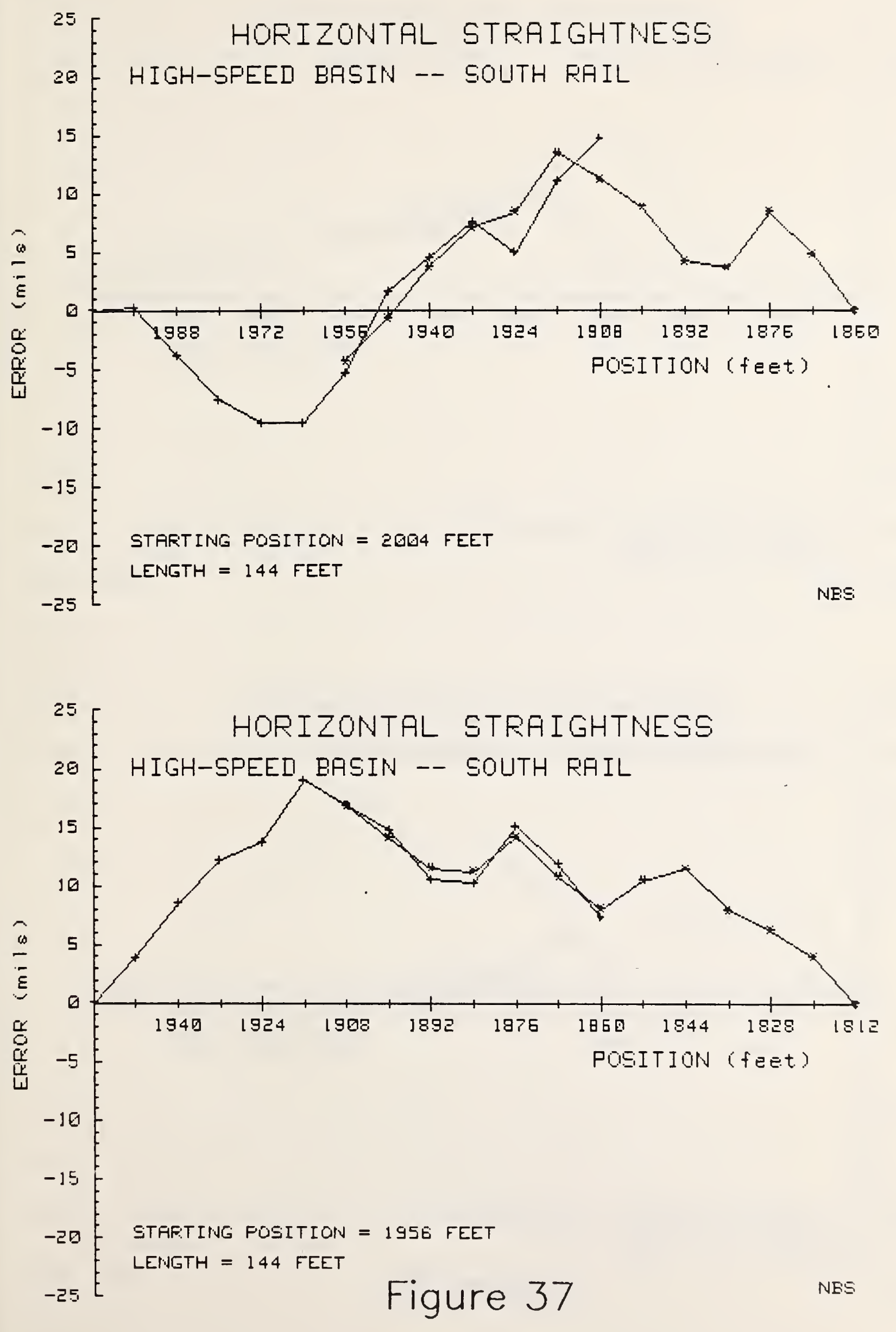

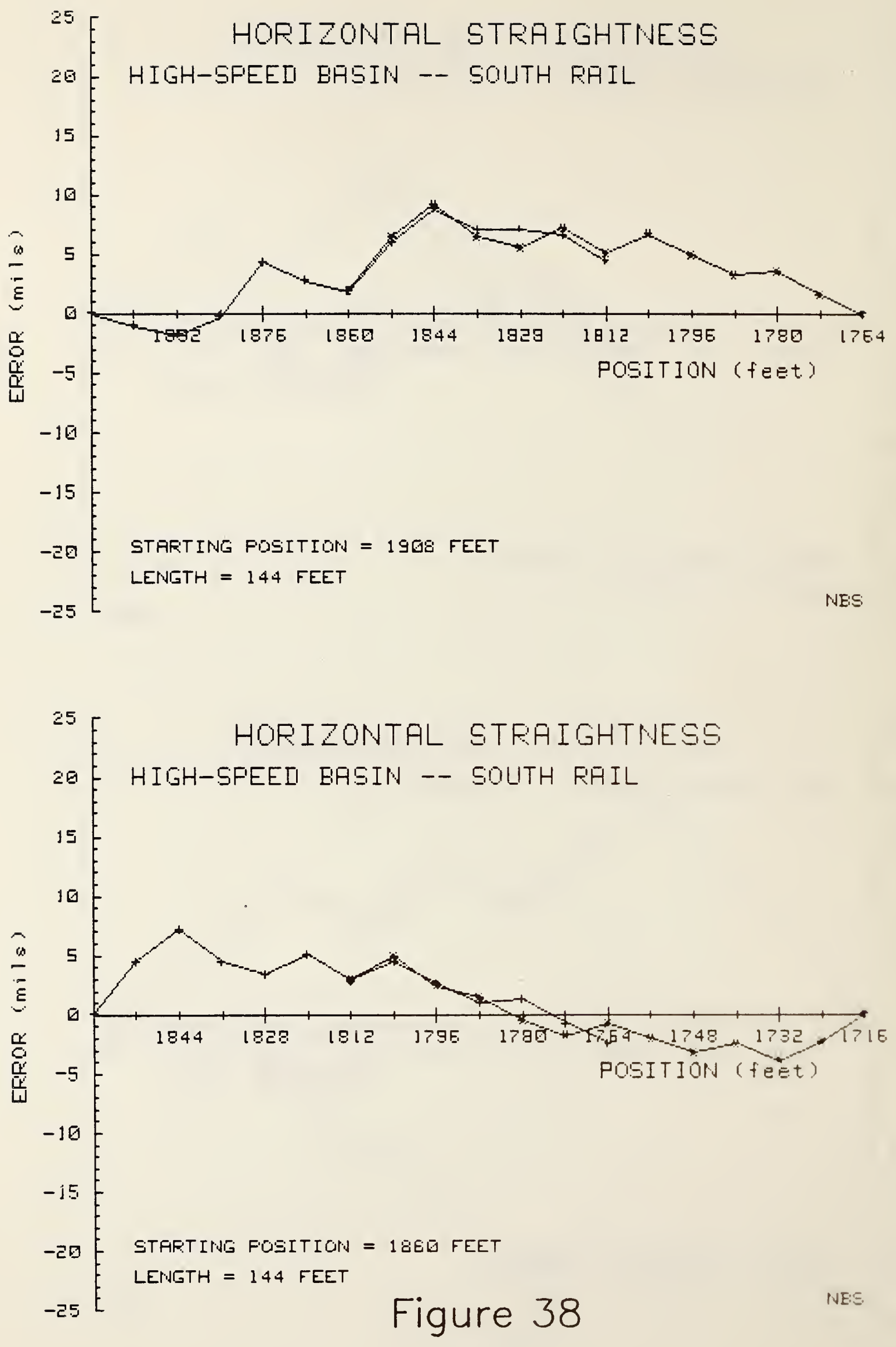

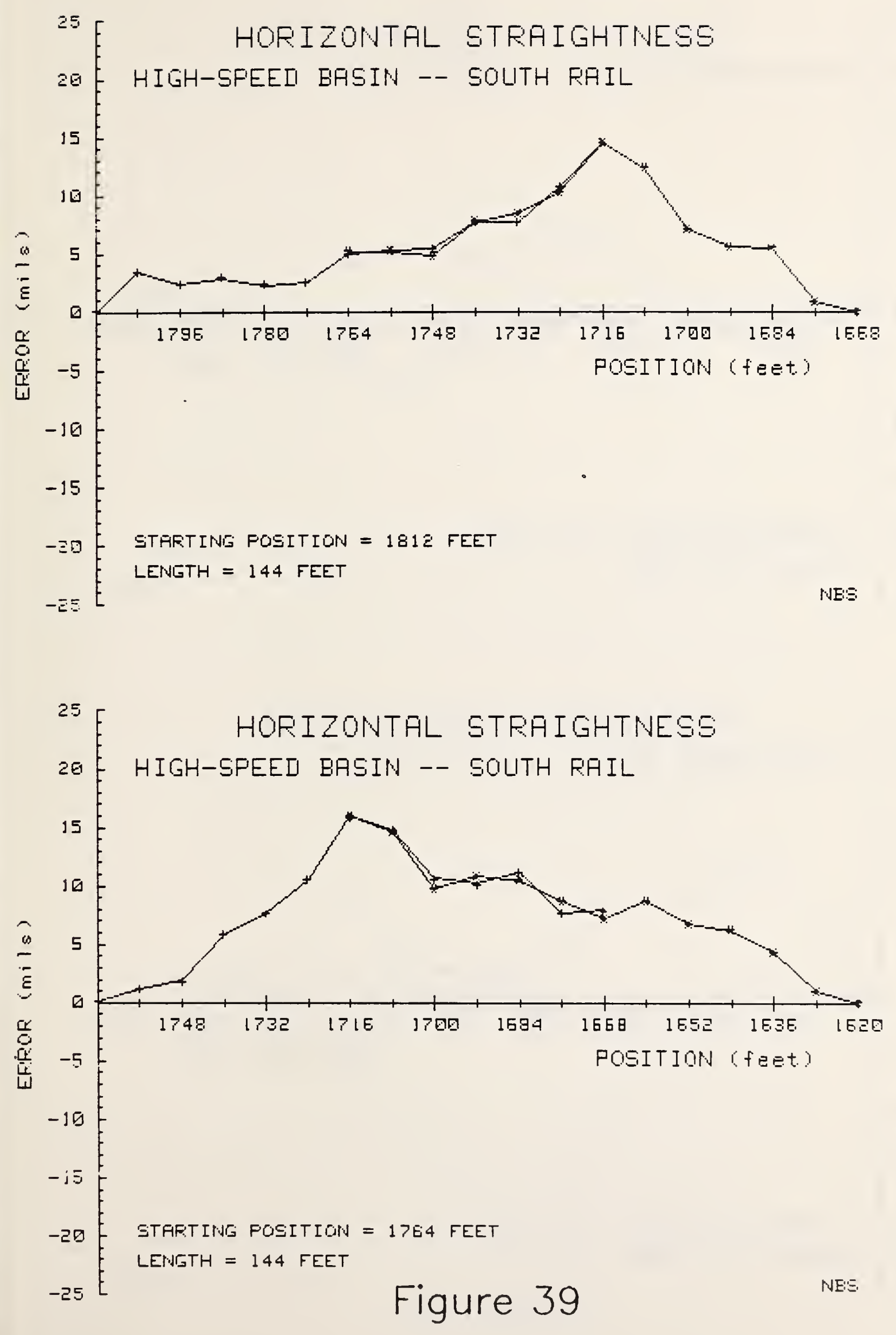

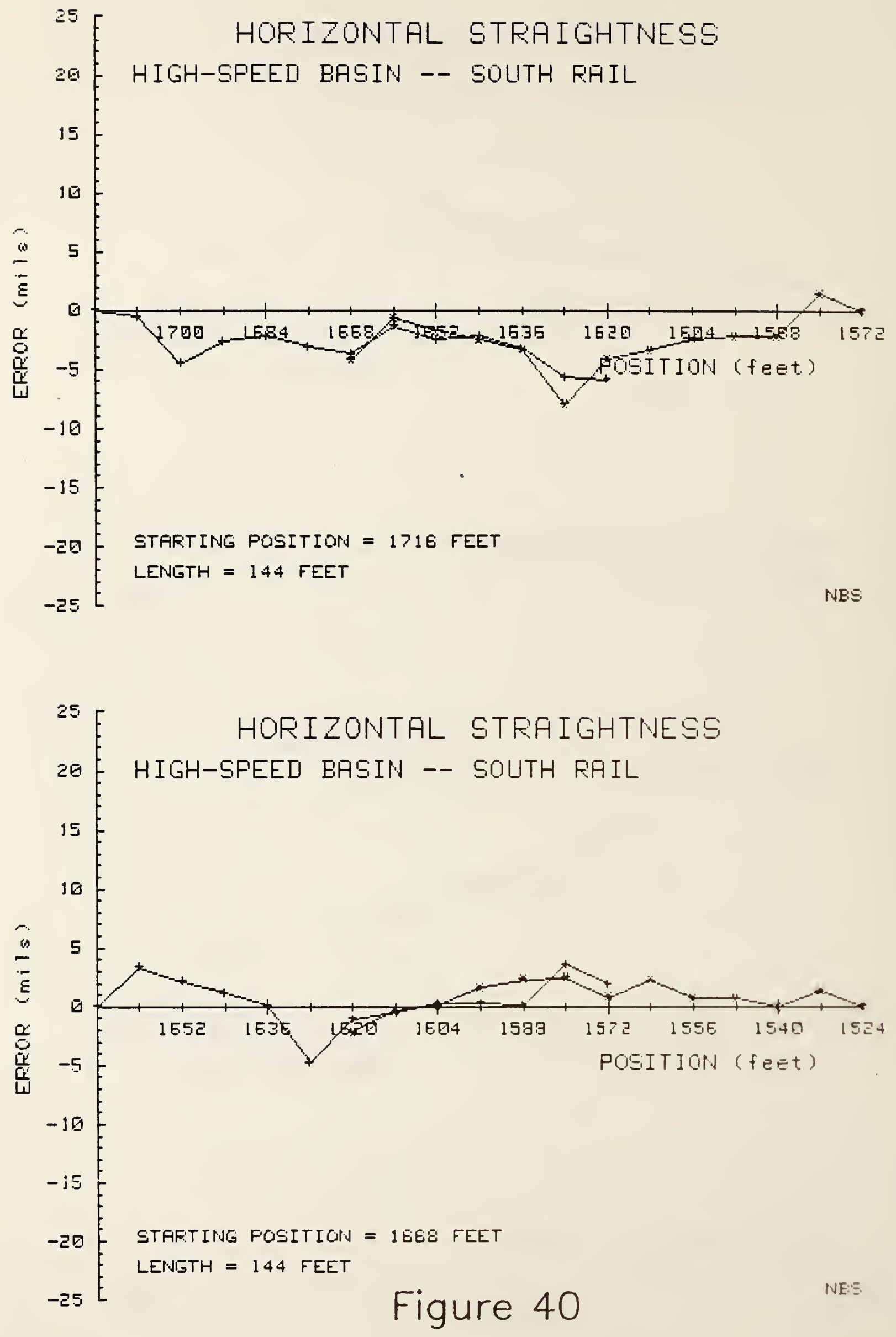

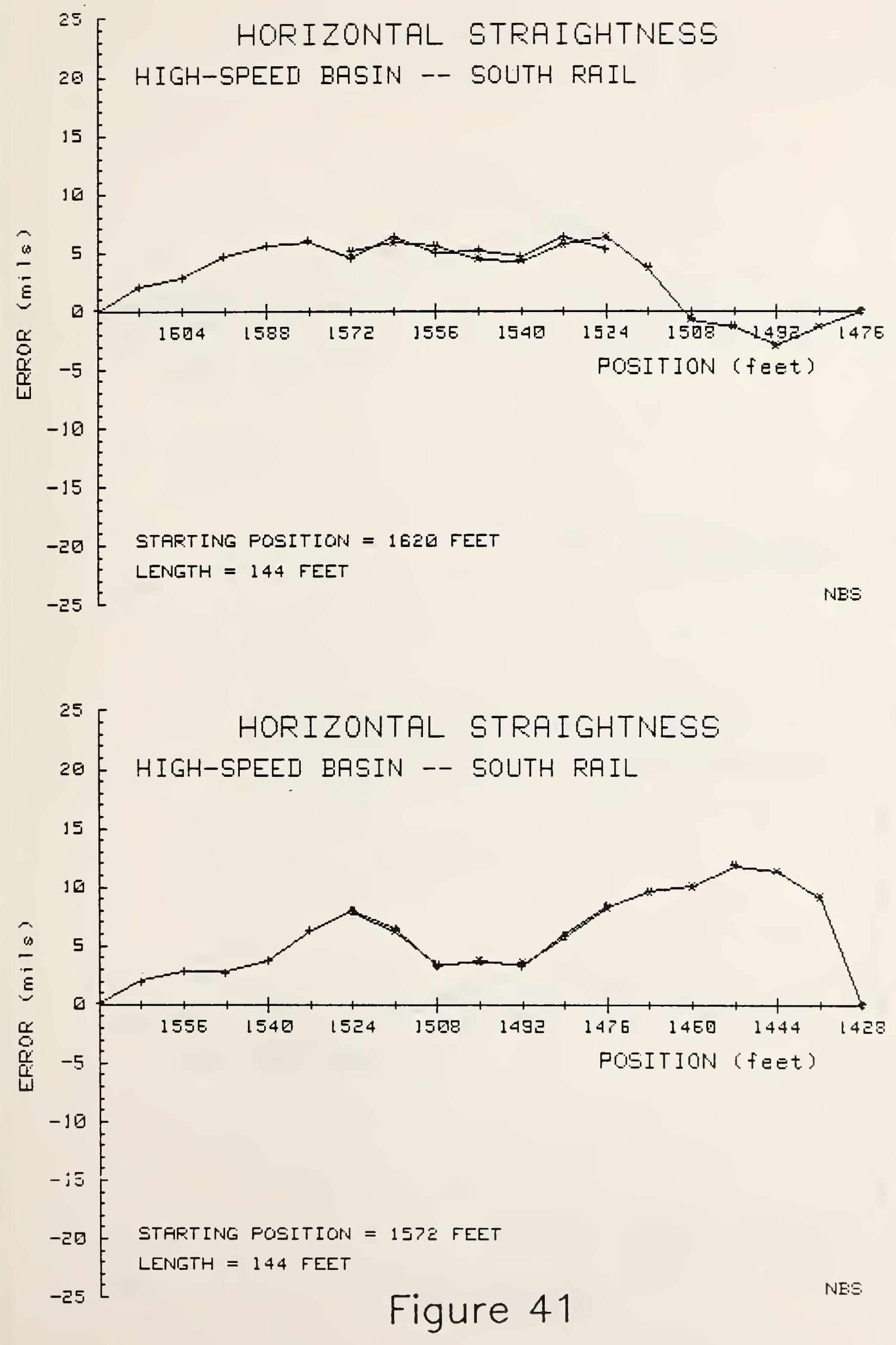

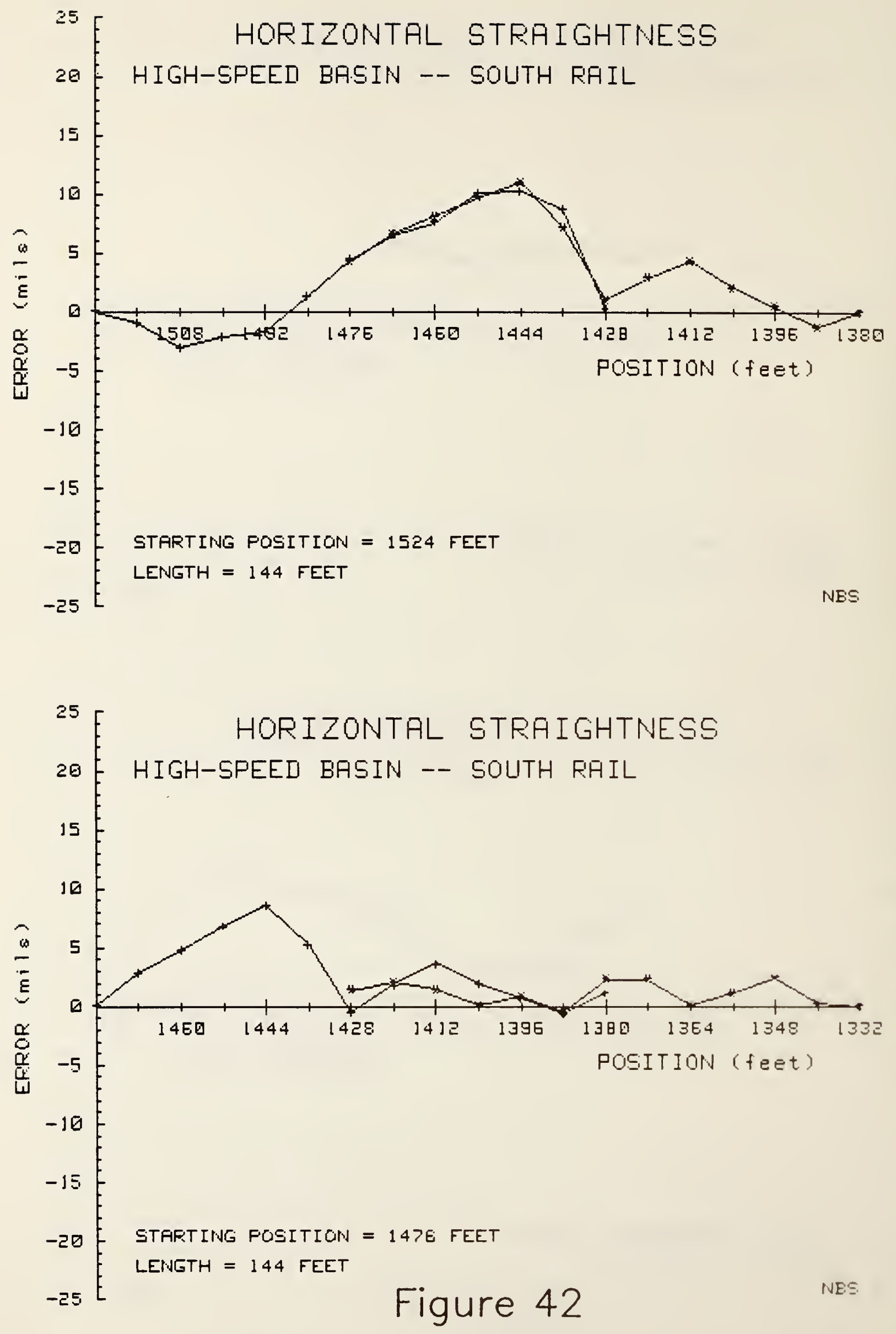

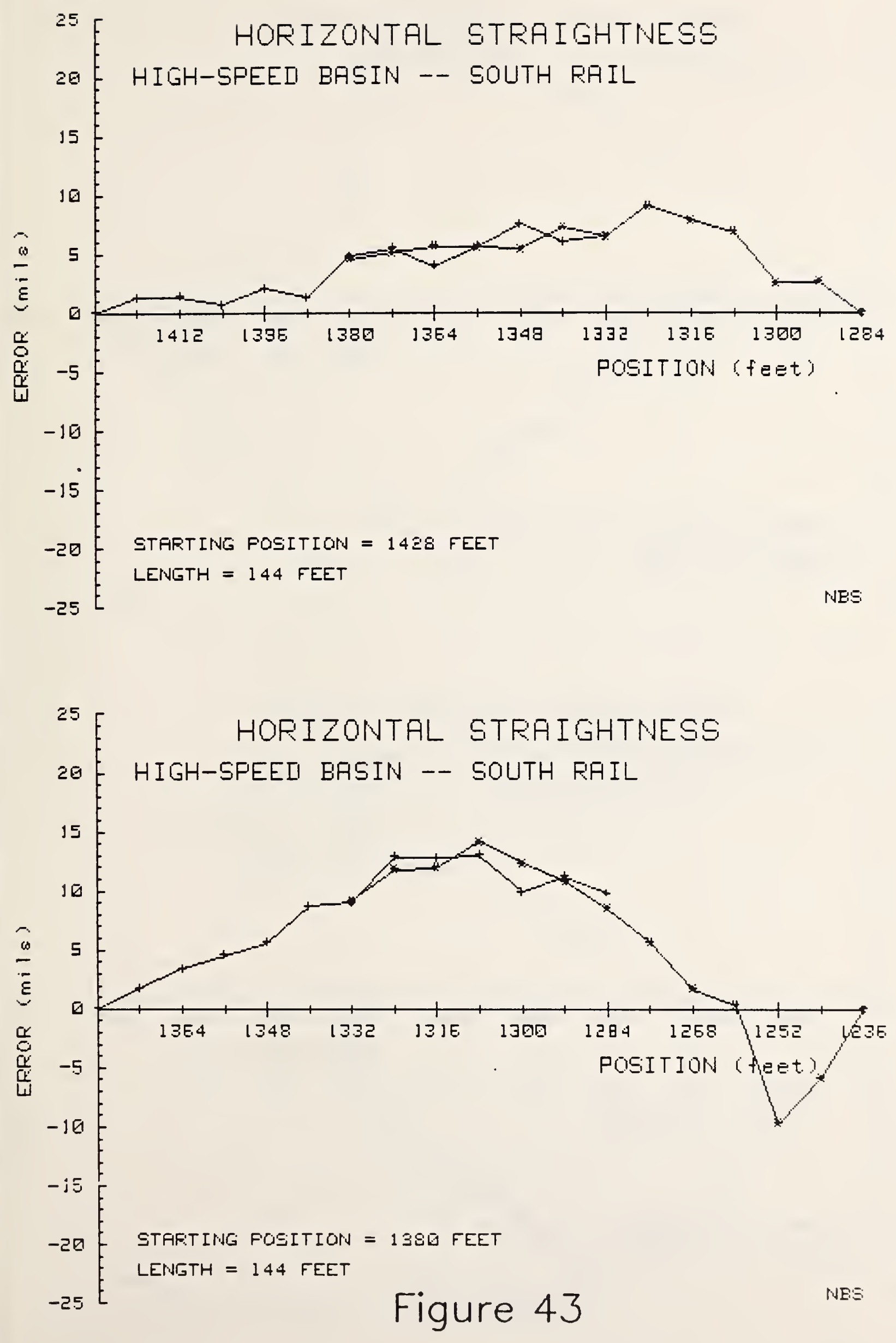

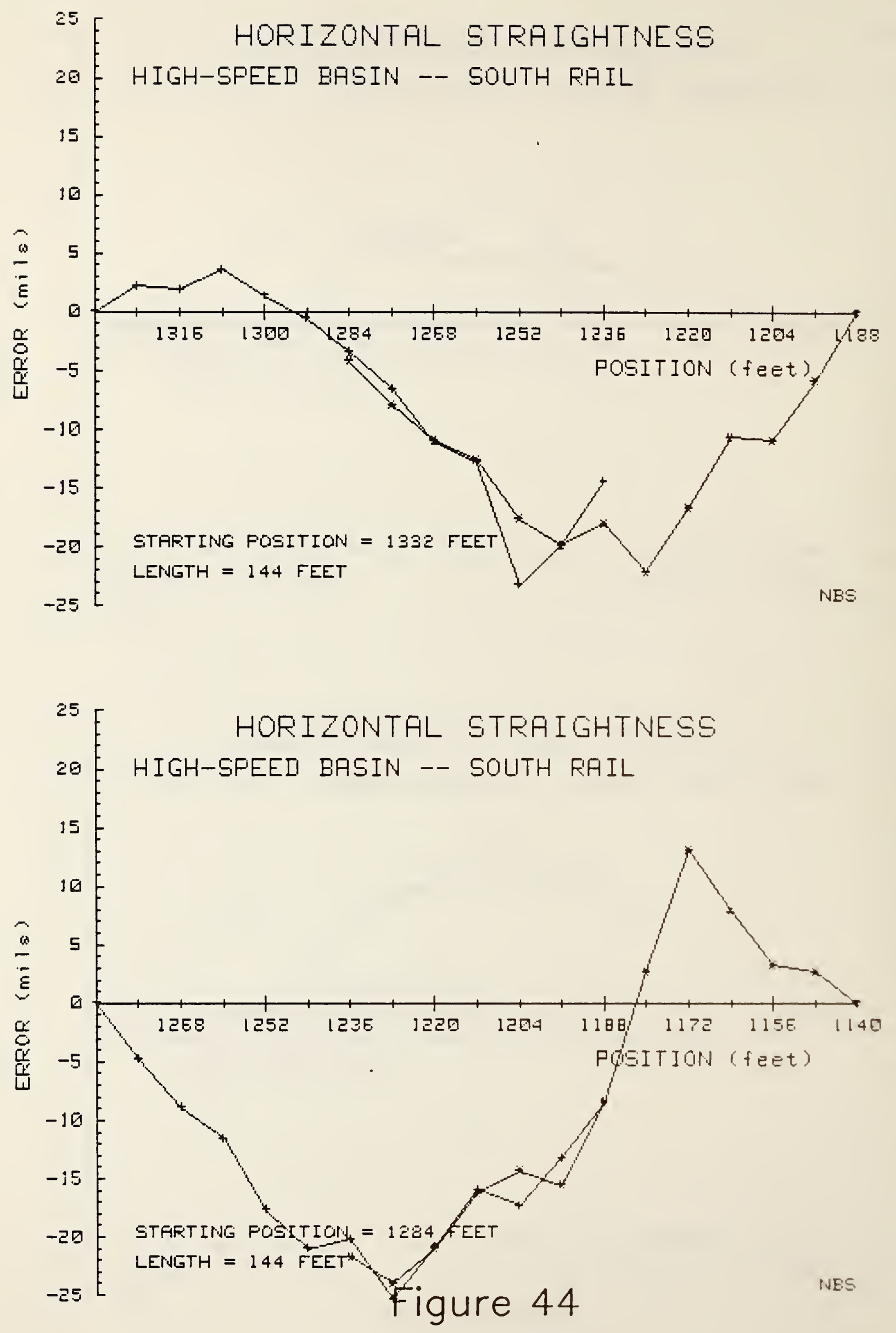

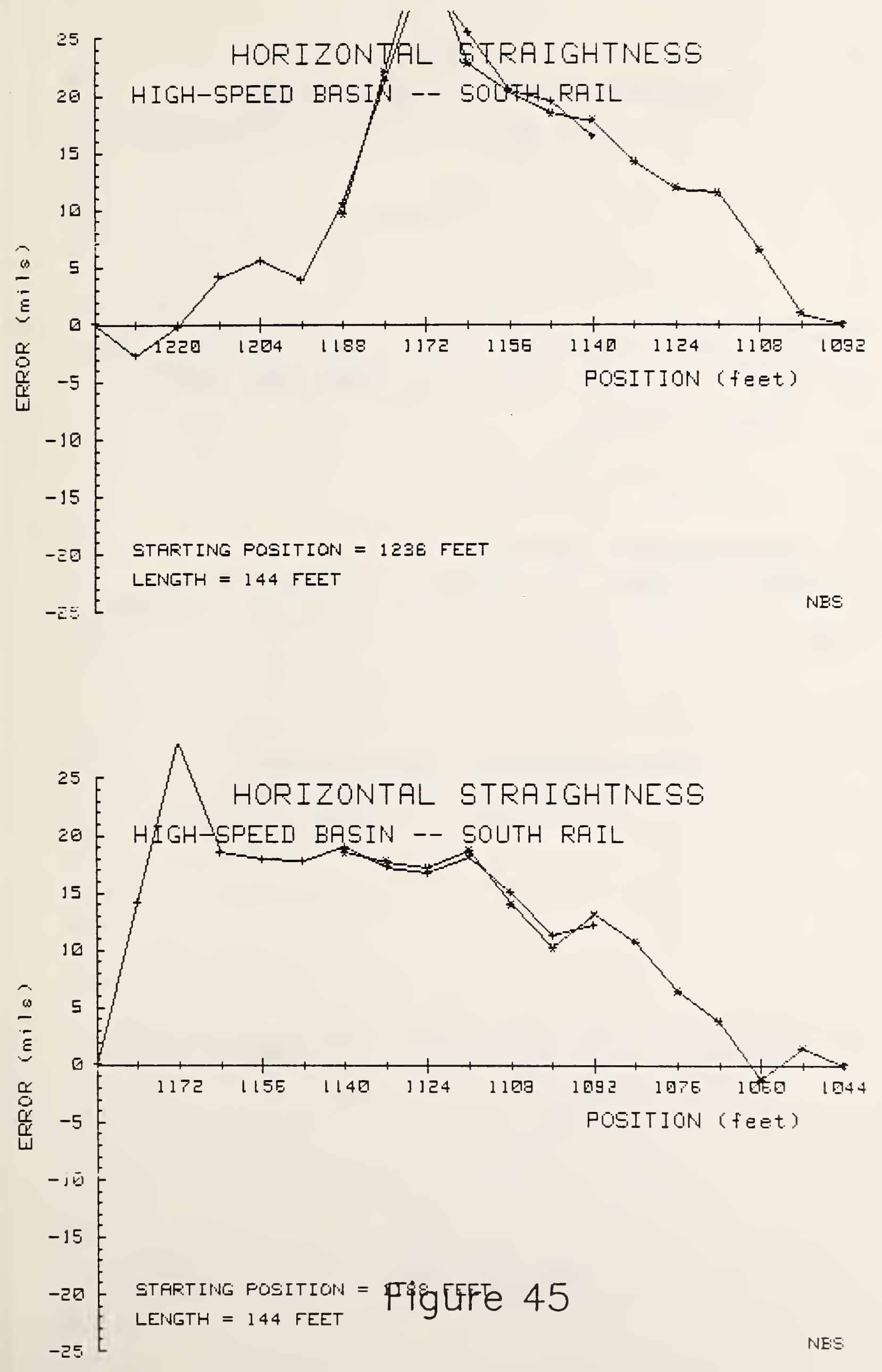


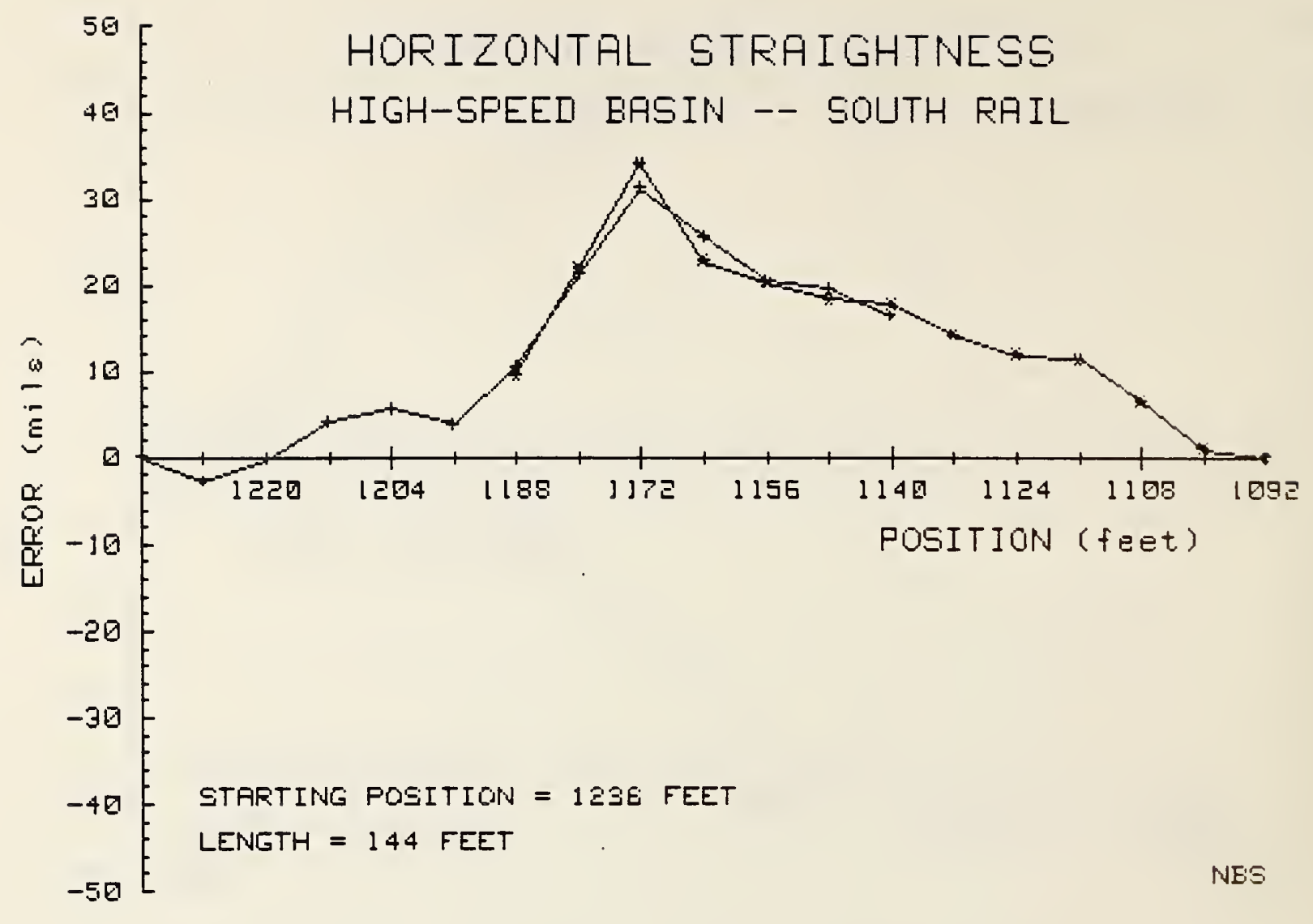

Figure 46 

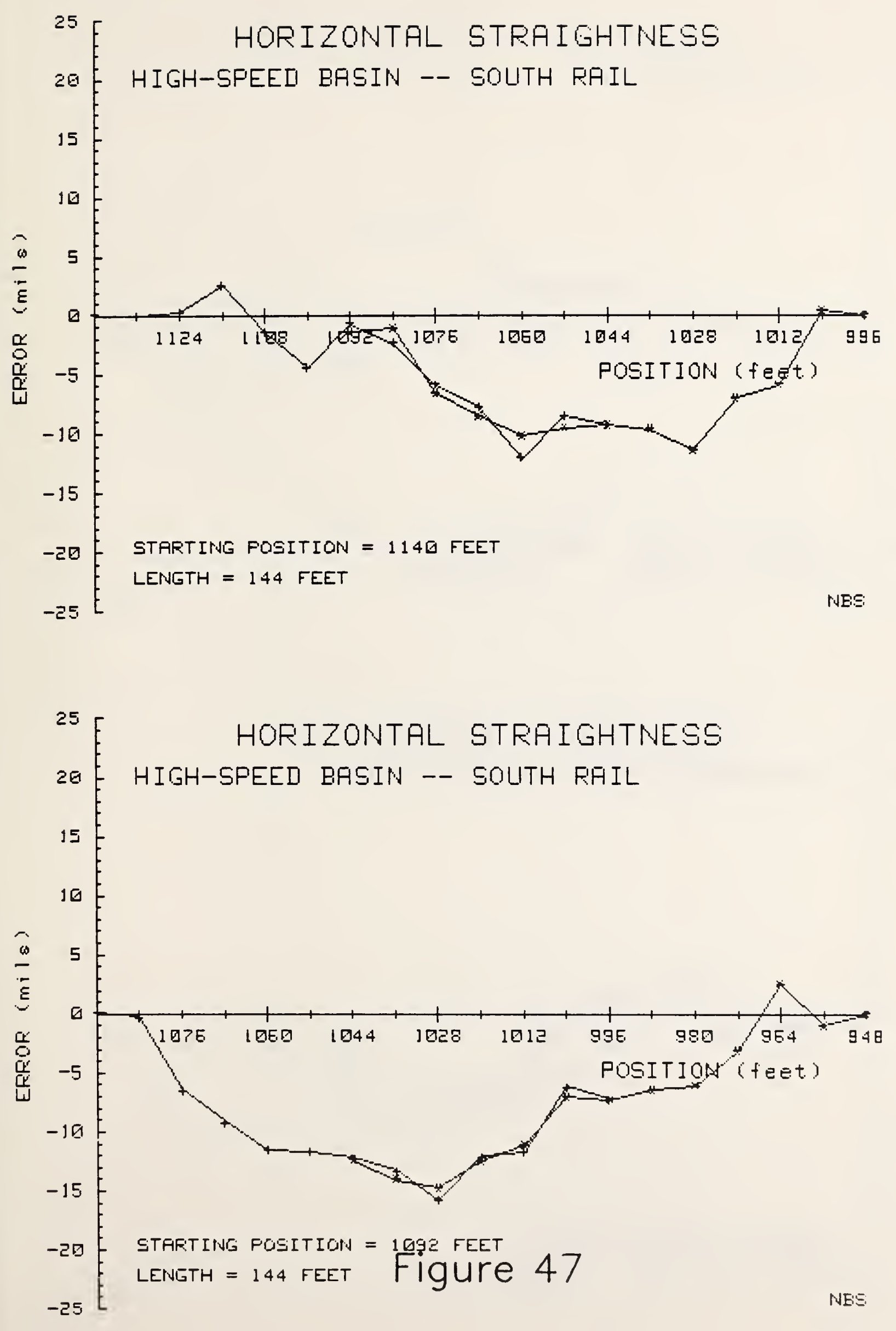

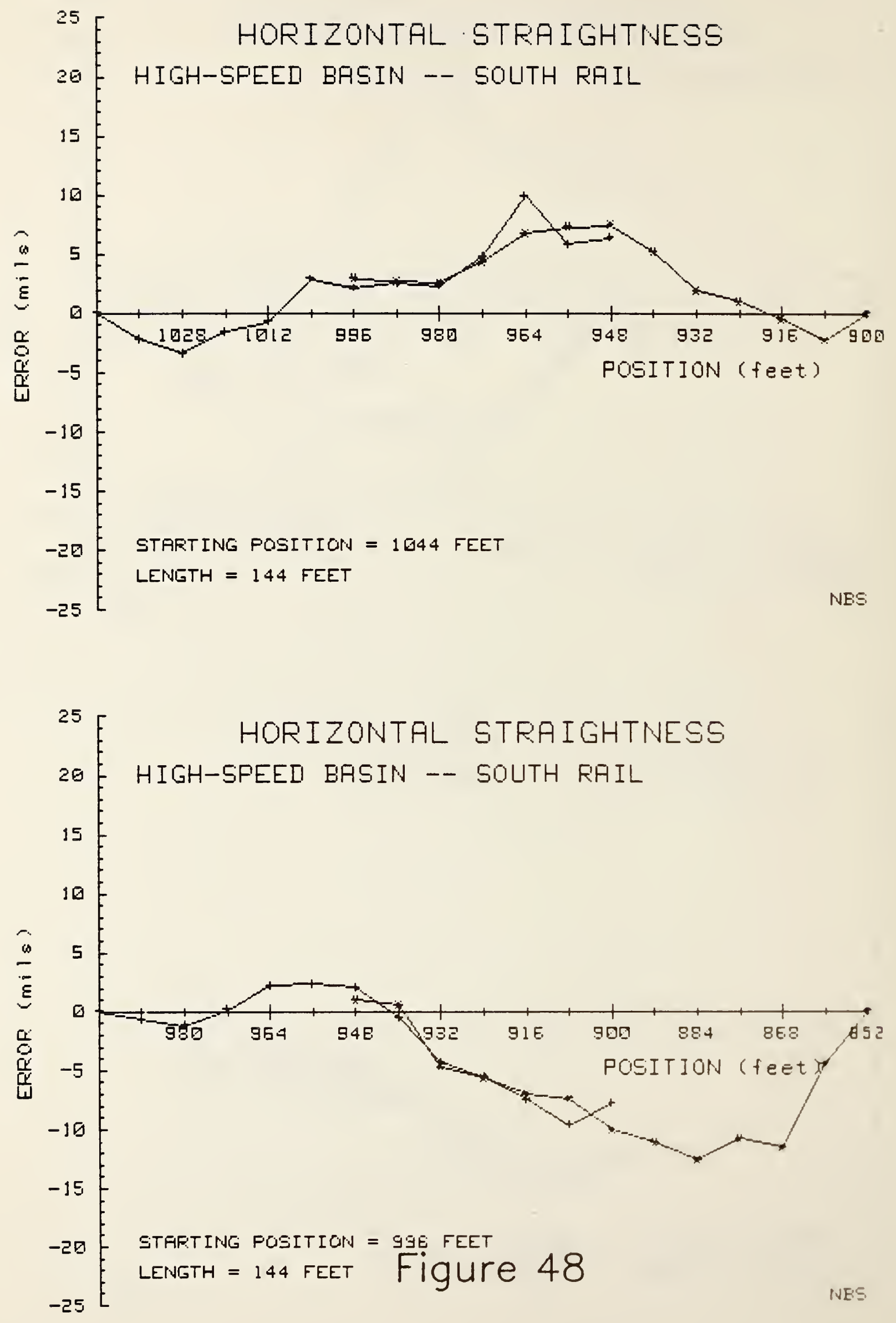

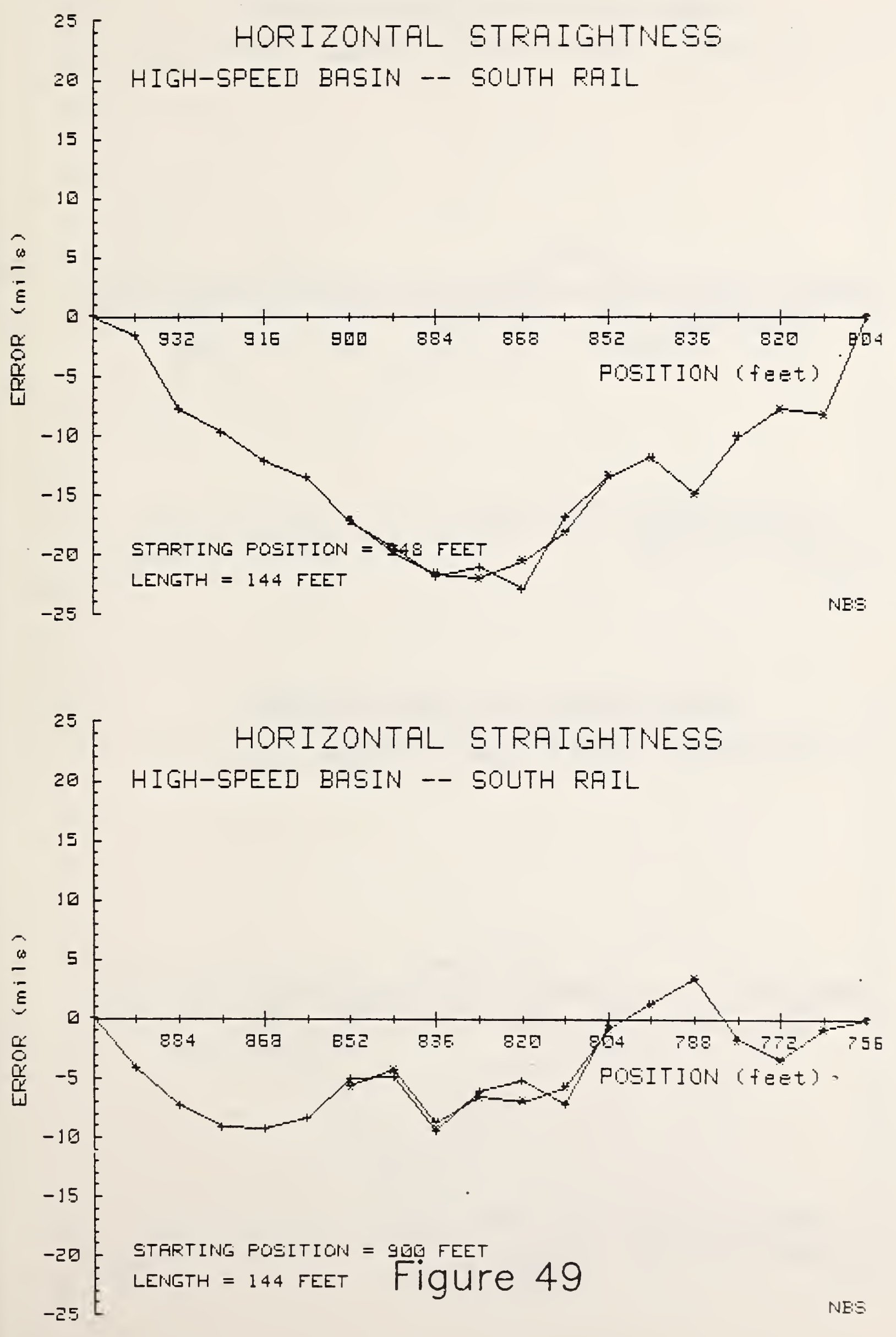

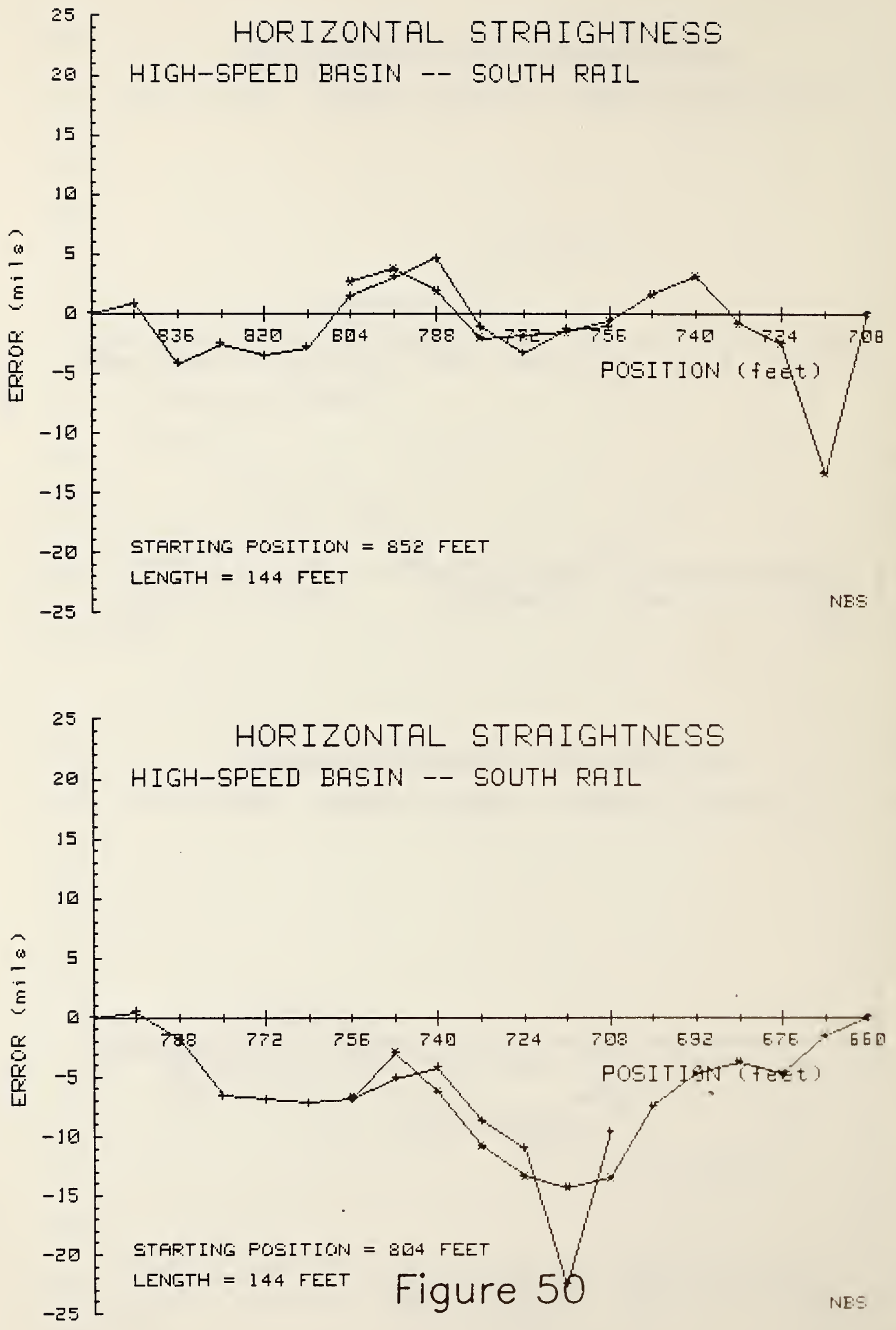

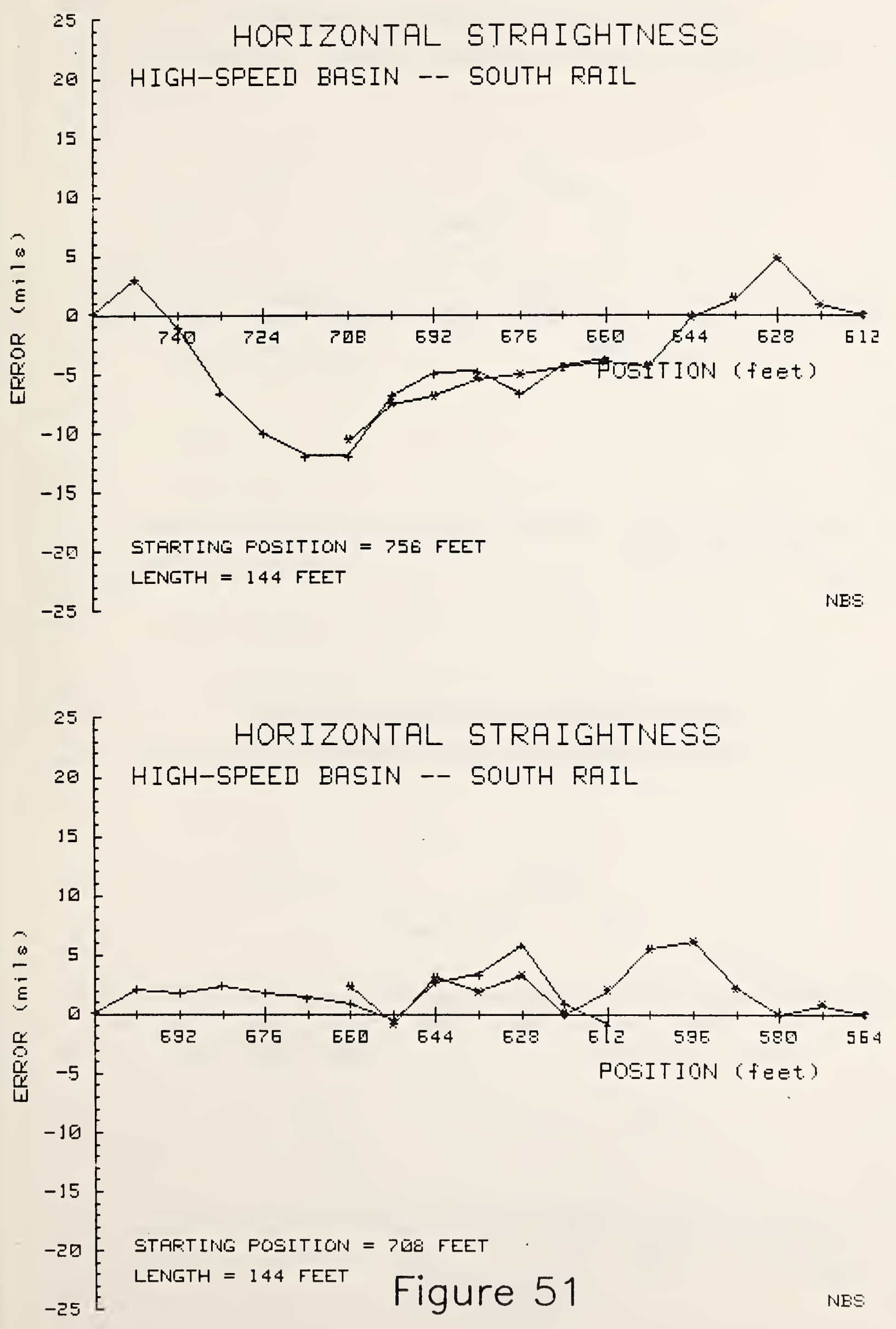

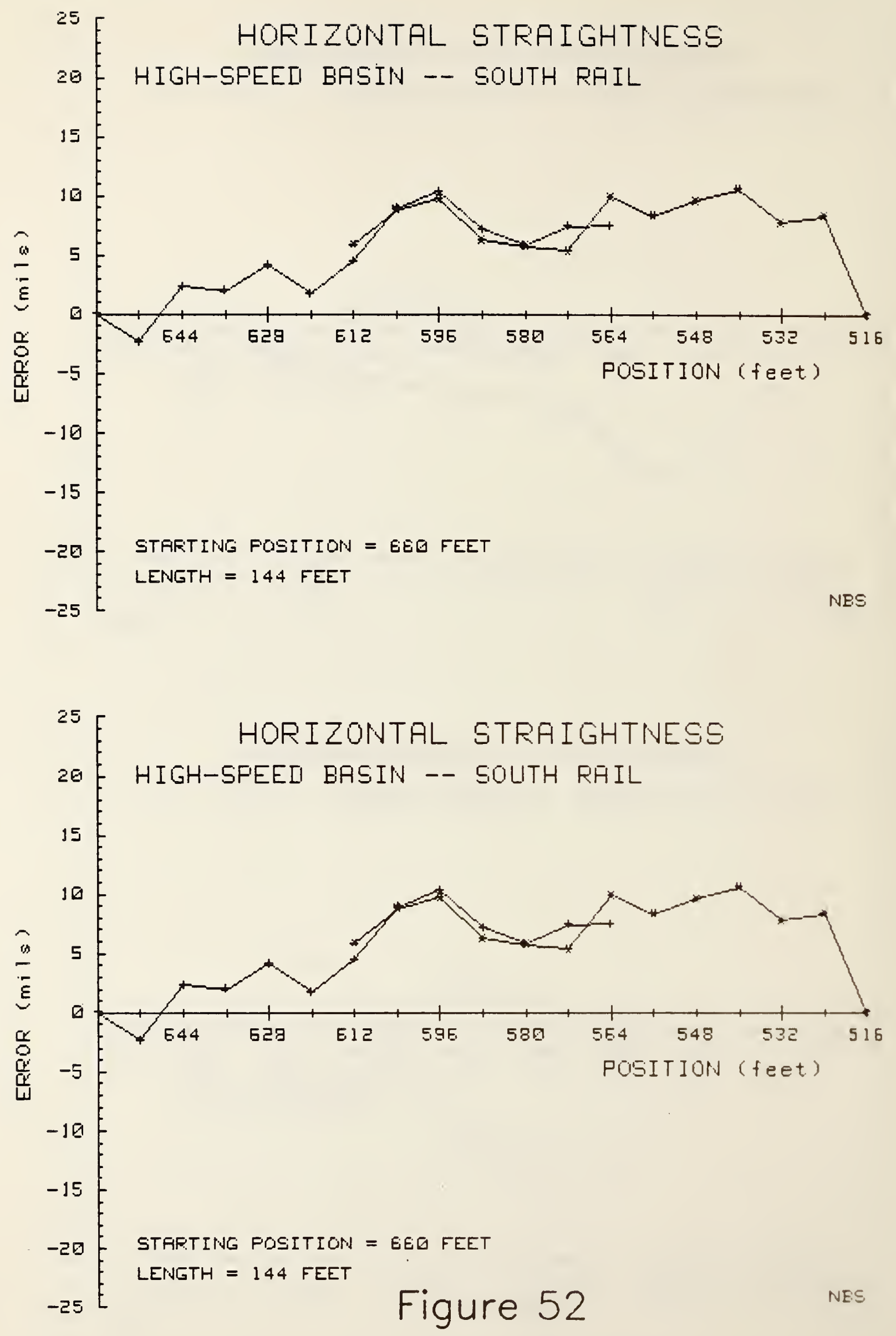

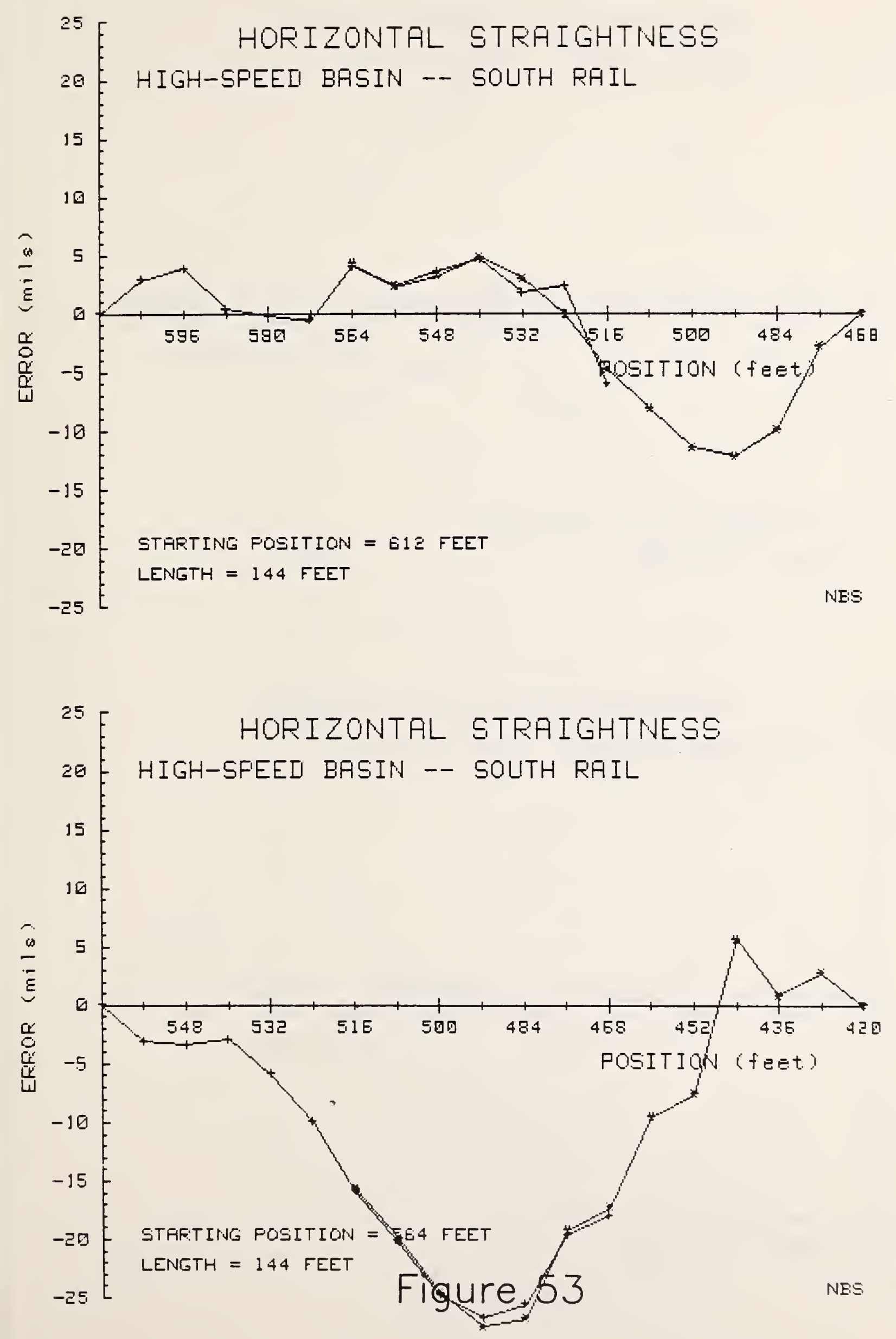

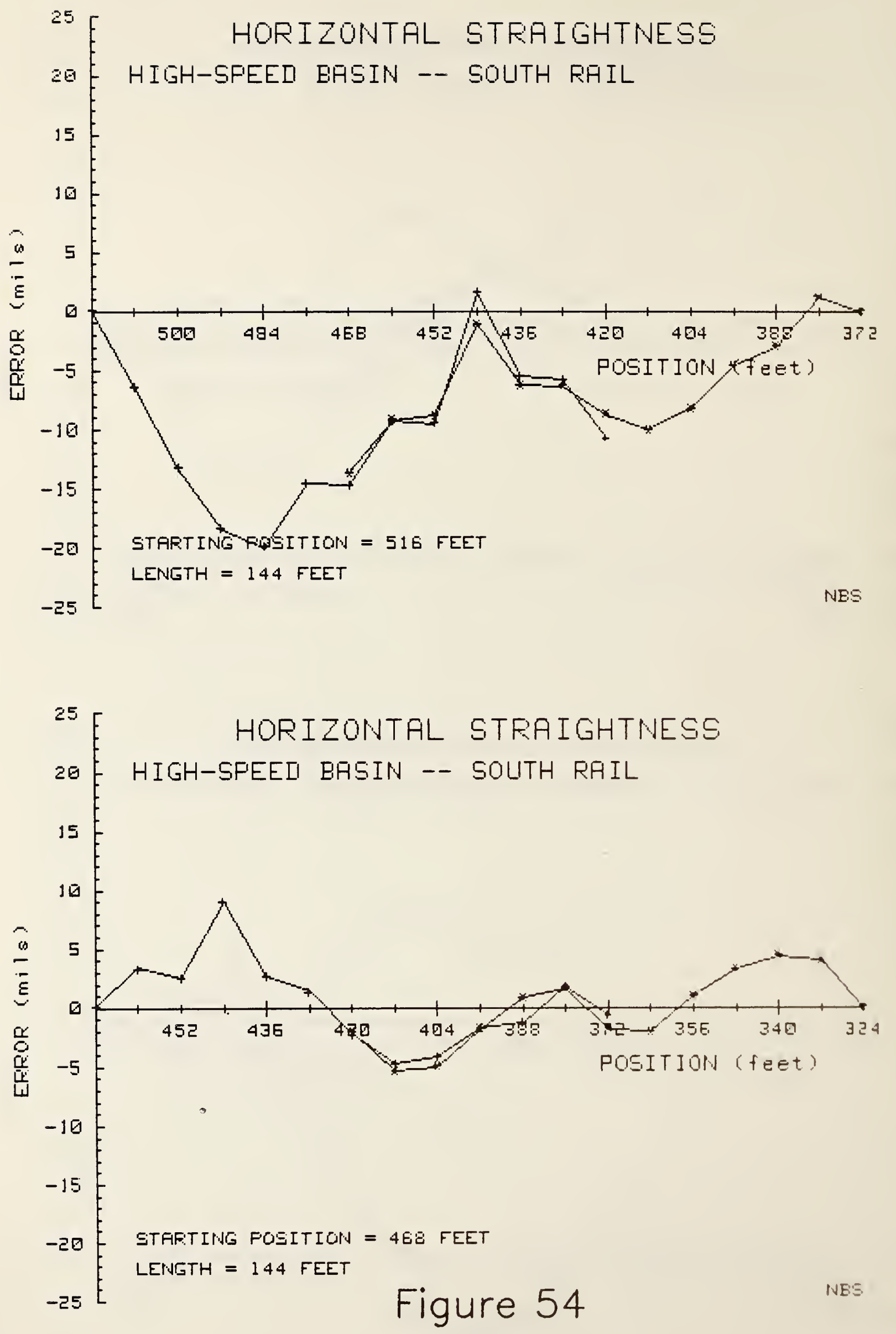

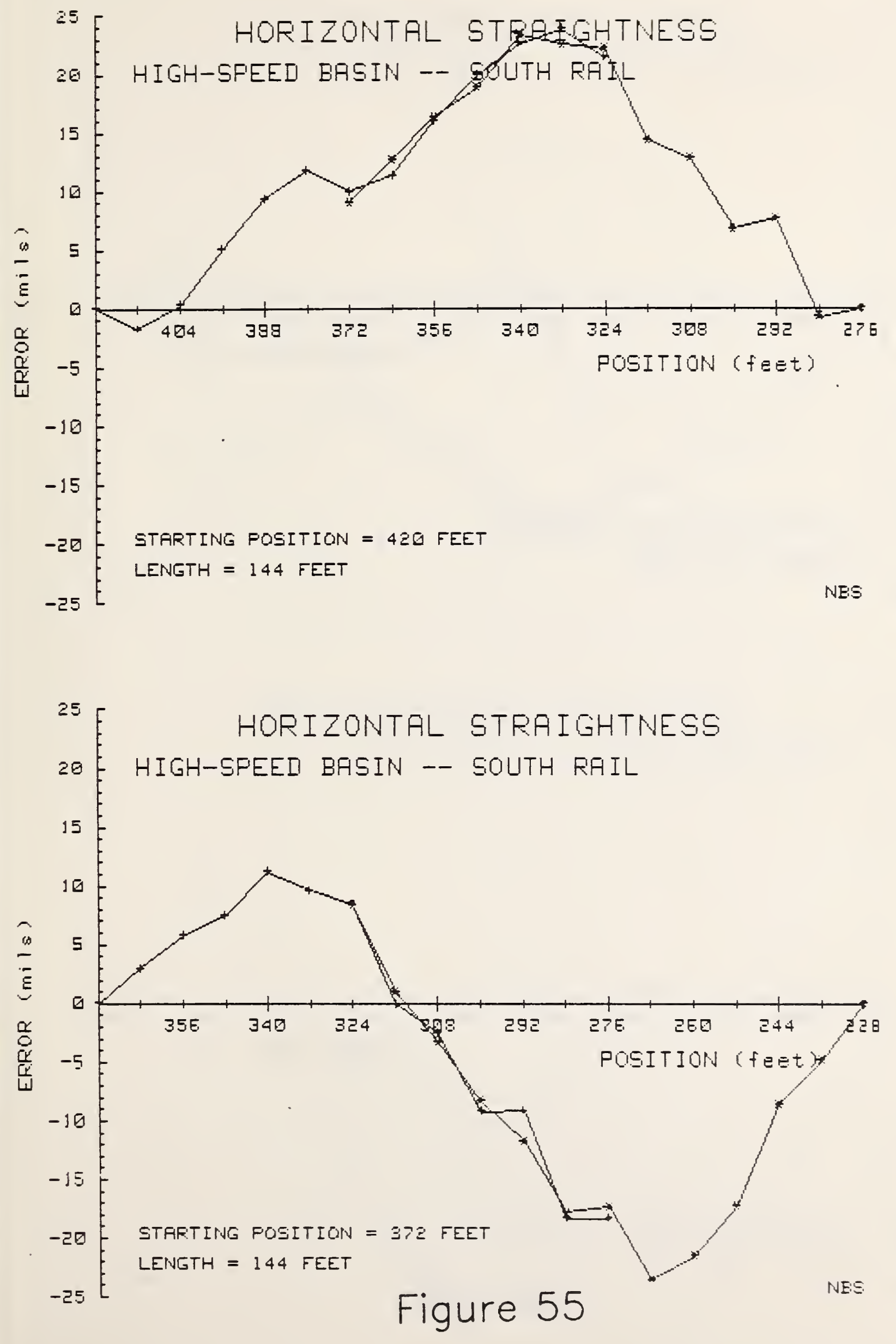

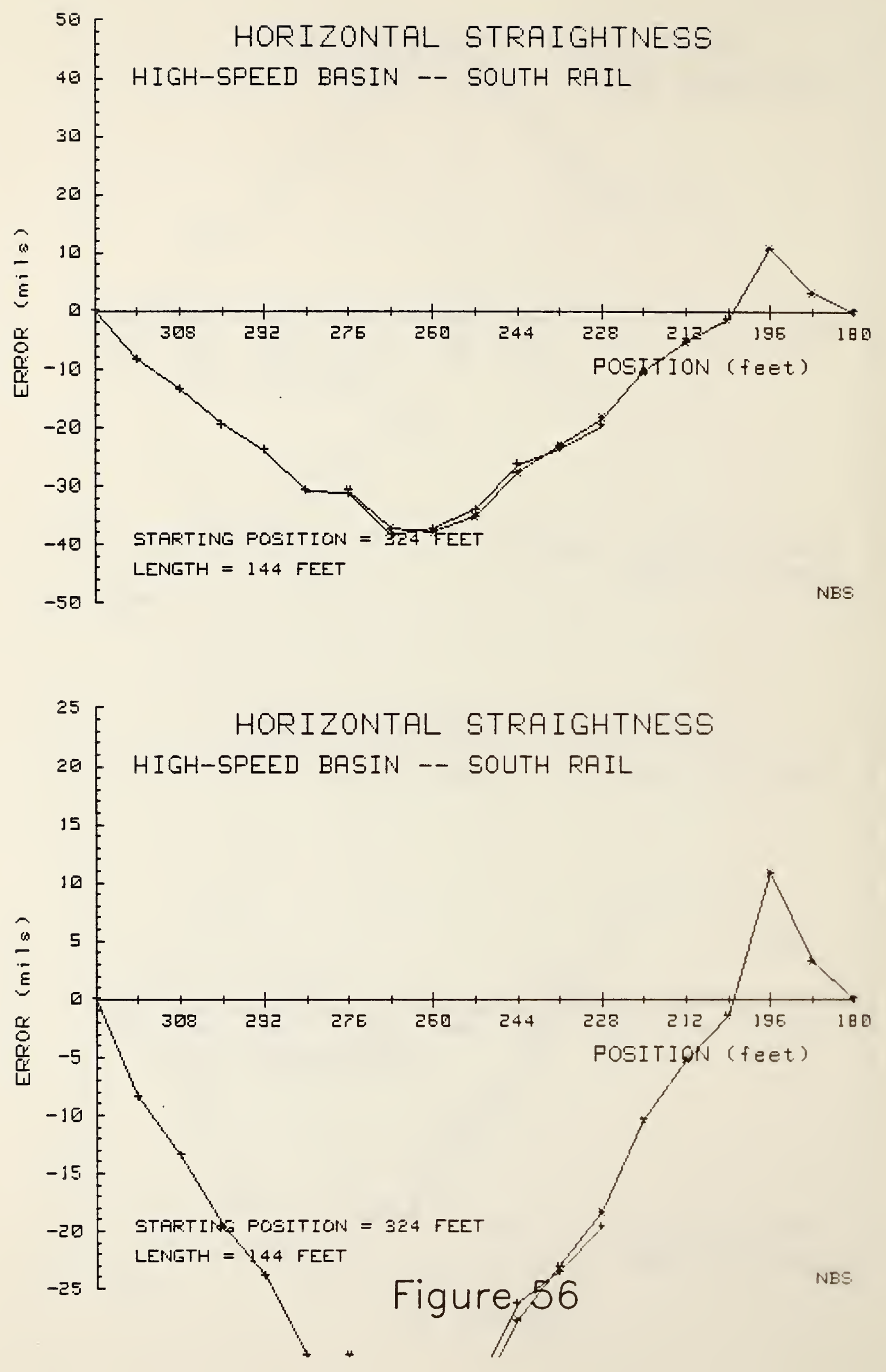

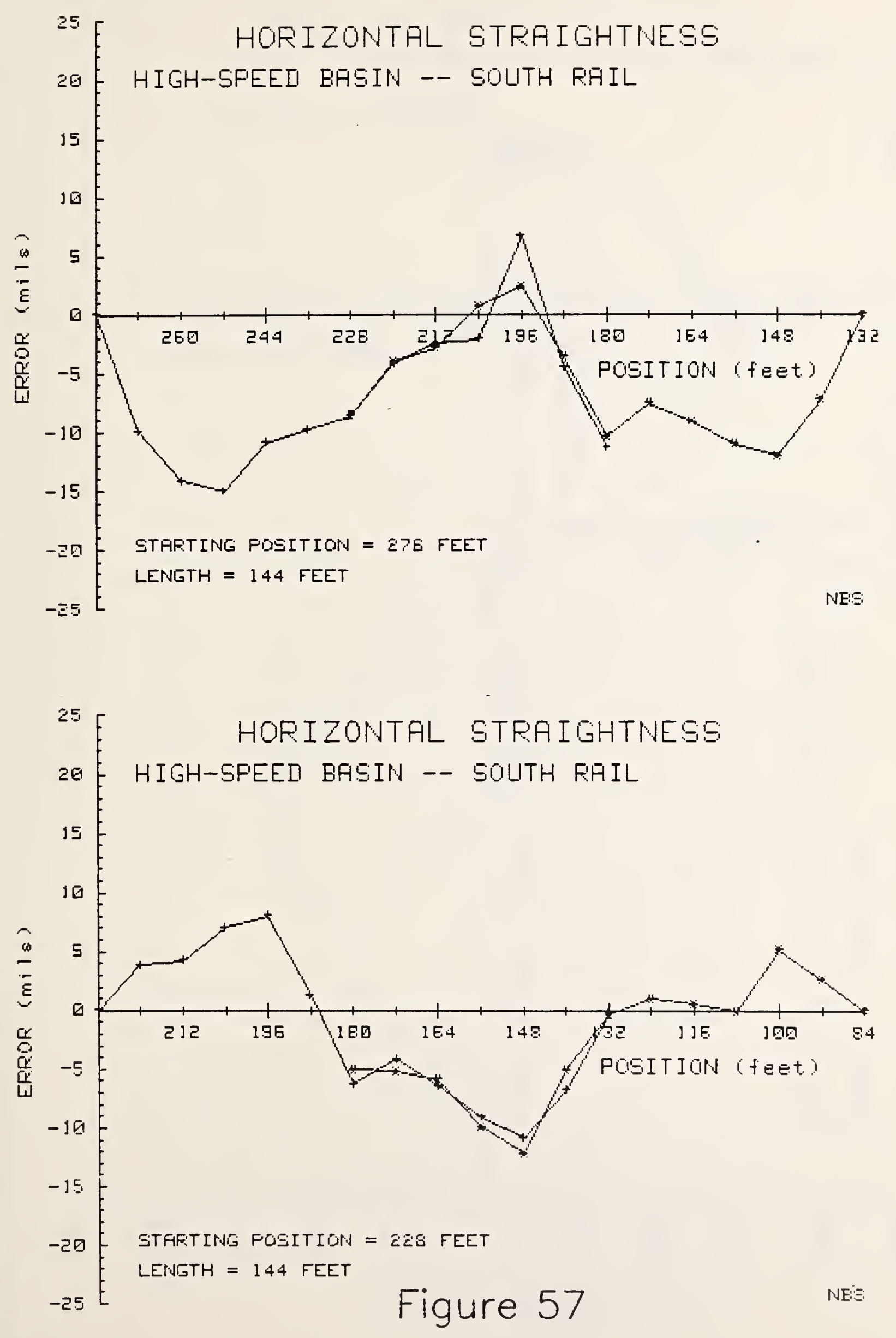


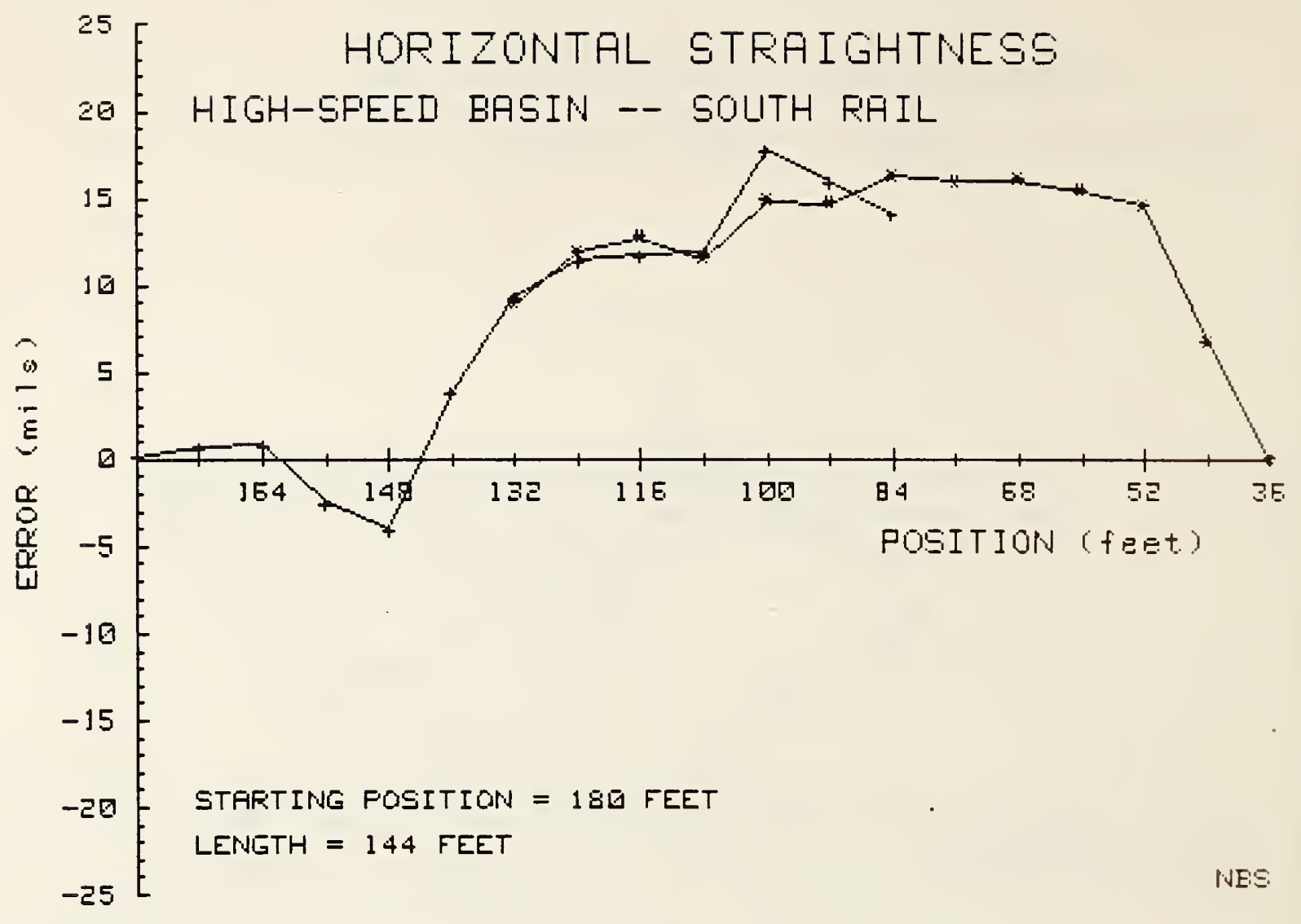

Figure 58 


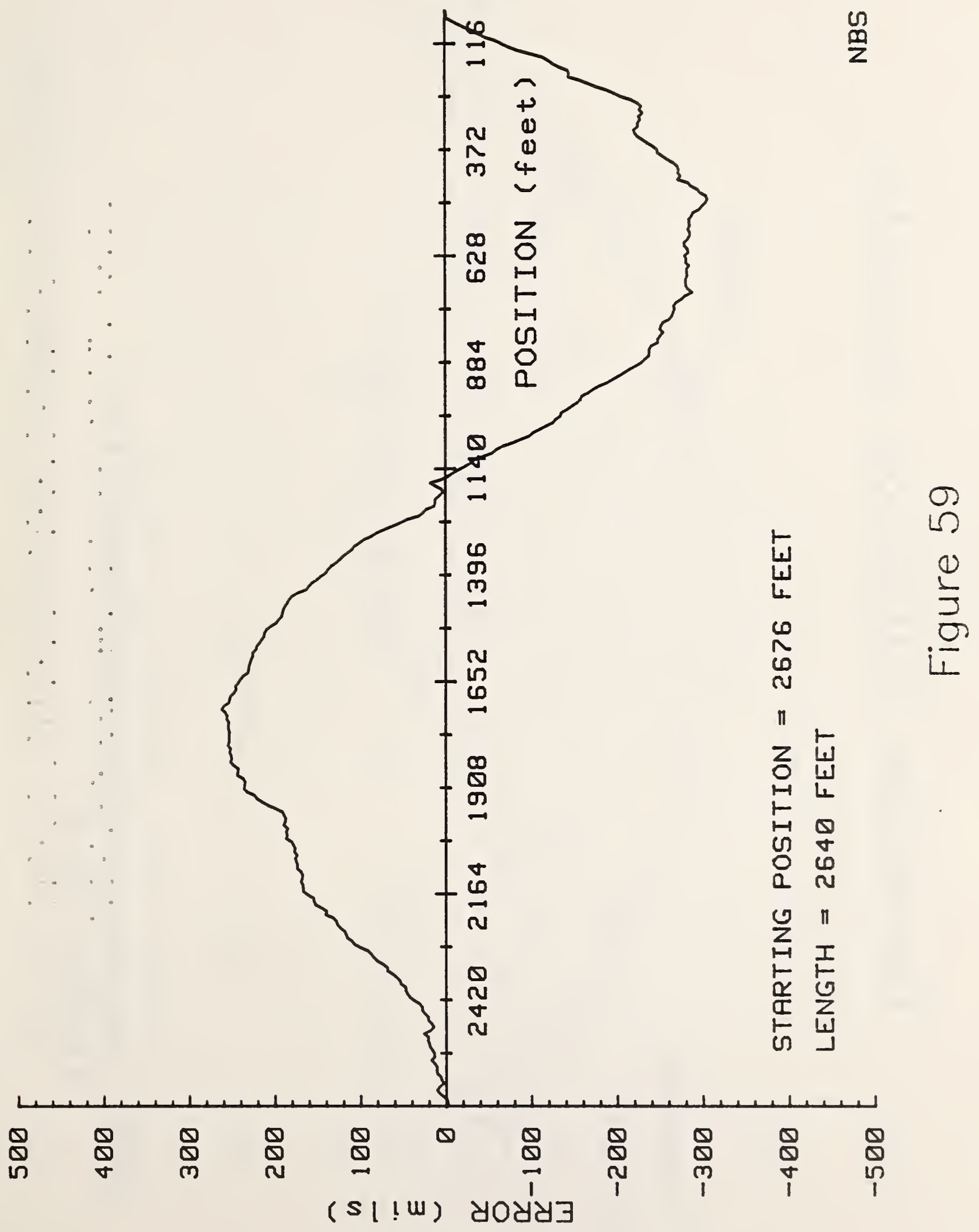




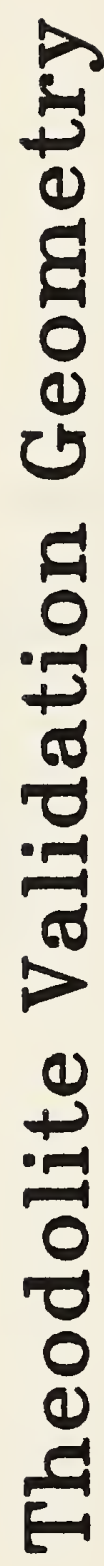

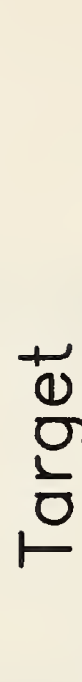

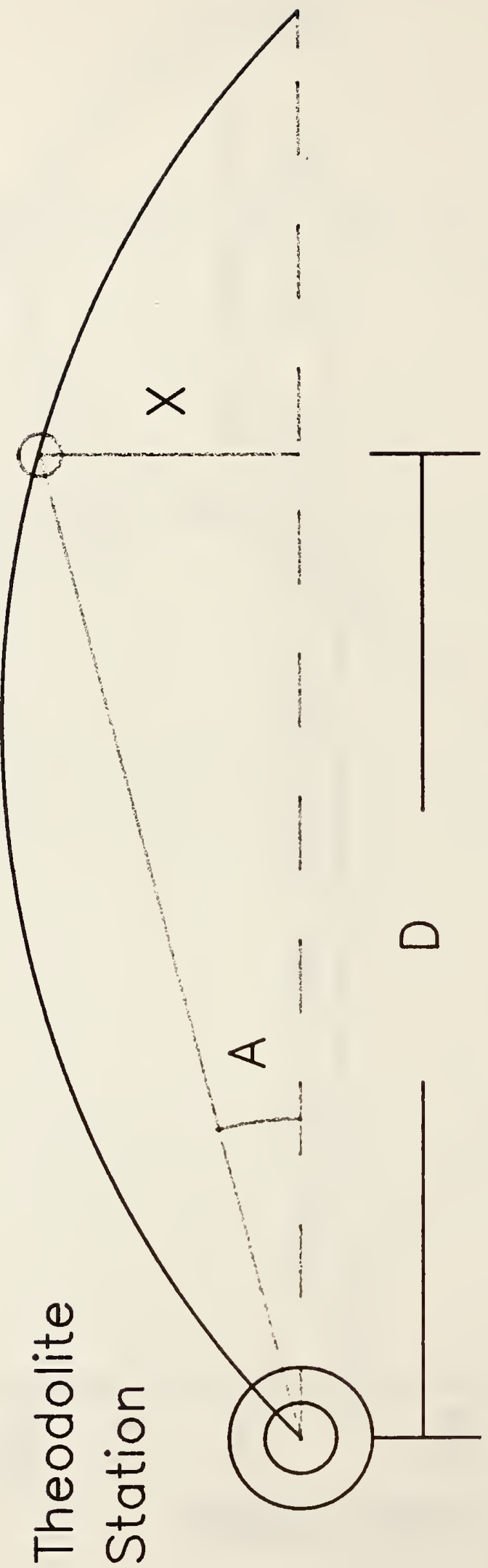

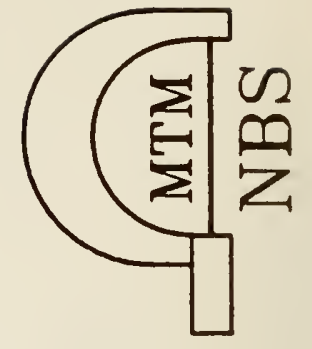

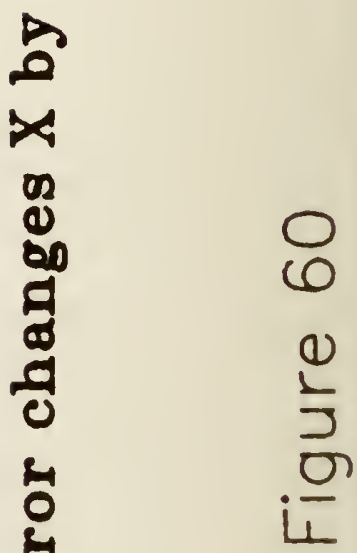

4

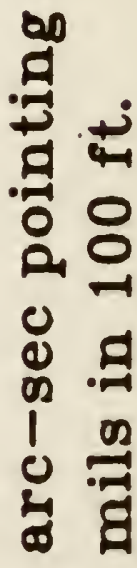

$-\infty$

E 

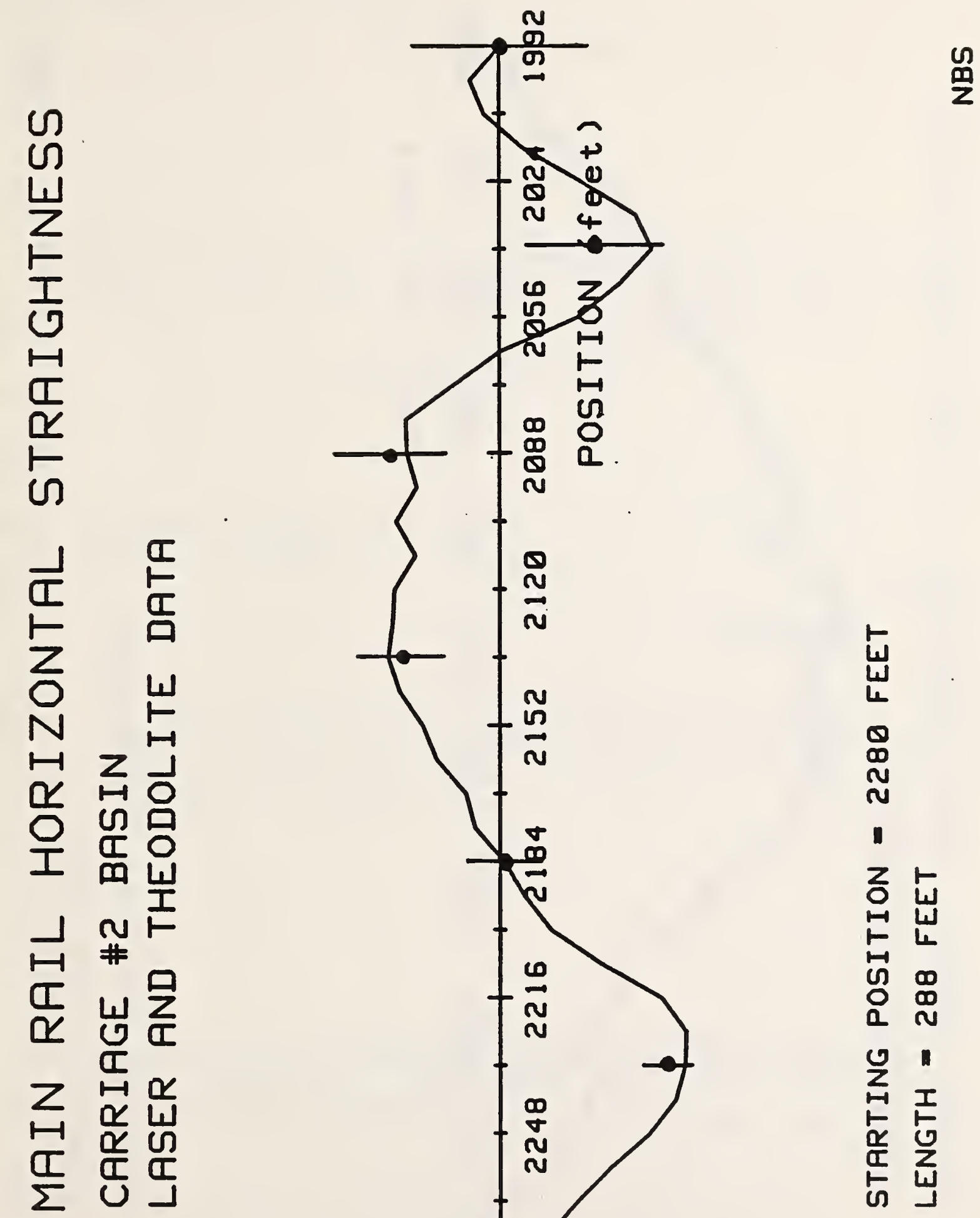

岂

占

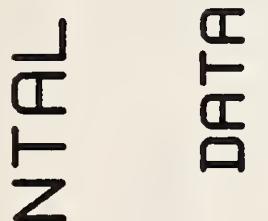

岕

$\overline{0}$

0

品

N

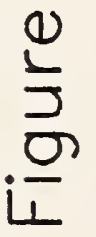

立

$\mapsto \omega$

$\leftarrow L$

ज $\infty$

○

a N

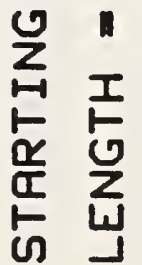

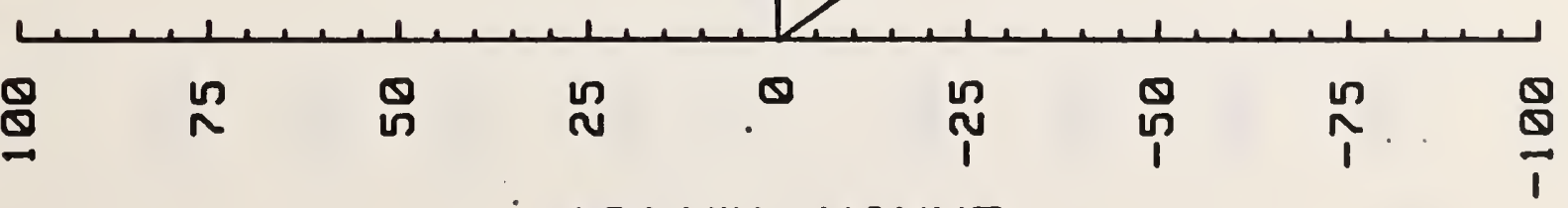

(s!lw) 미미 


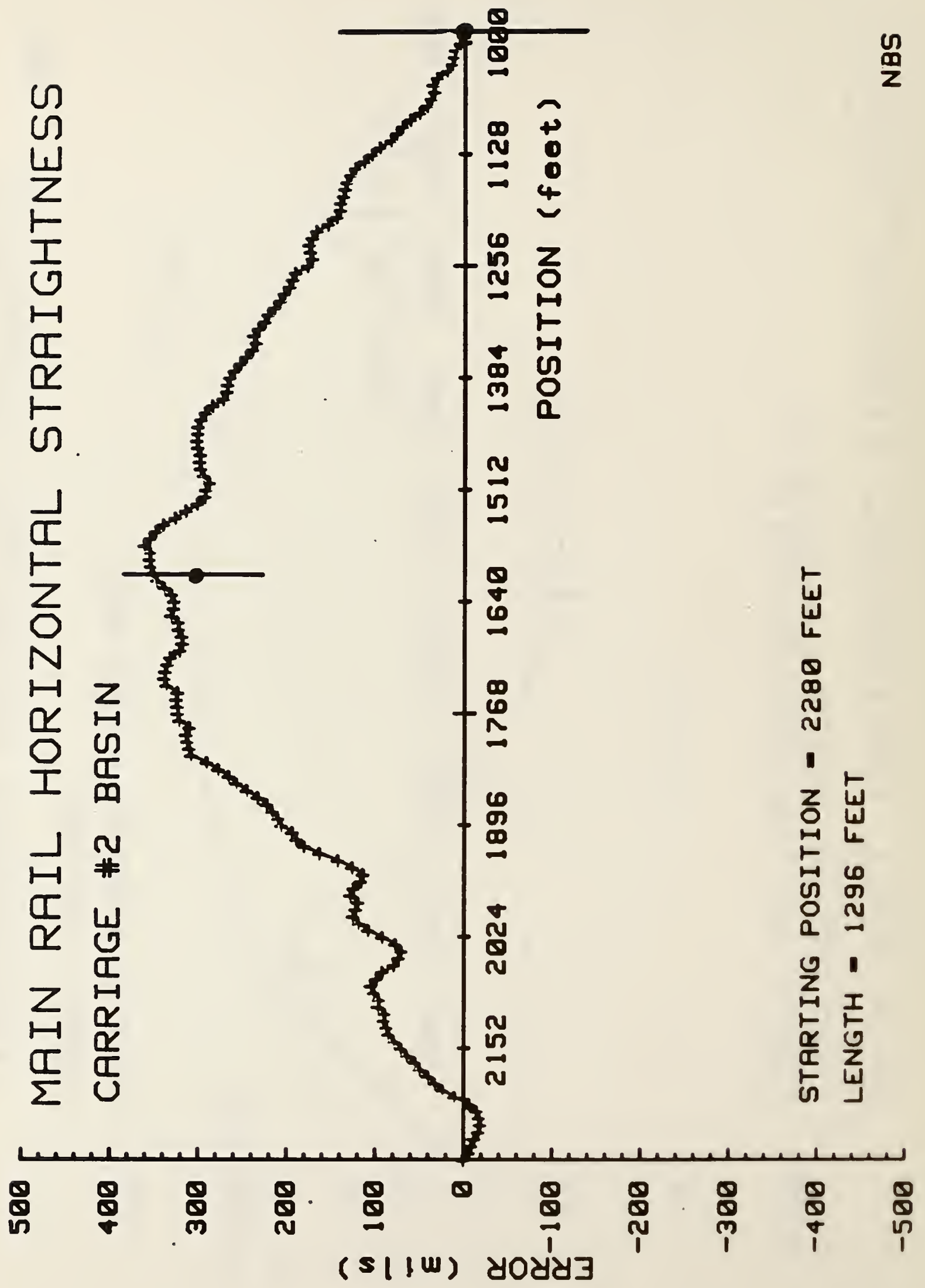



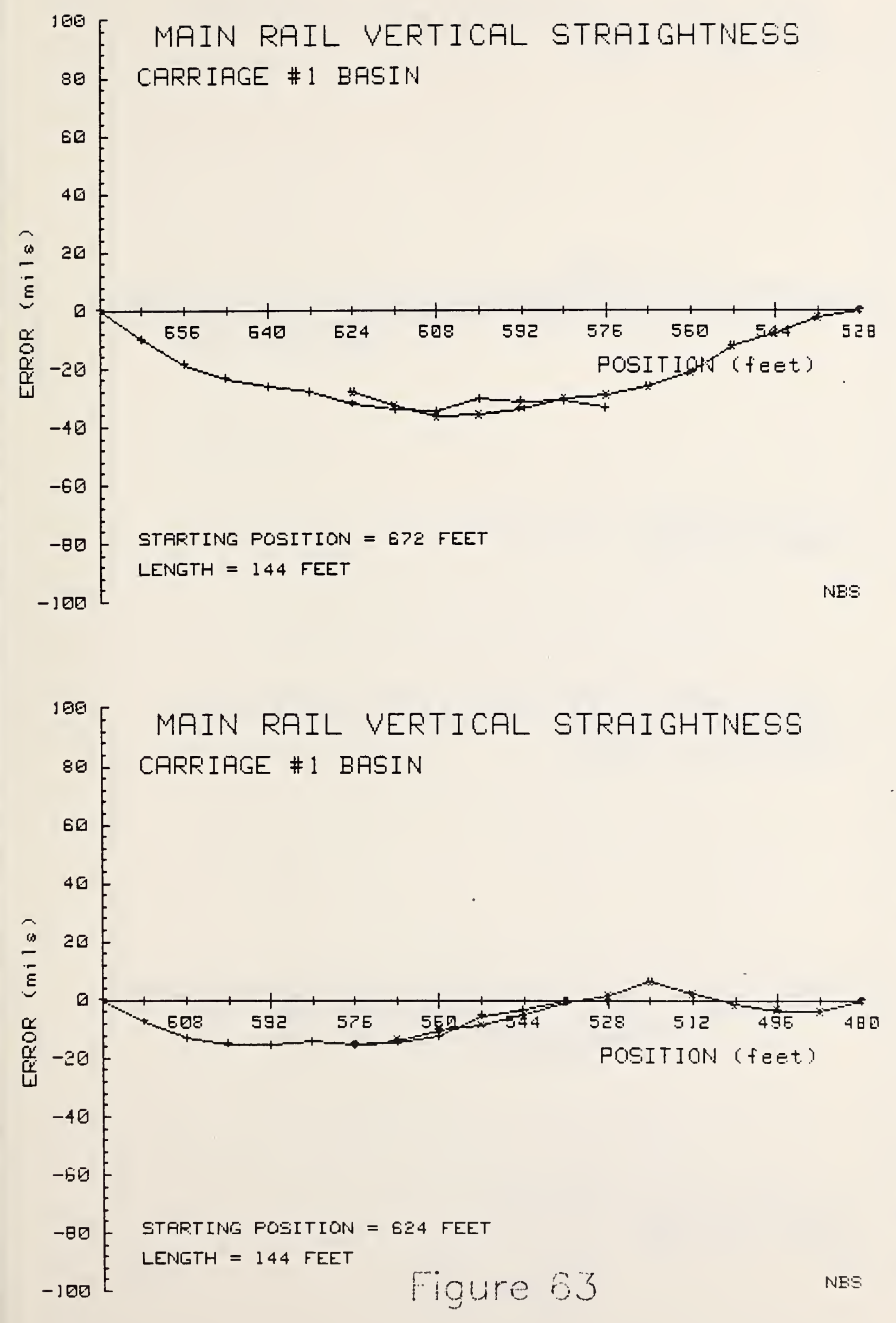

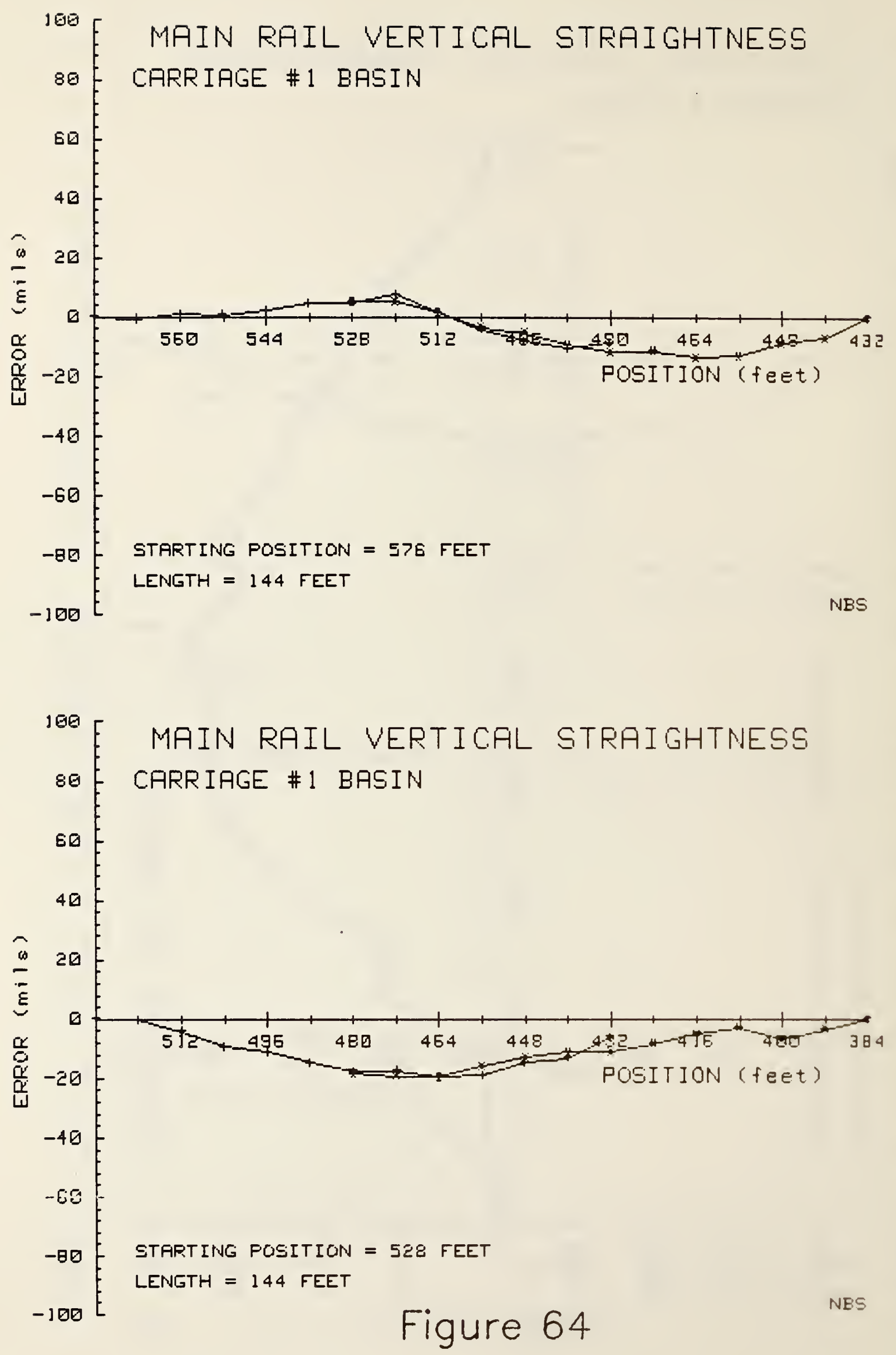

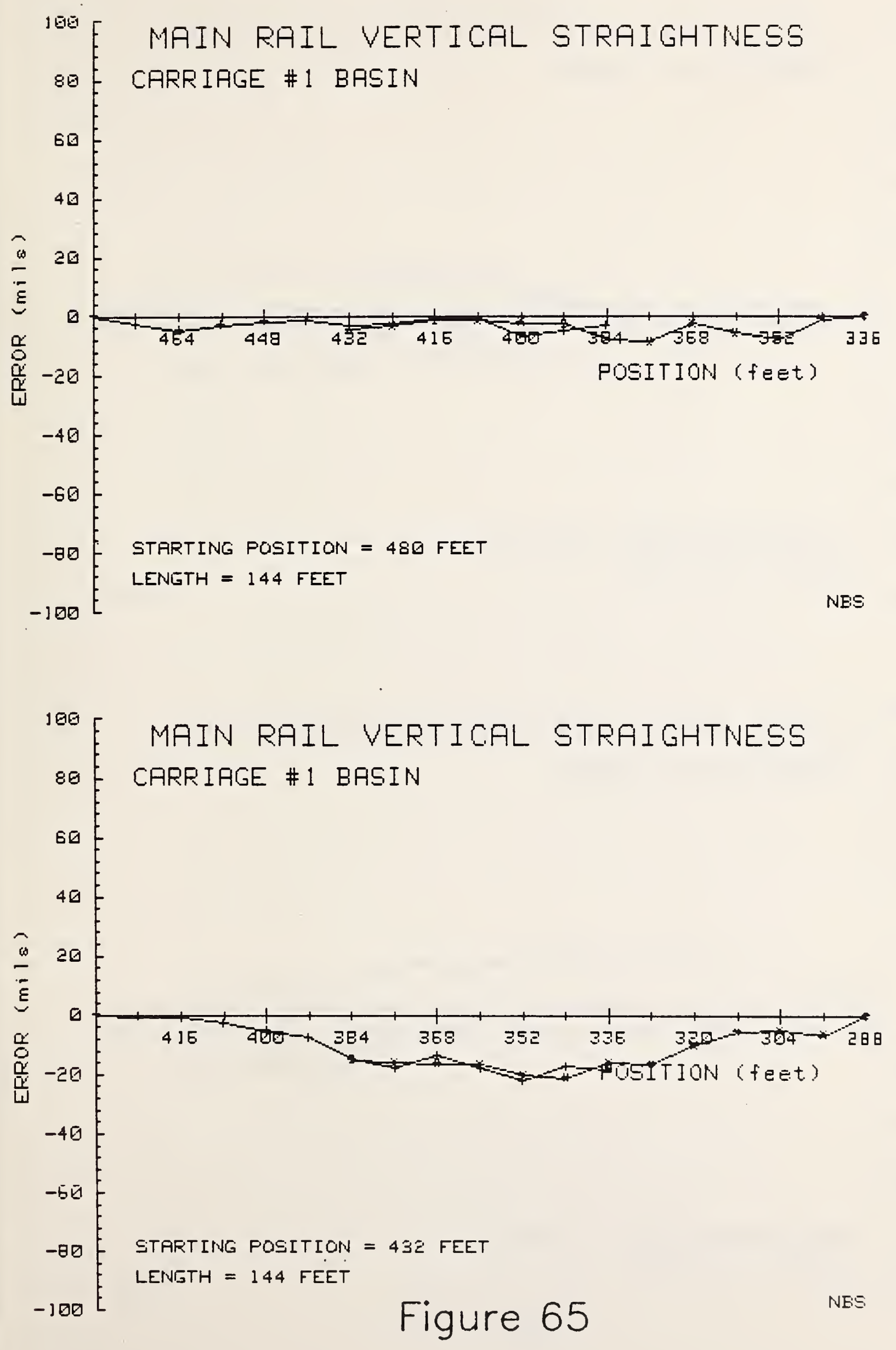

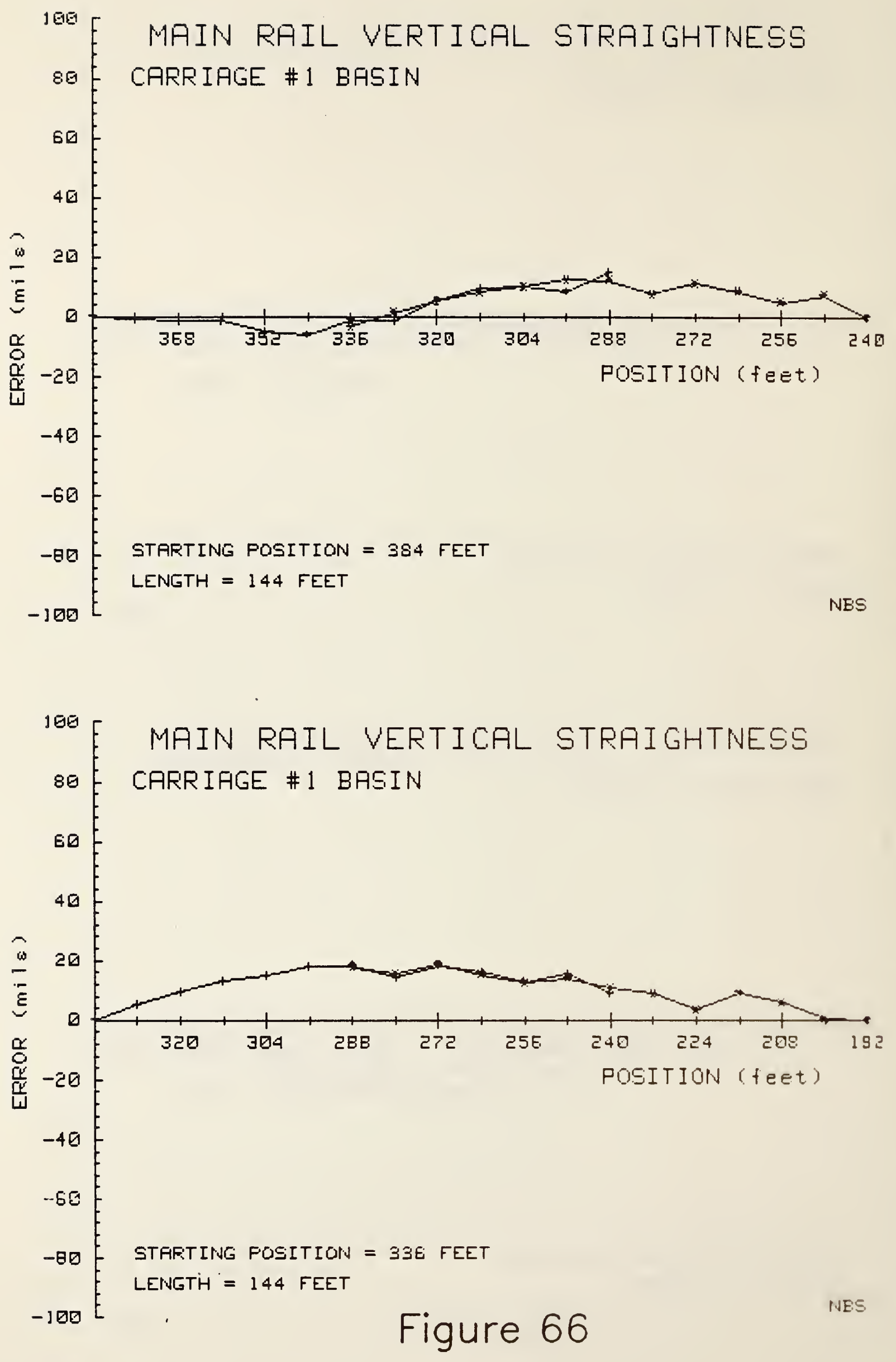

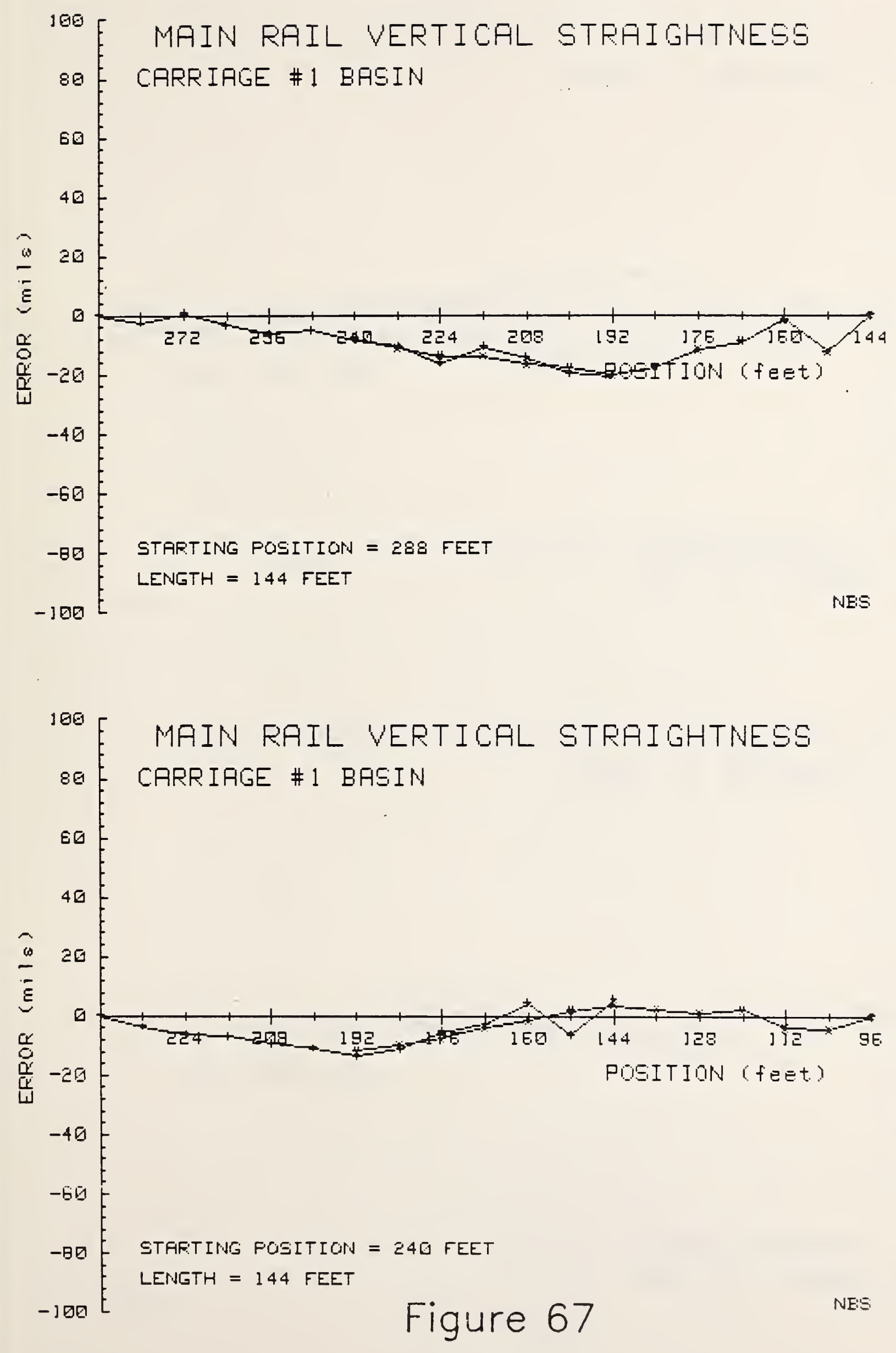

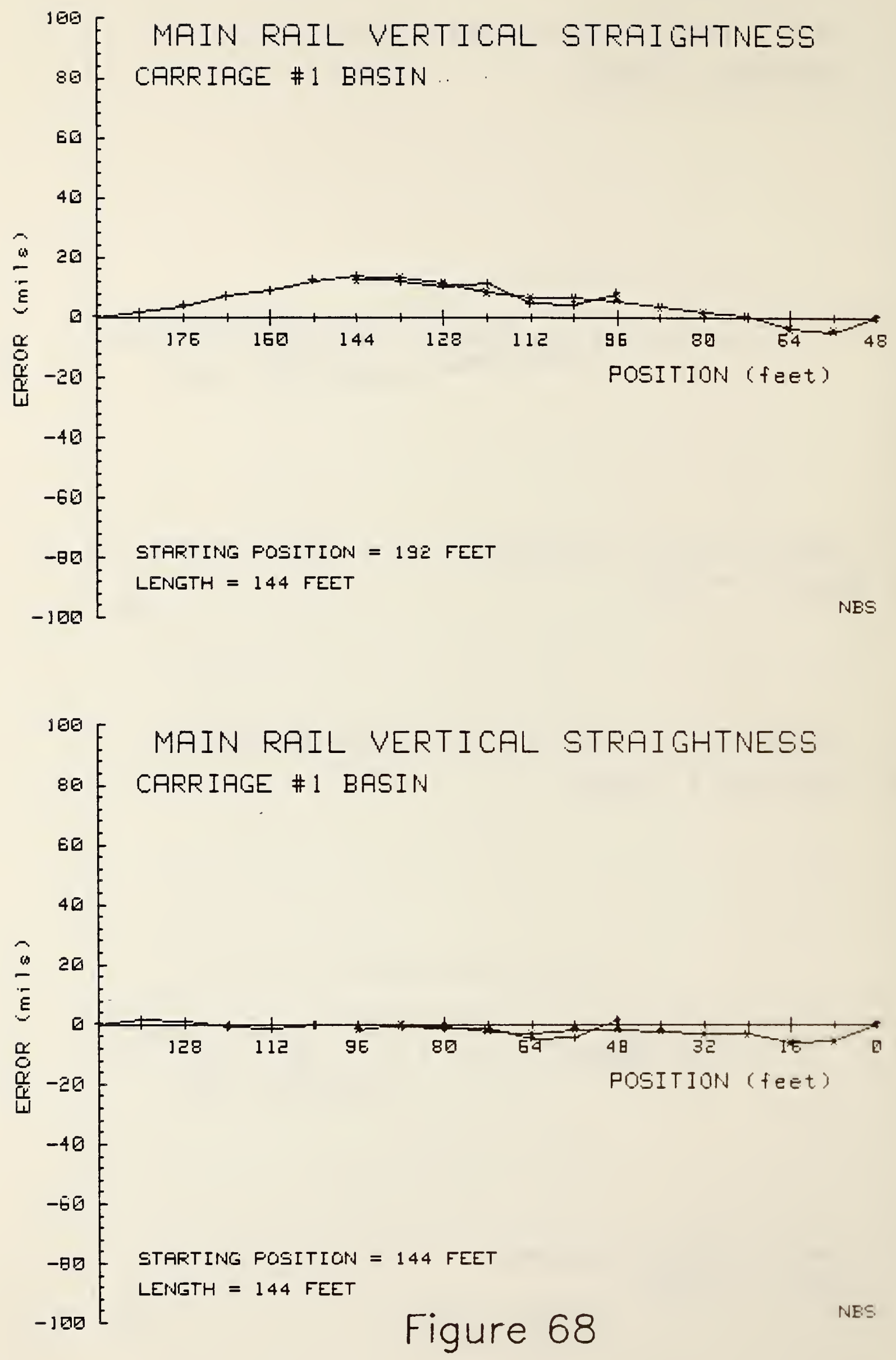

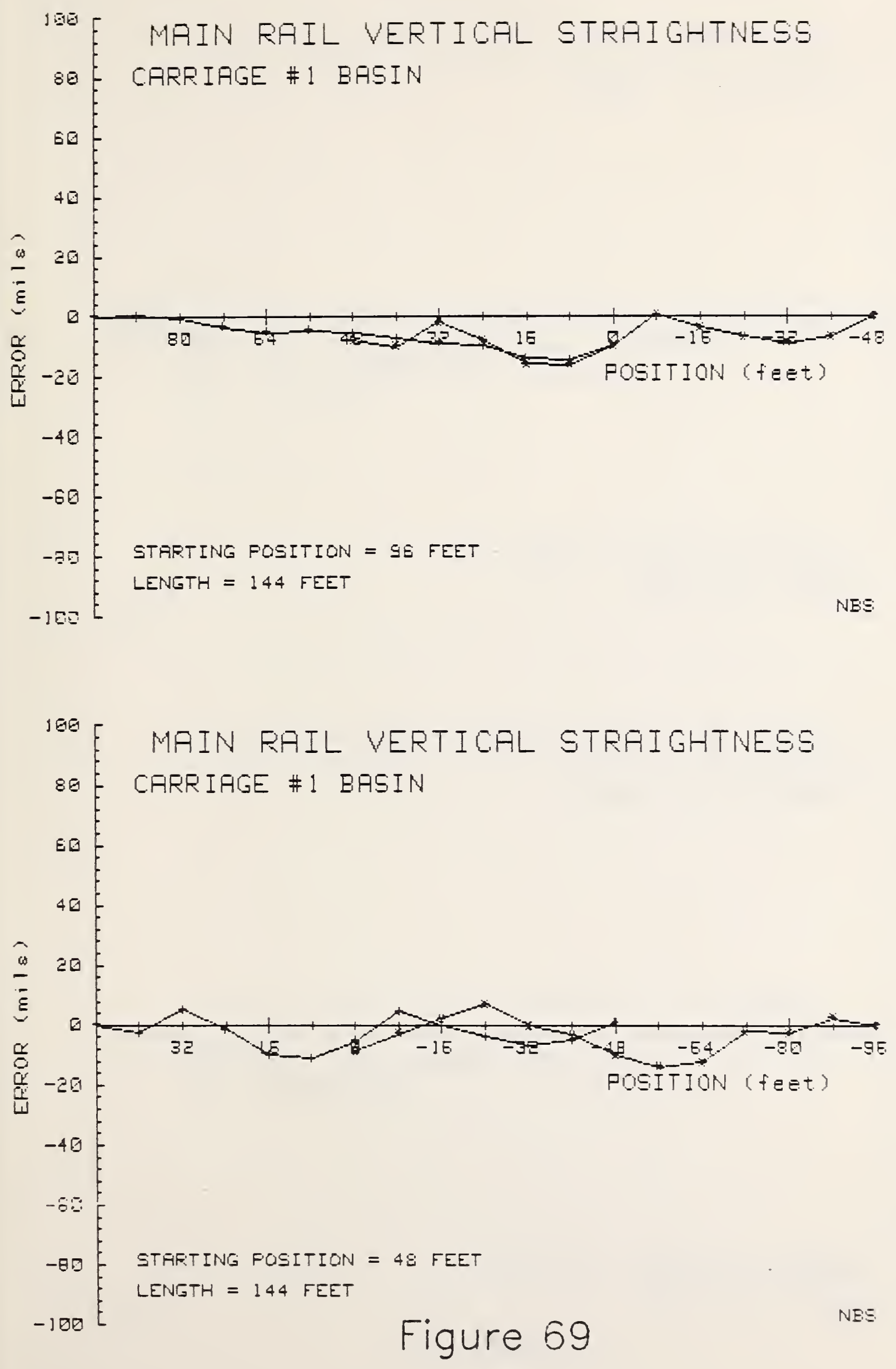

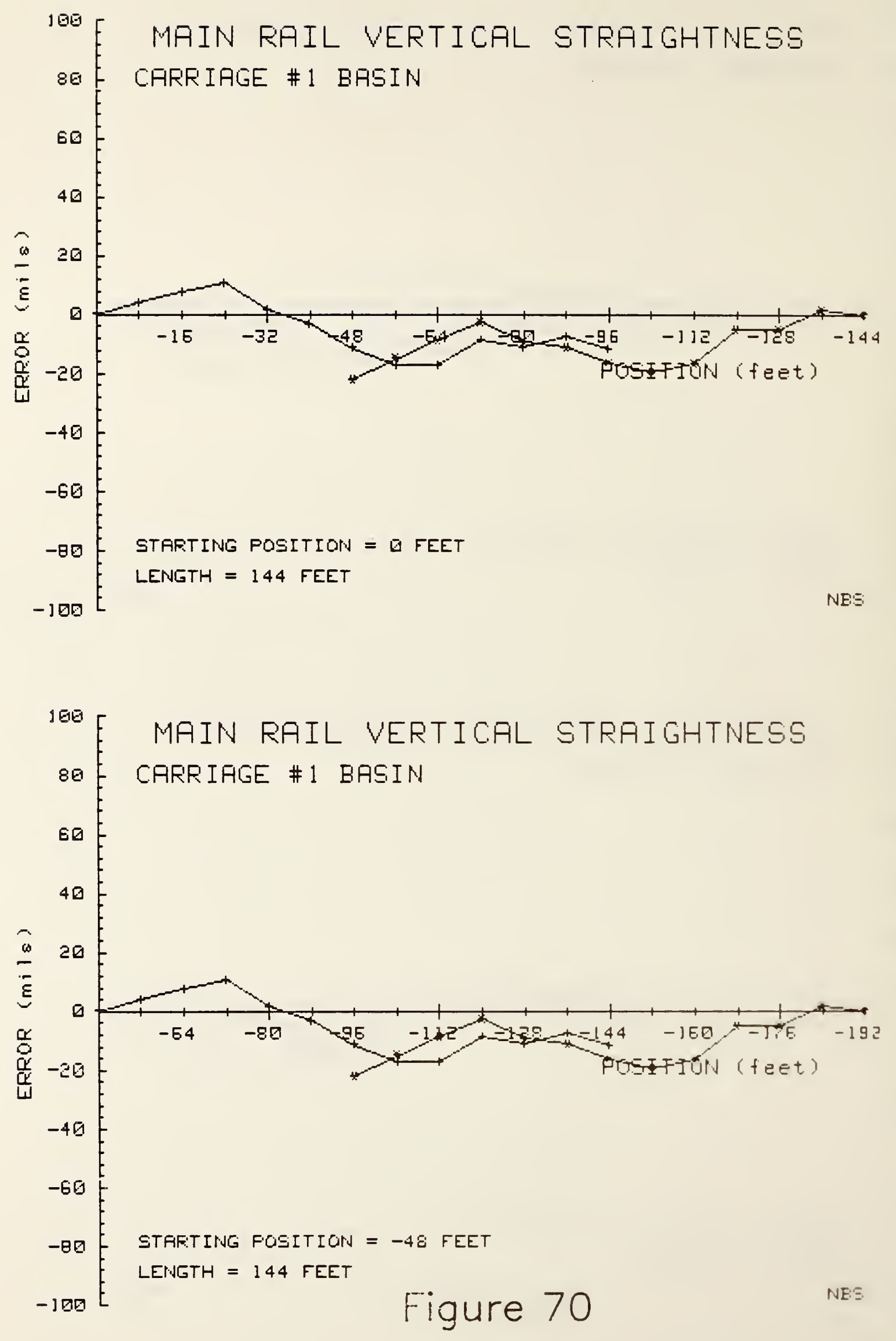

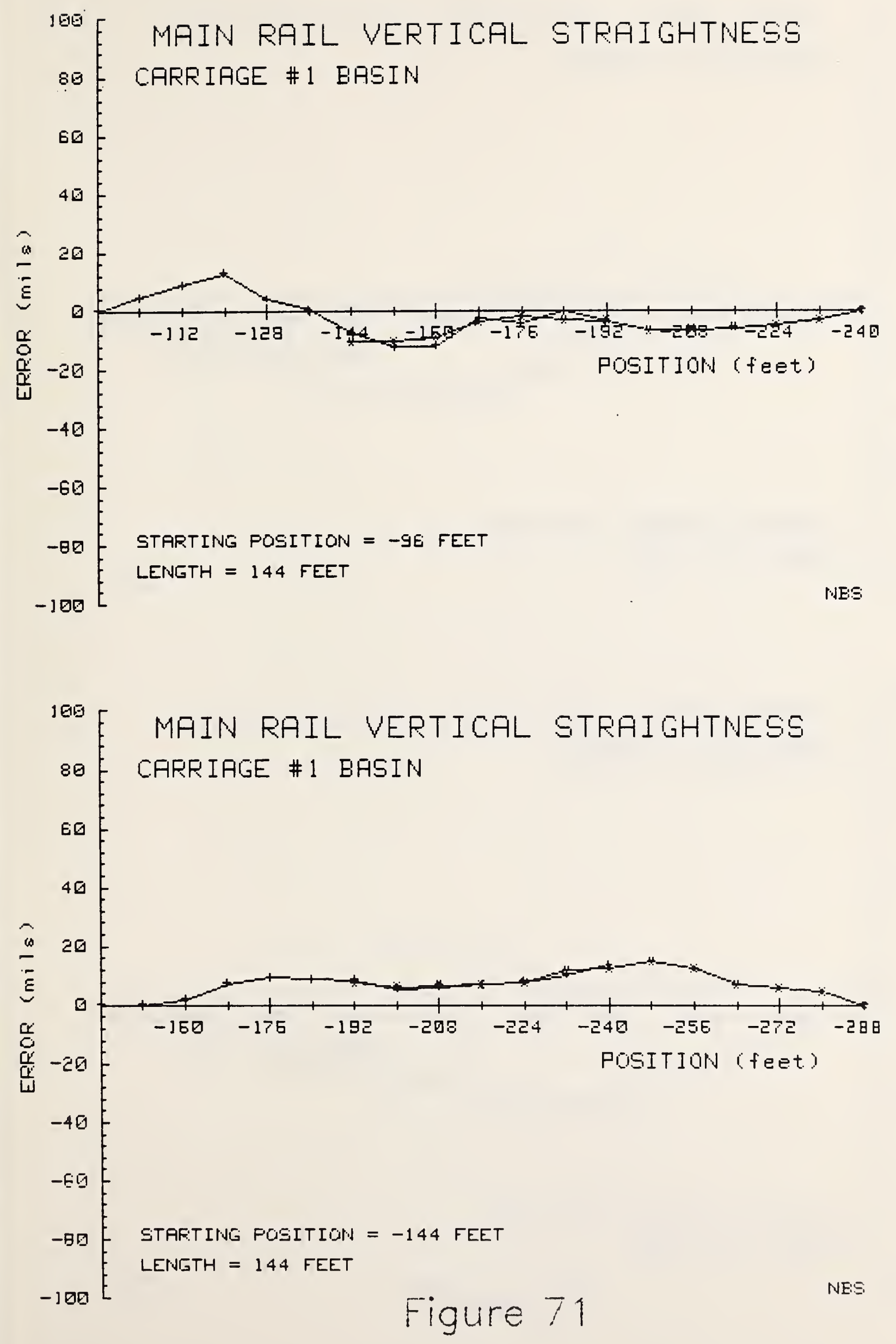

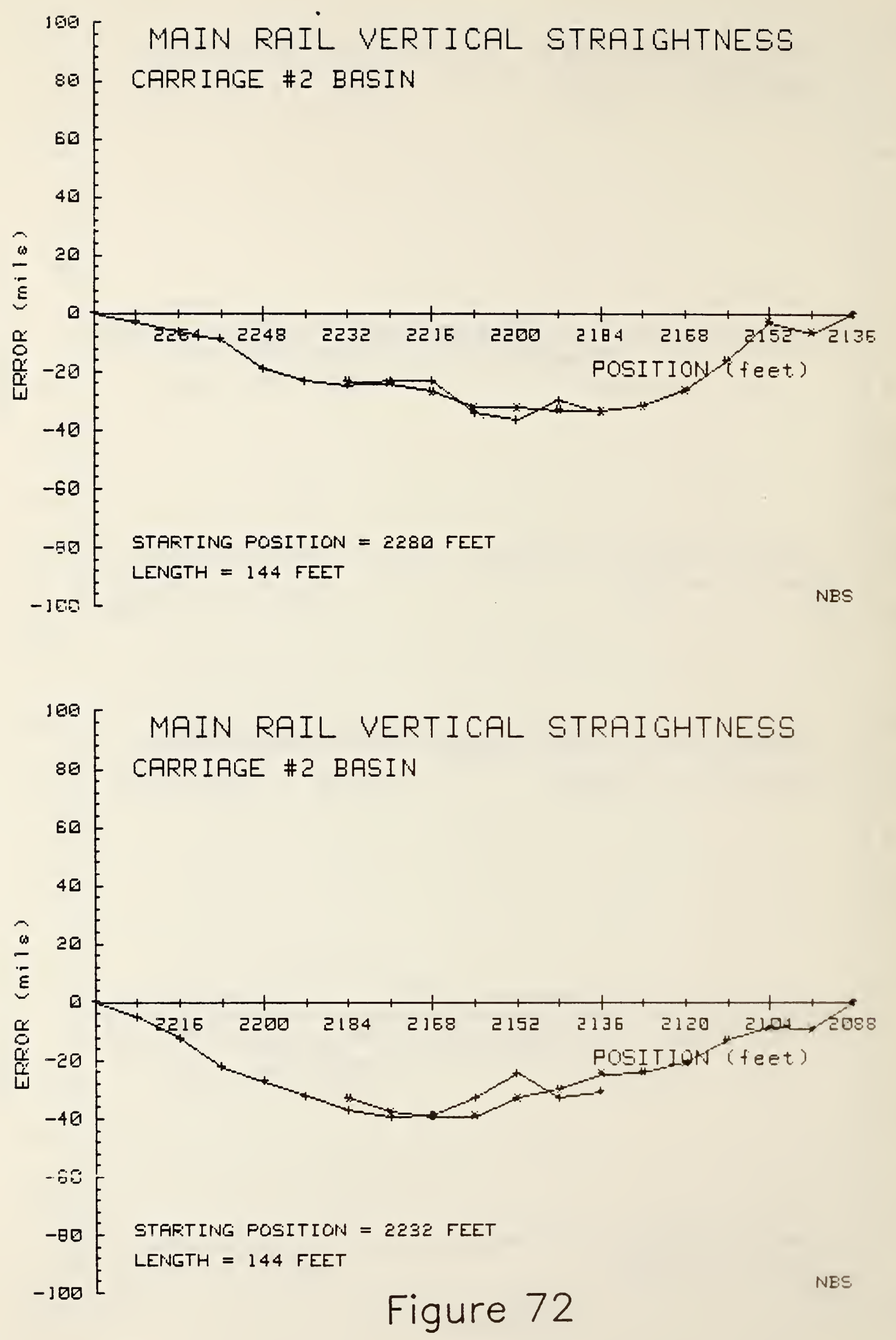

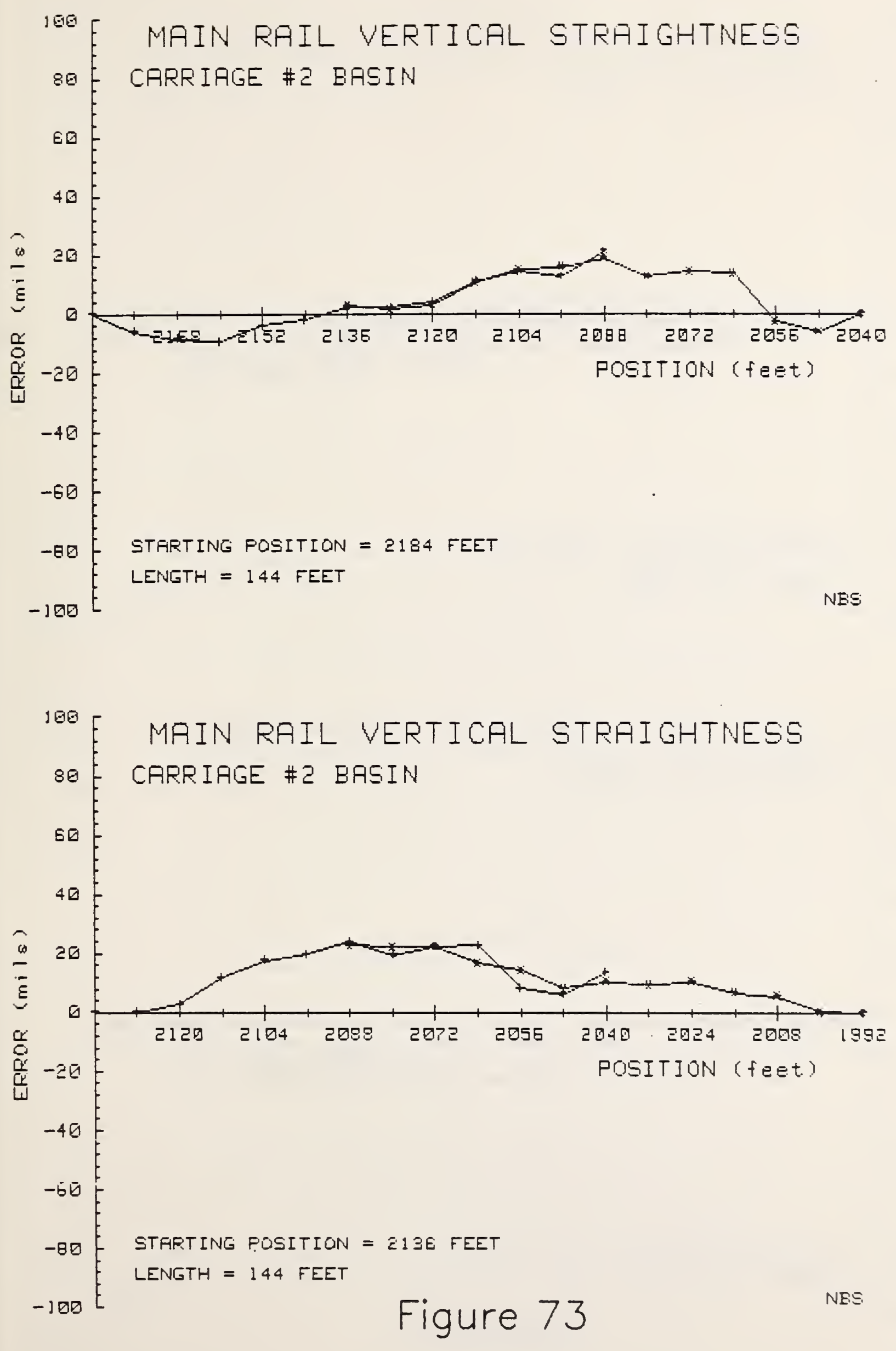

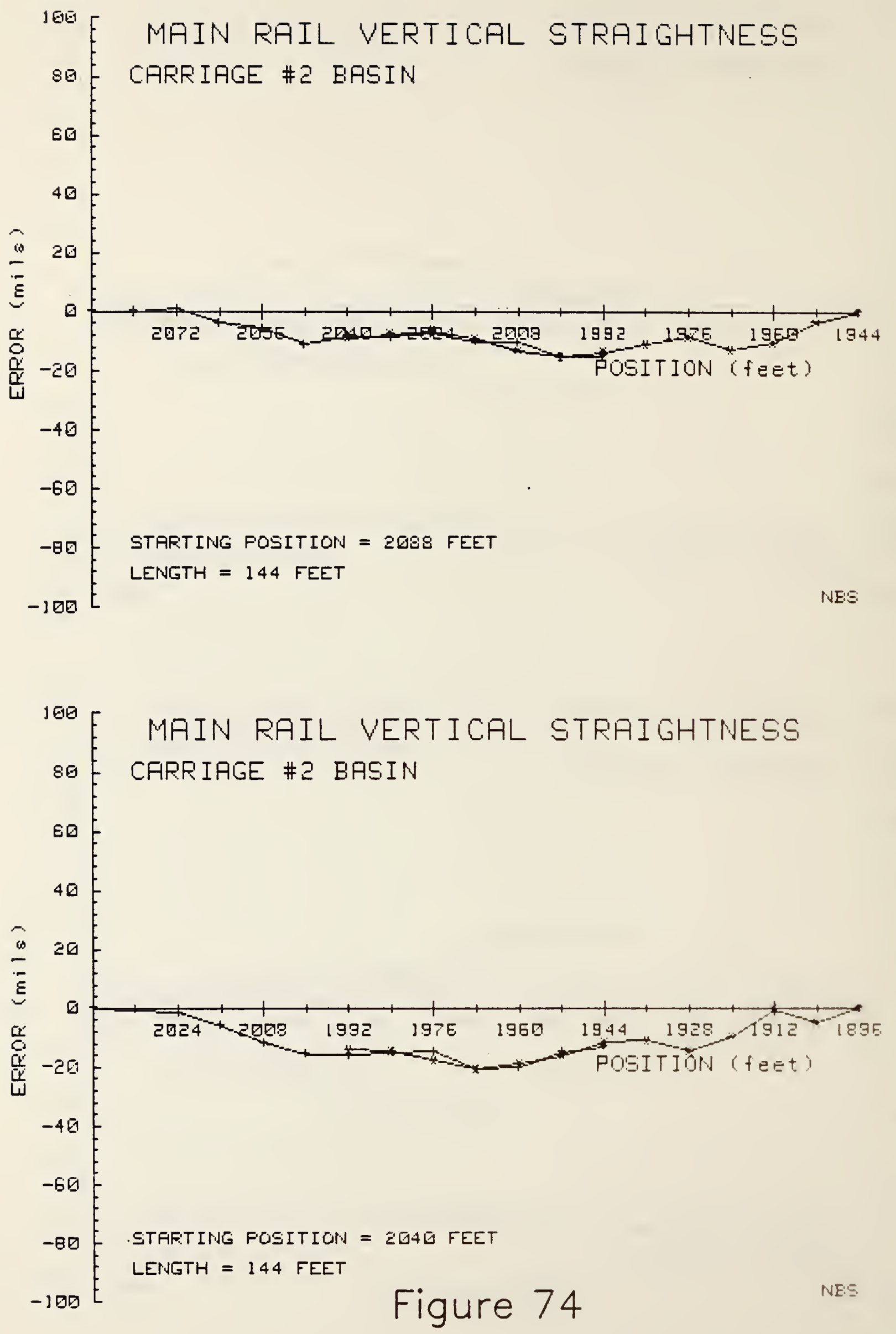

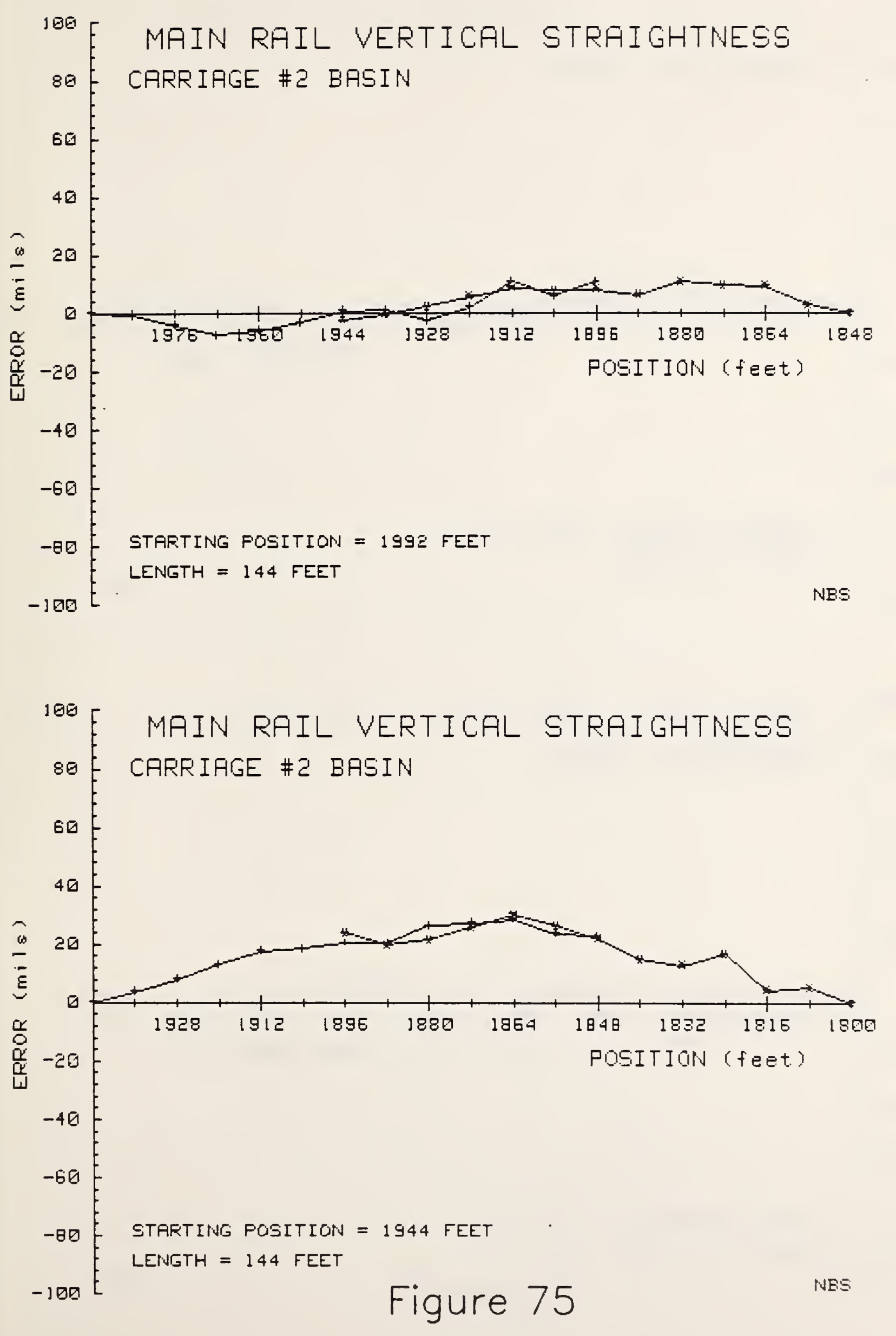

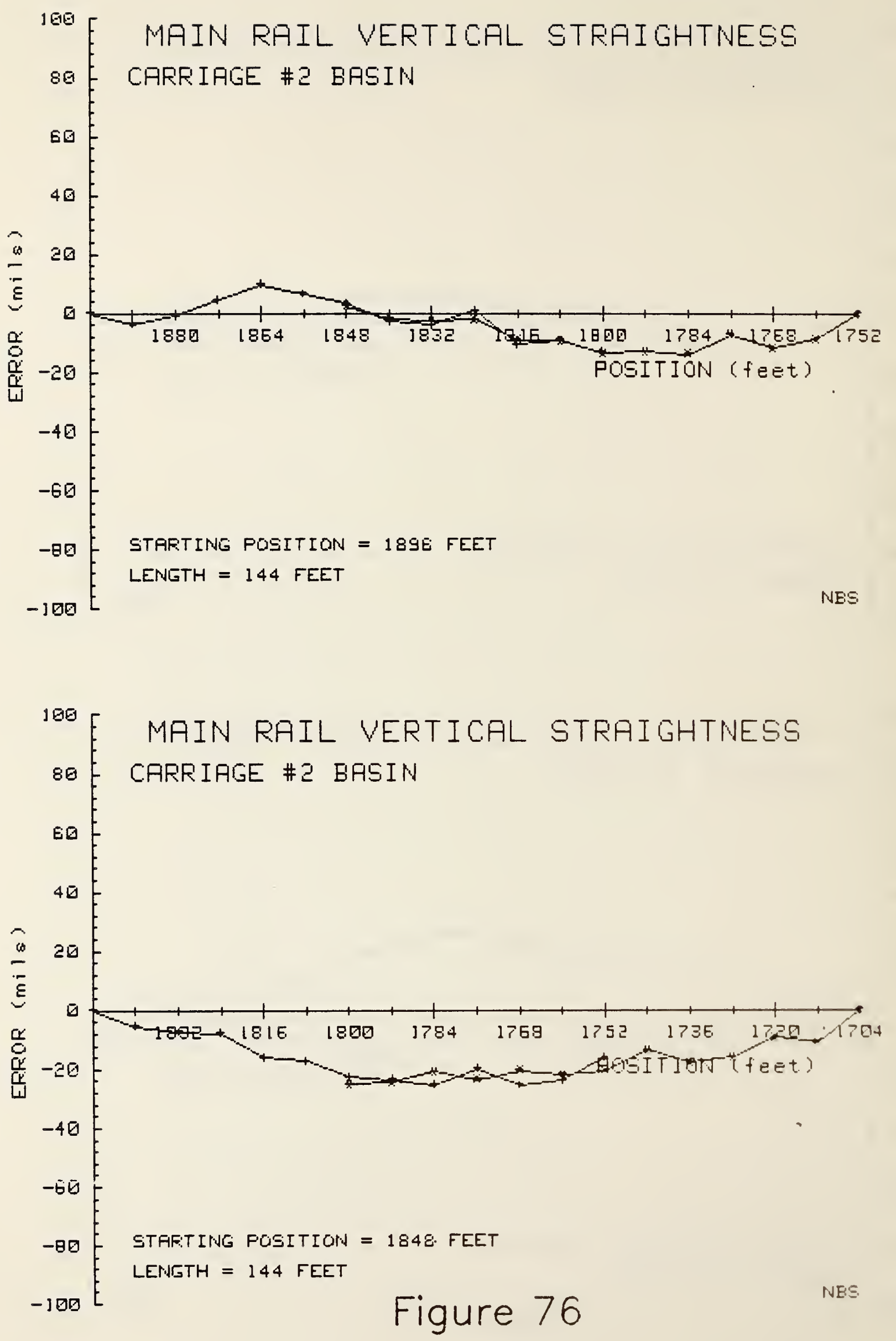

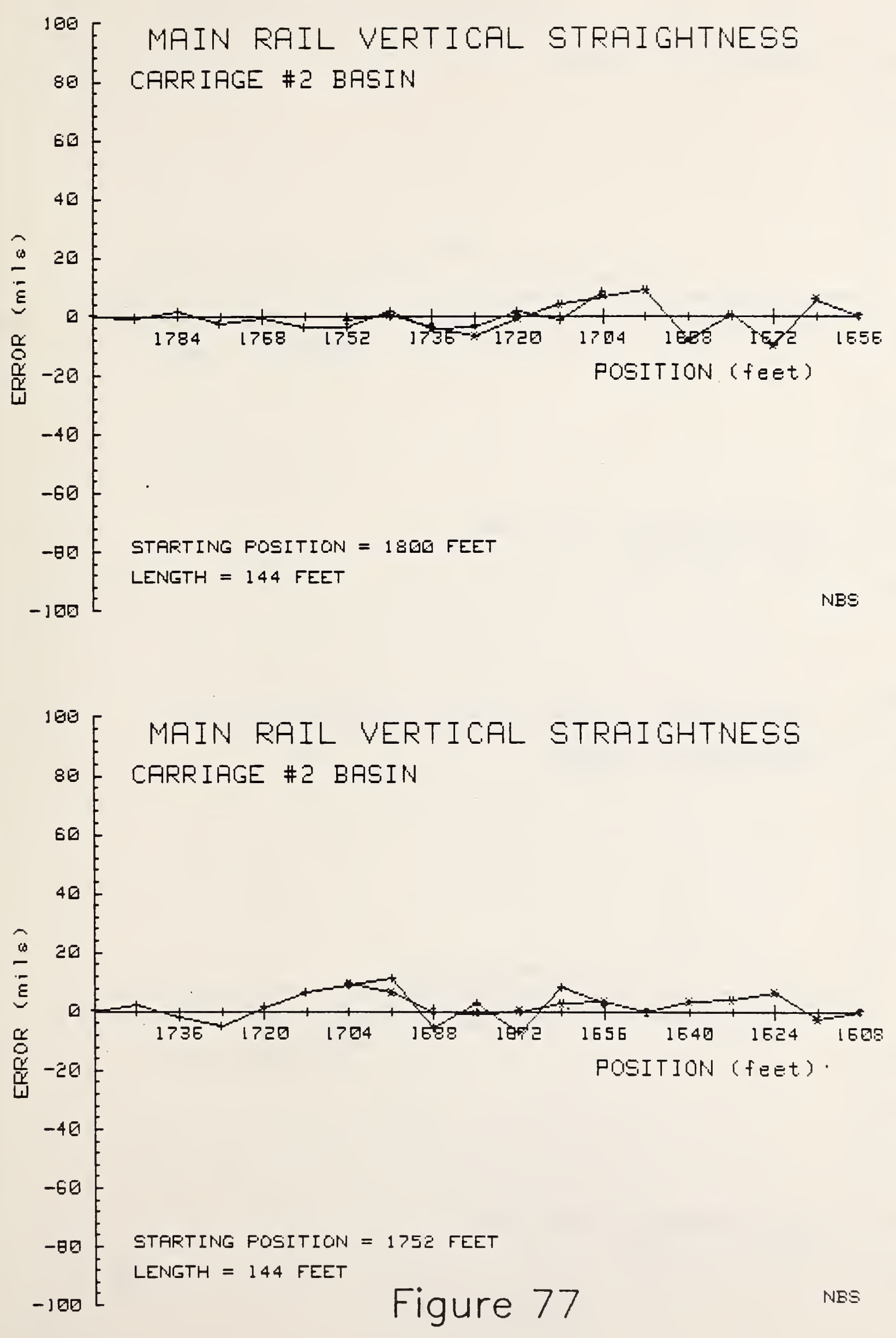

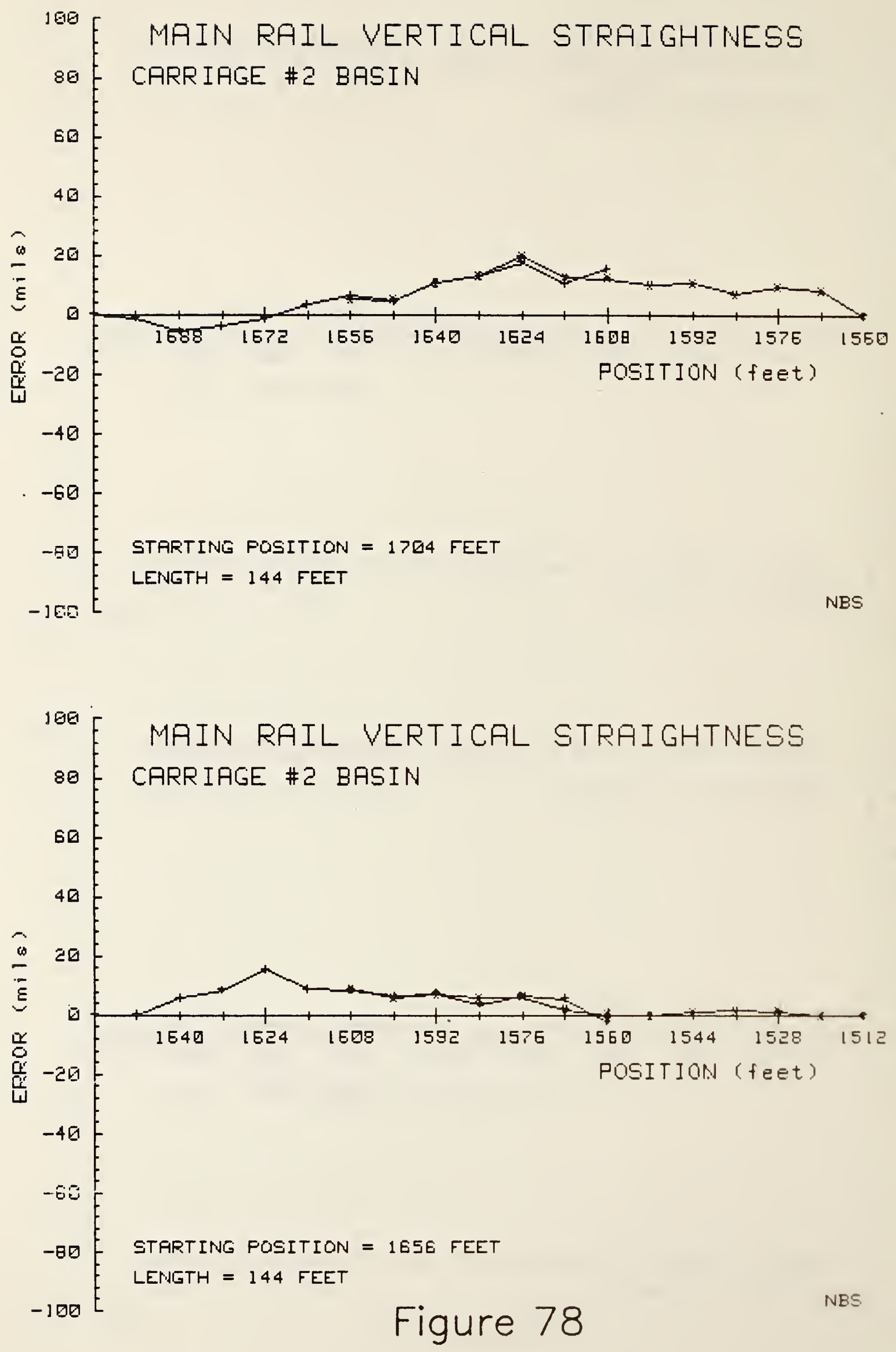

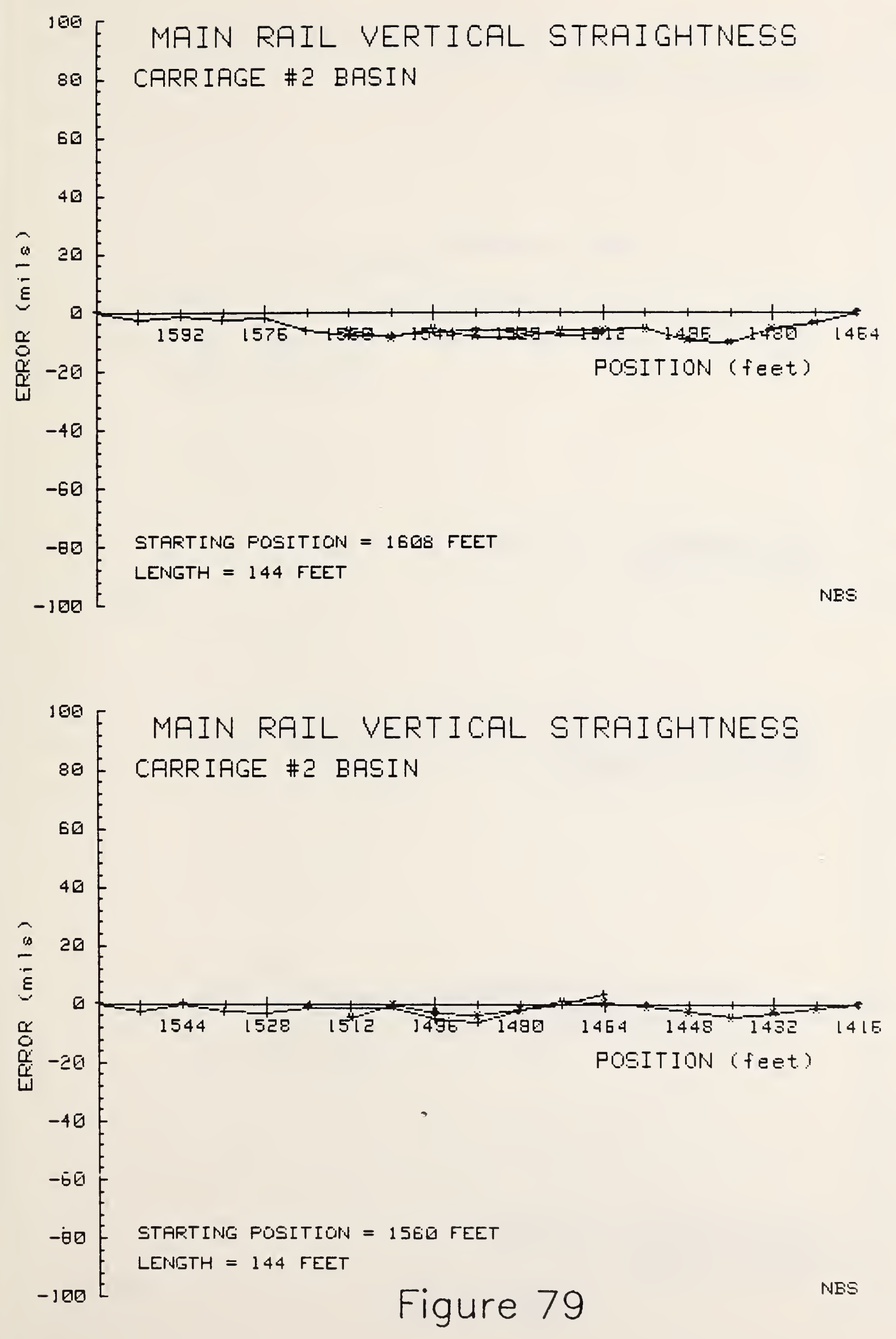

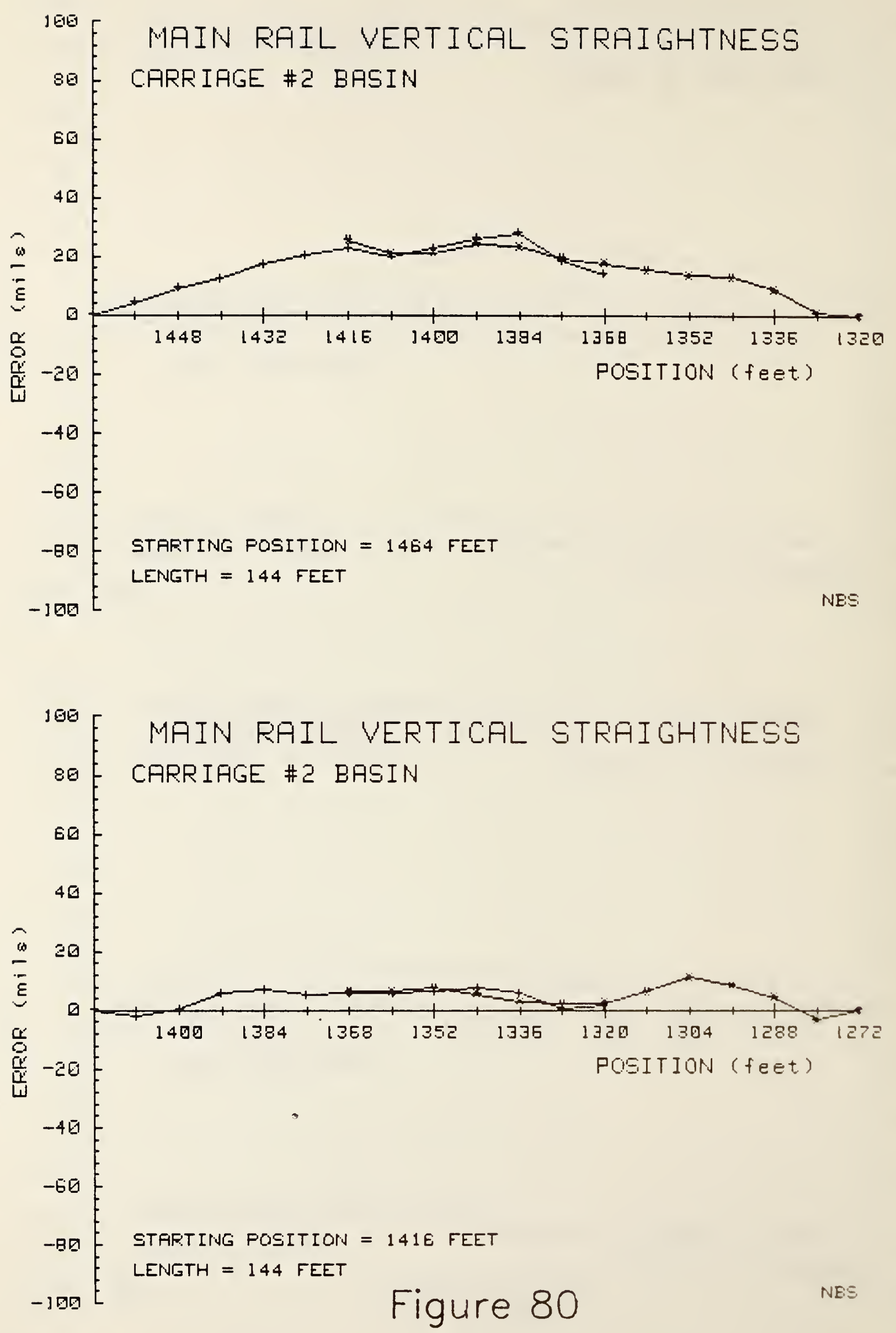

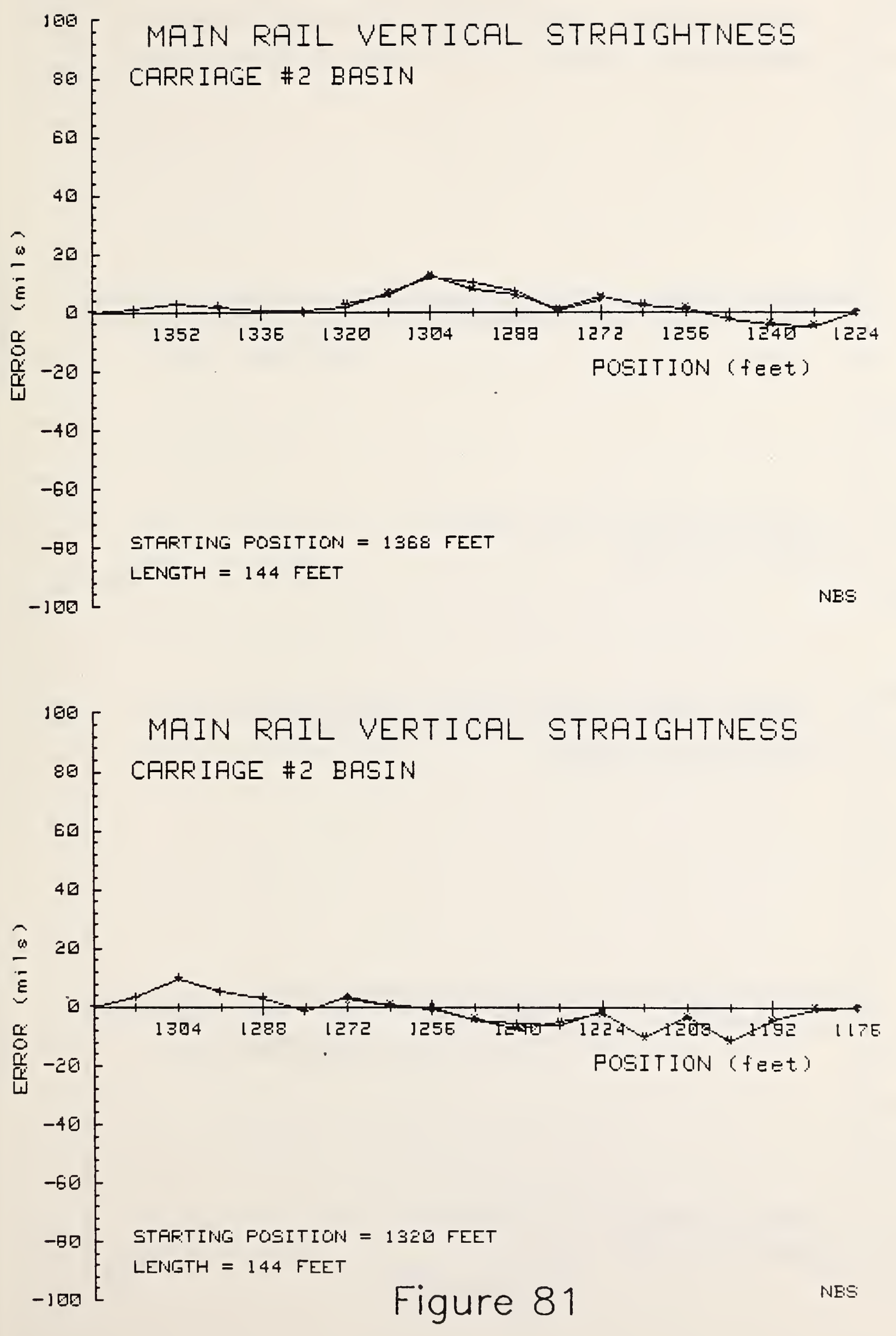

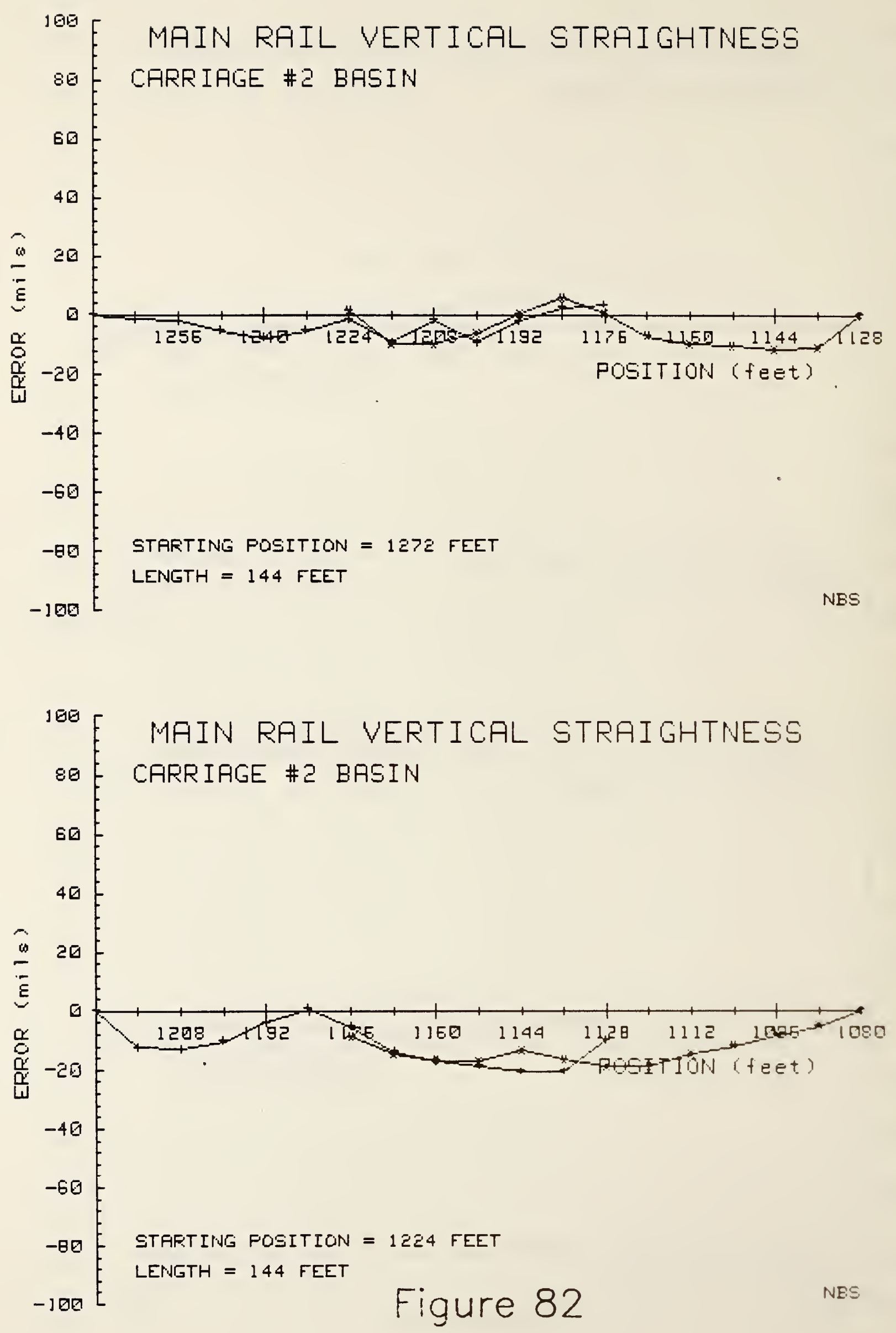

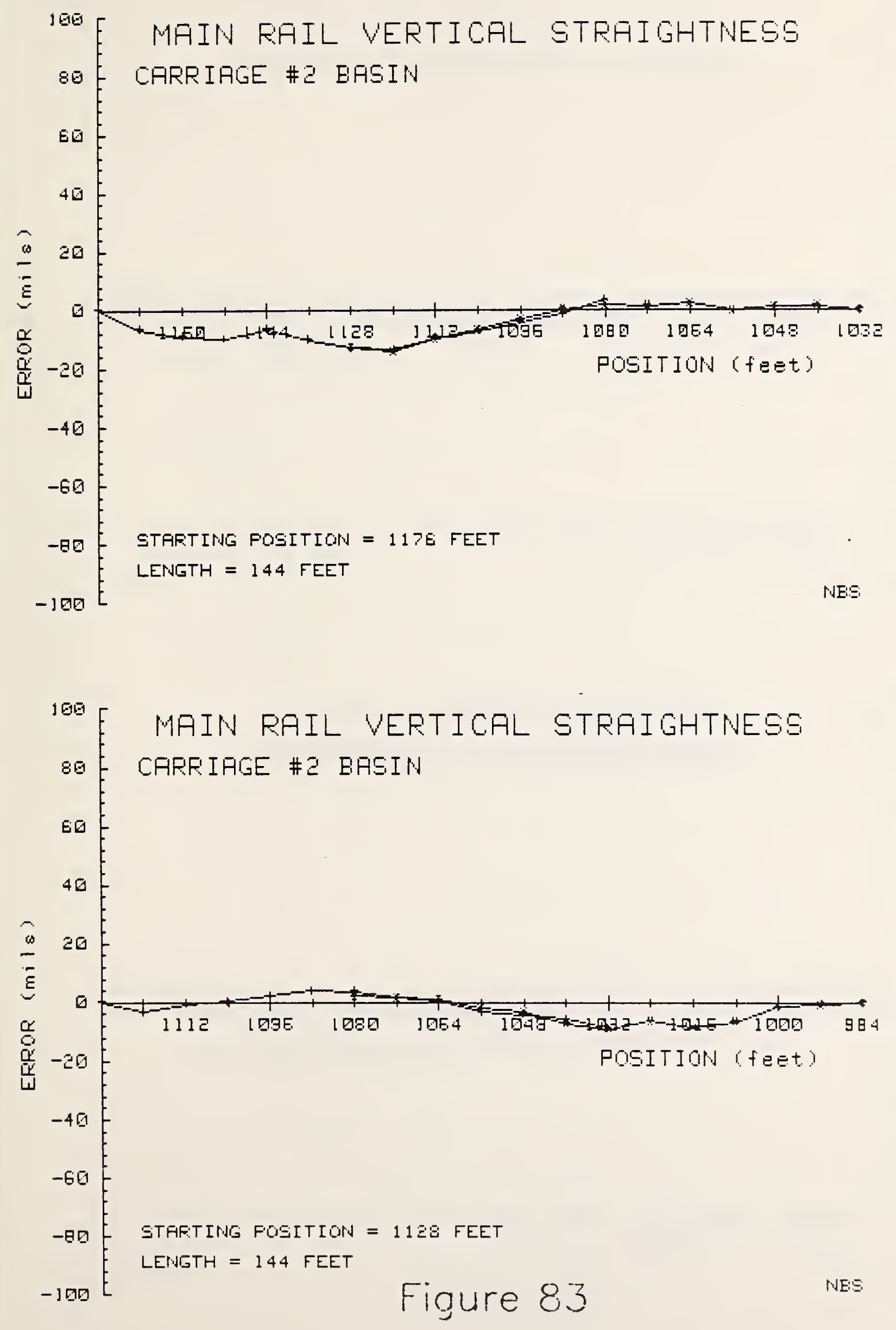

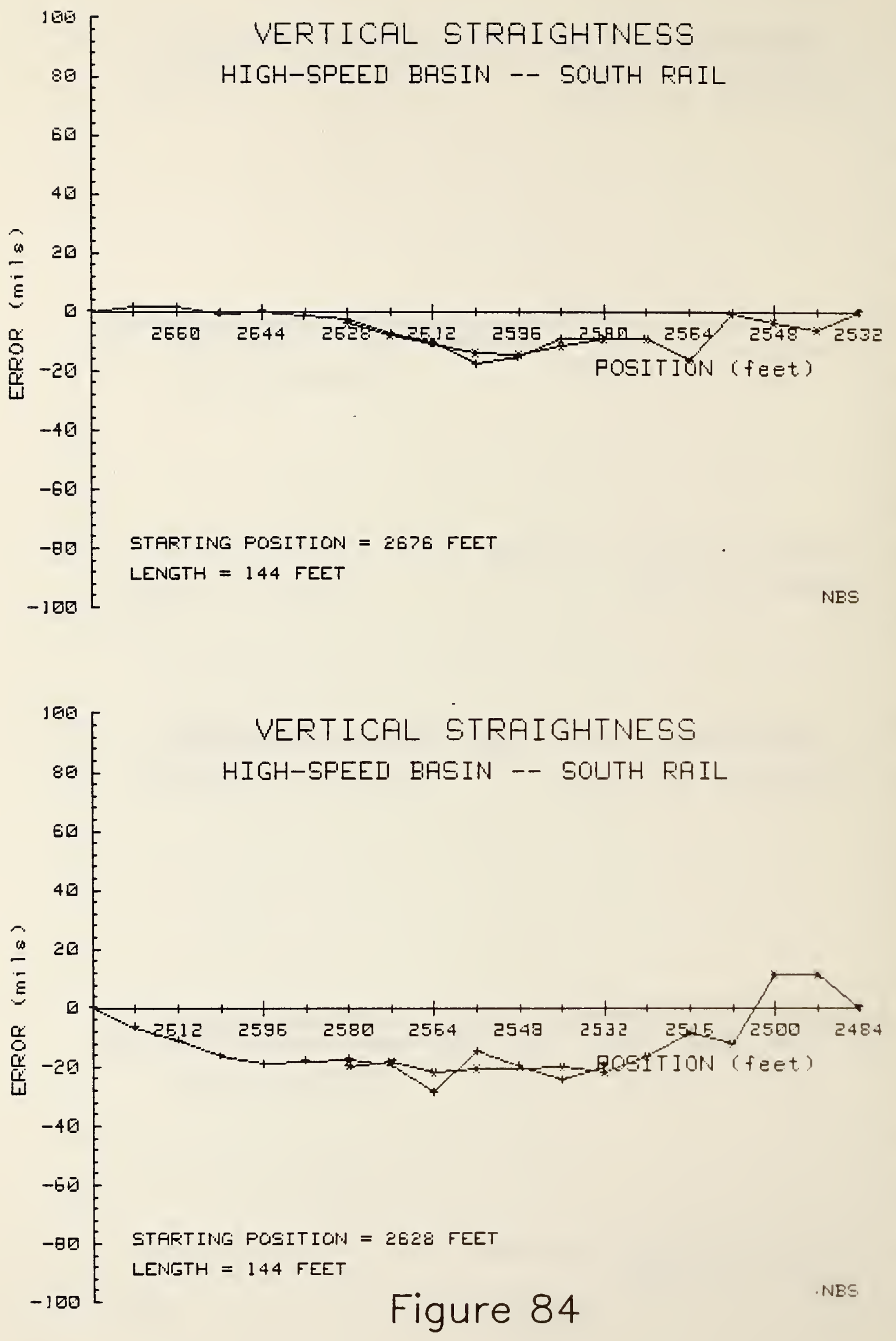

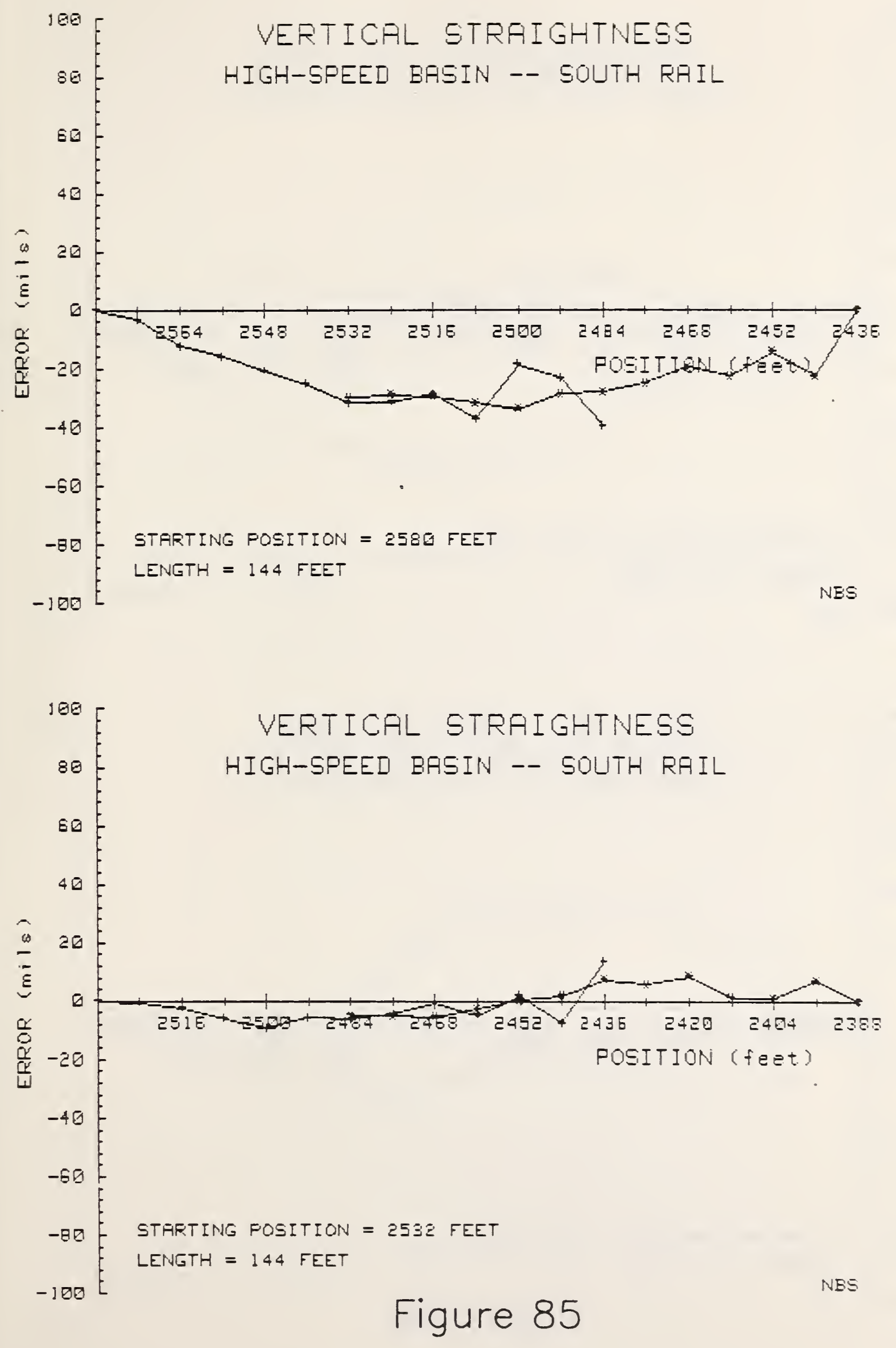

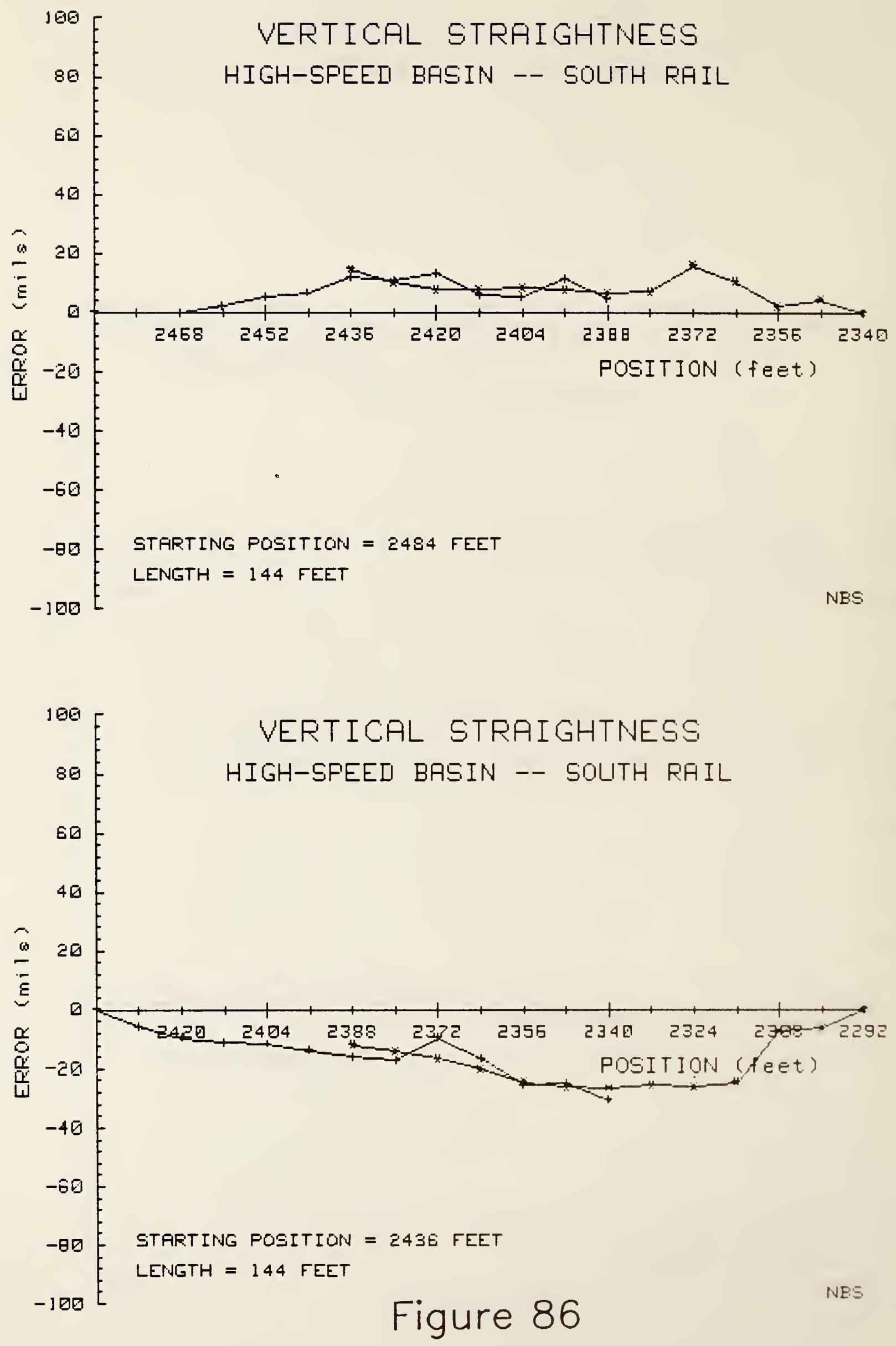

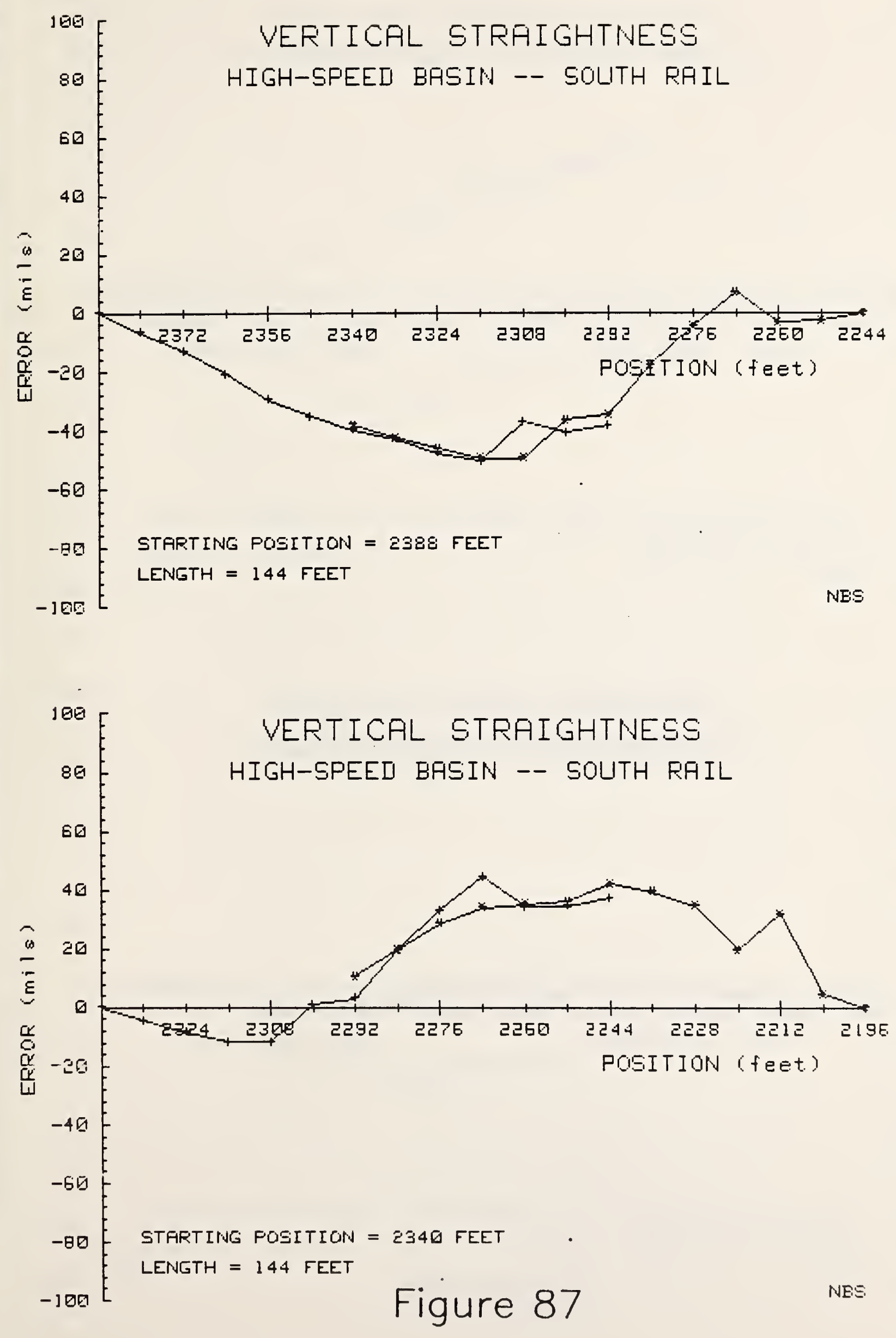

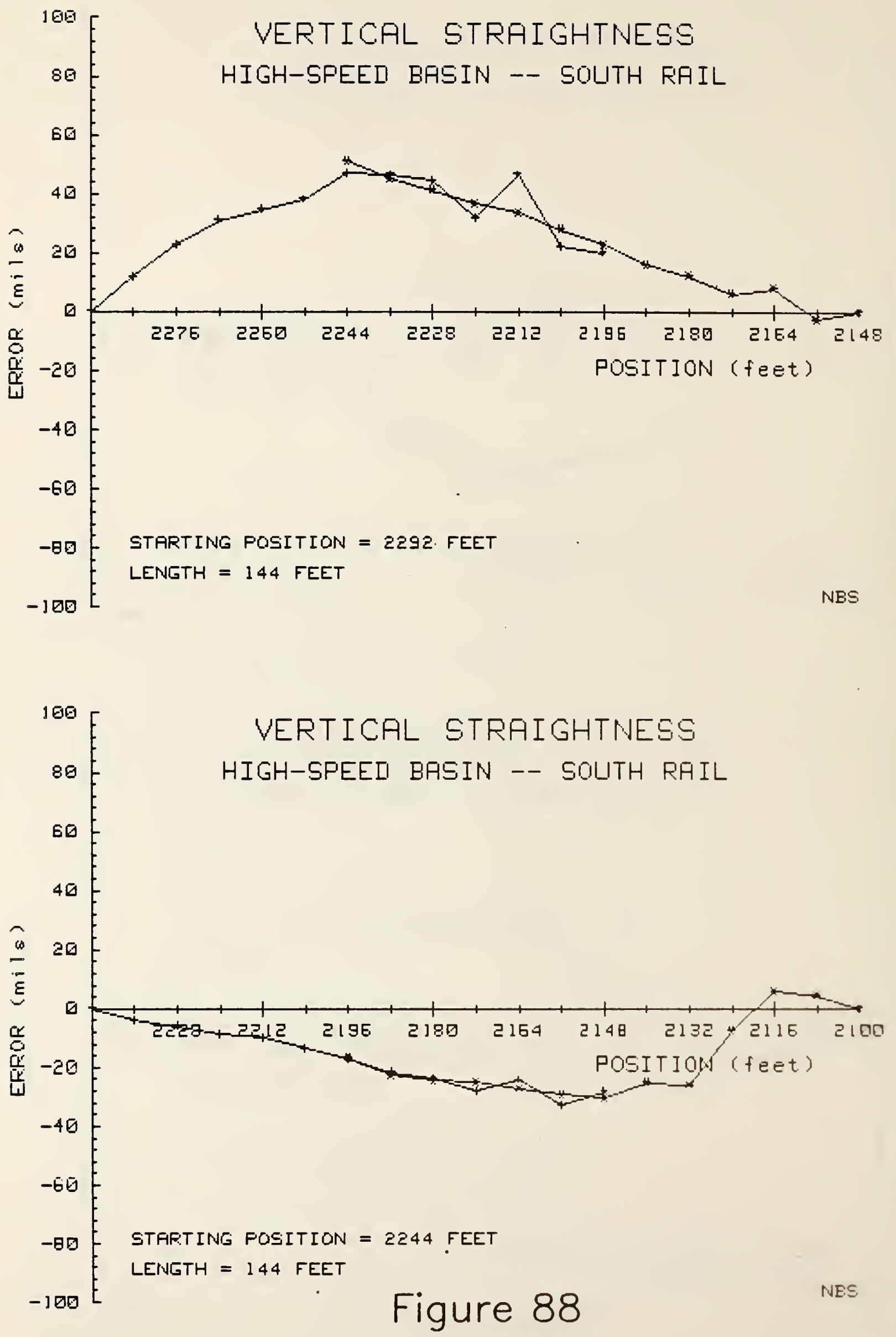

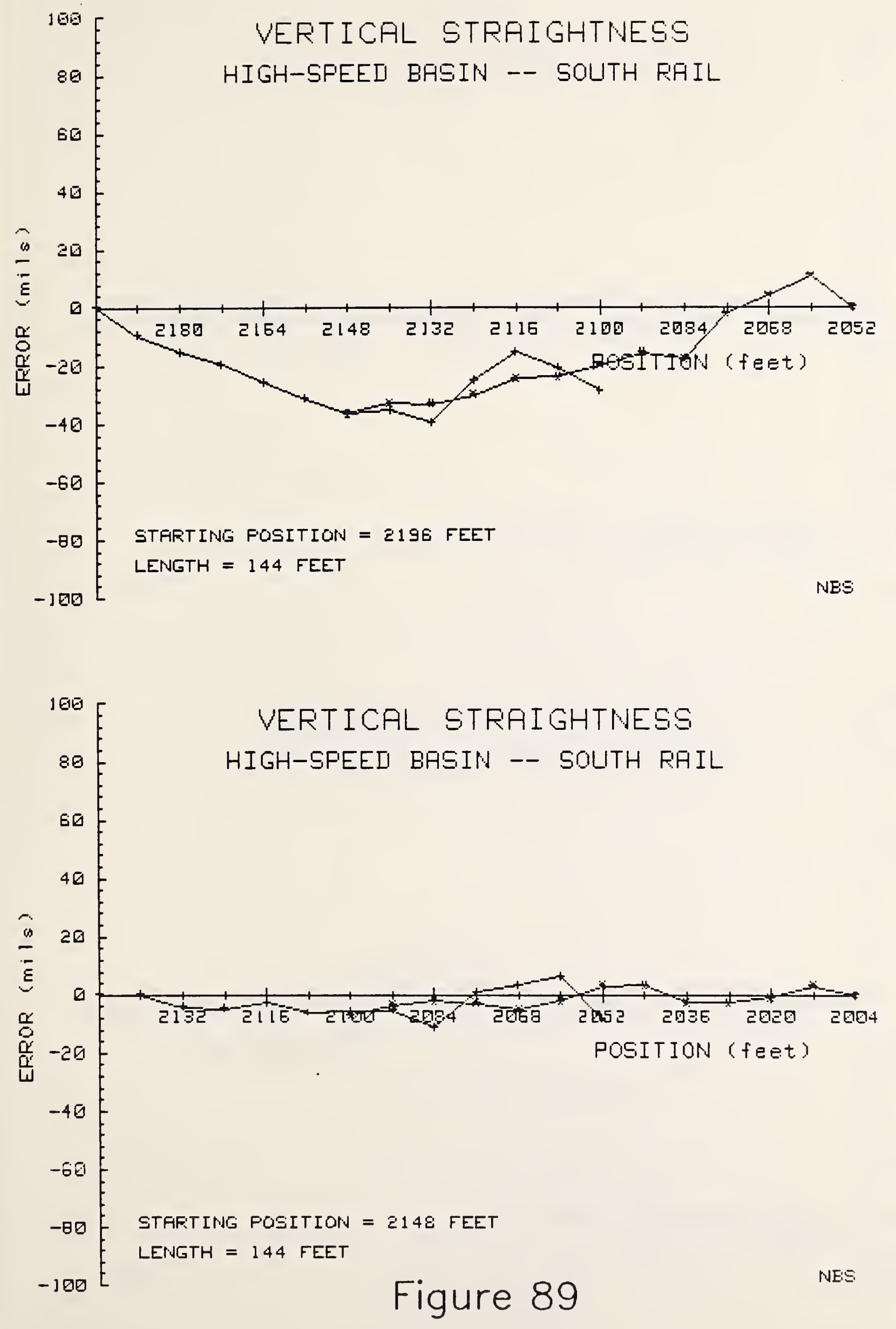

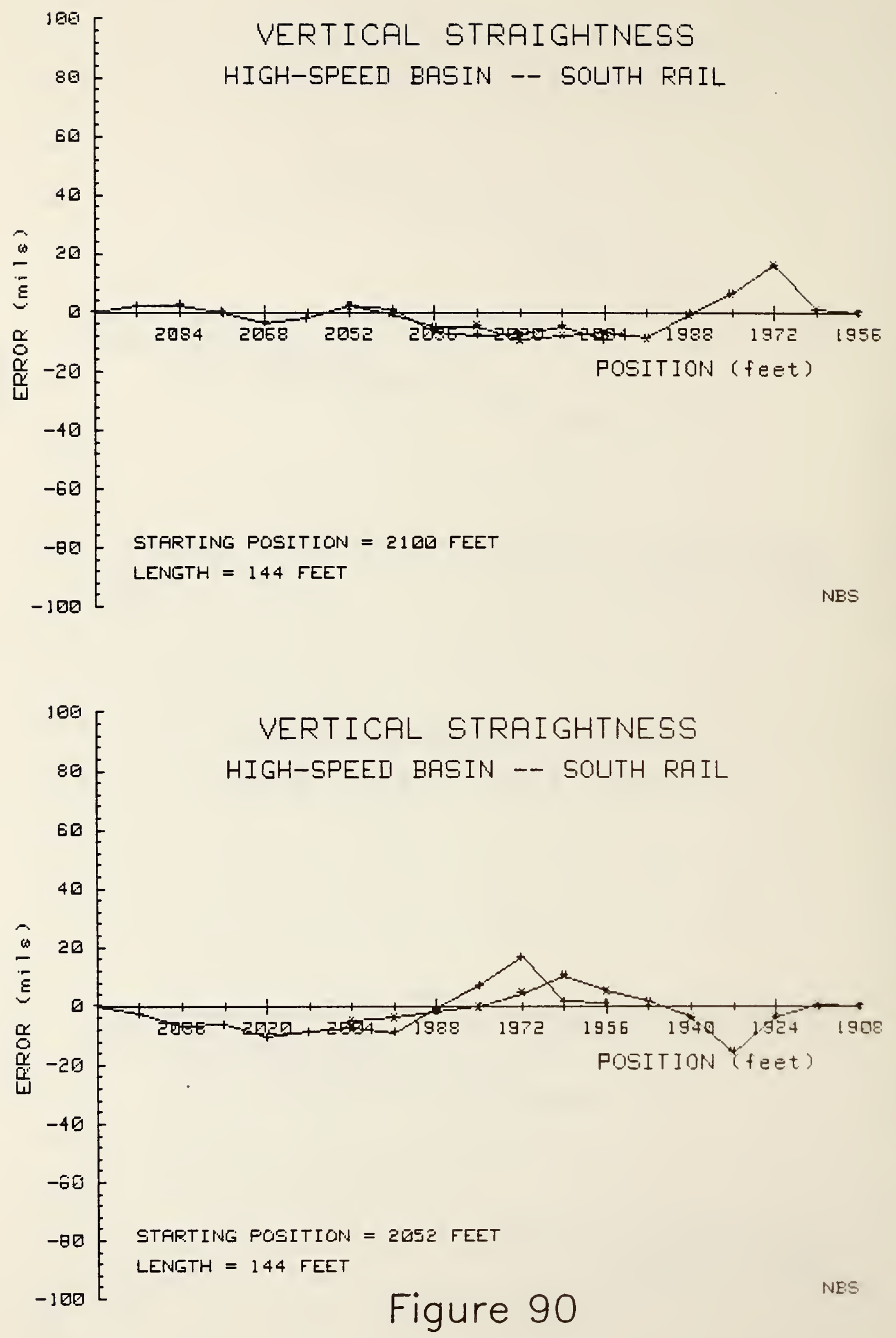

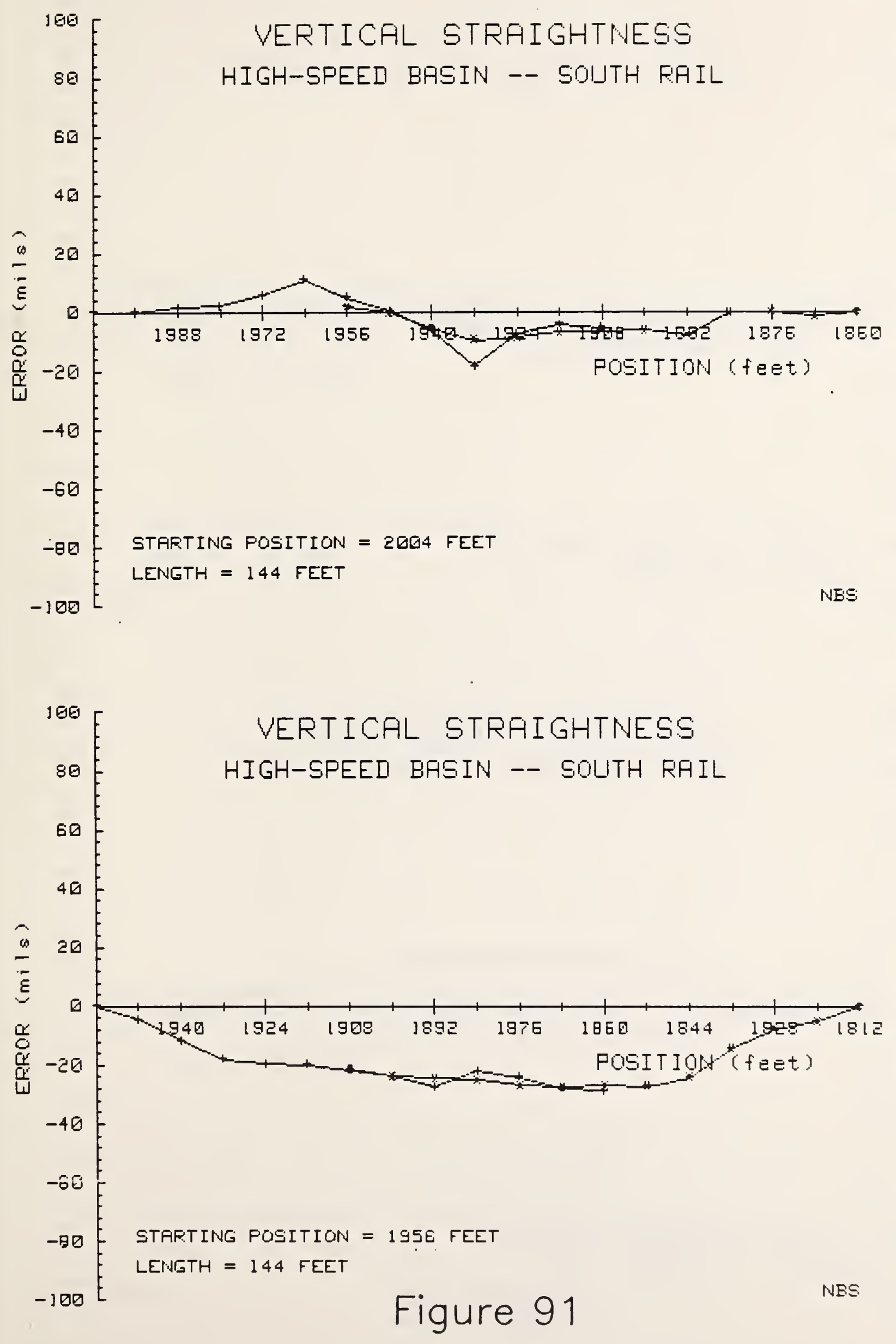

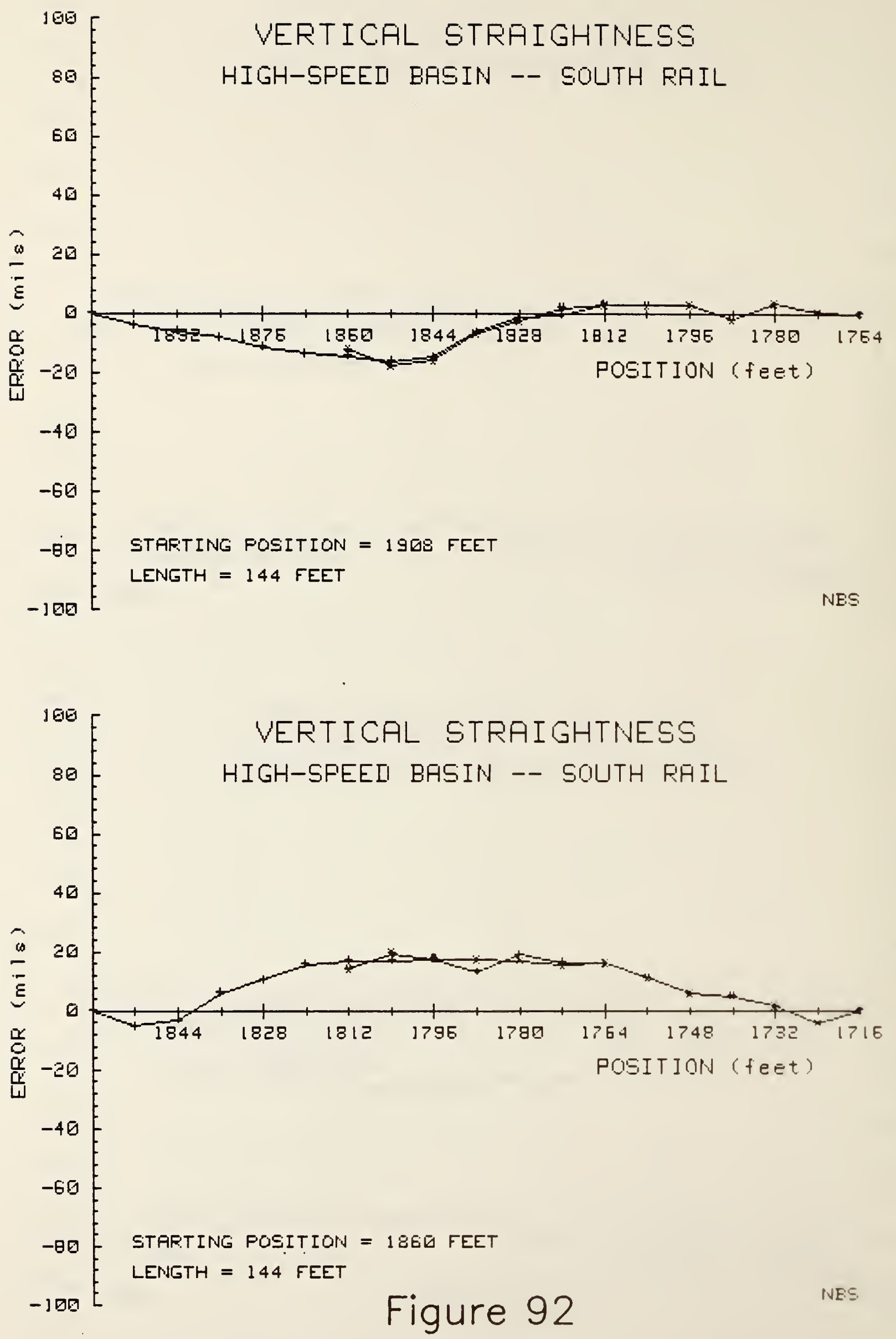

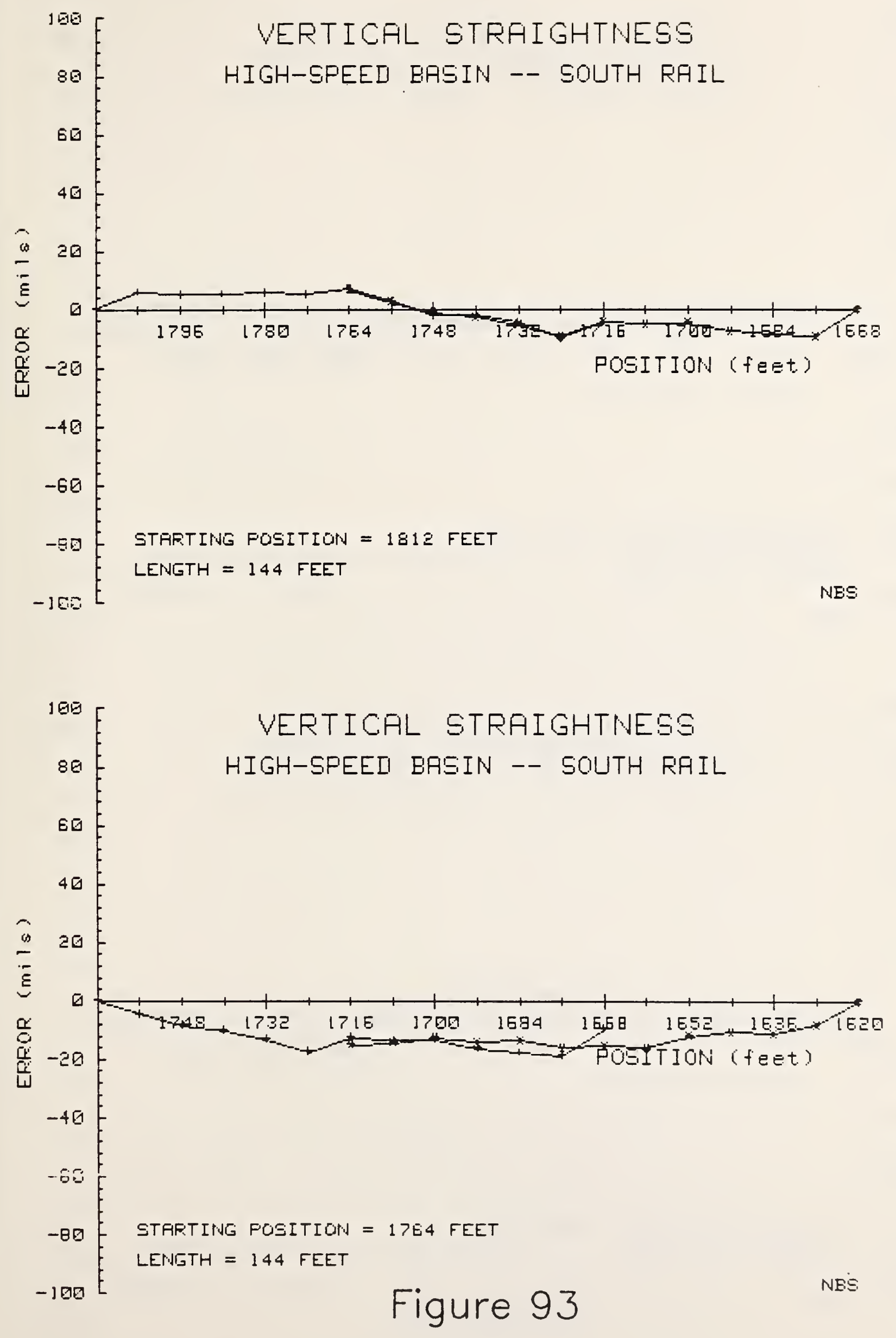

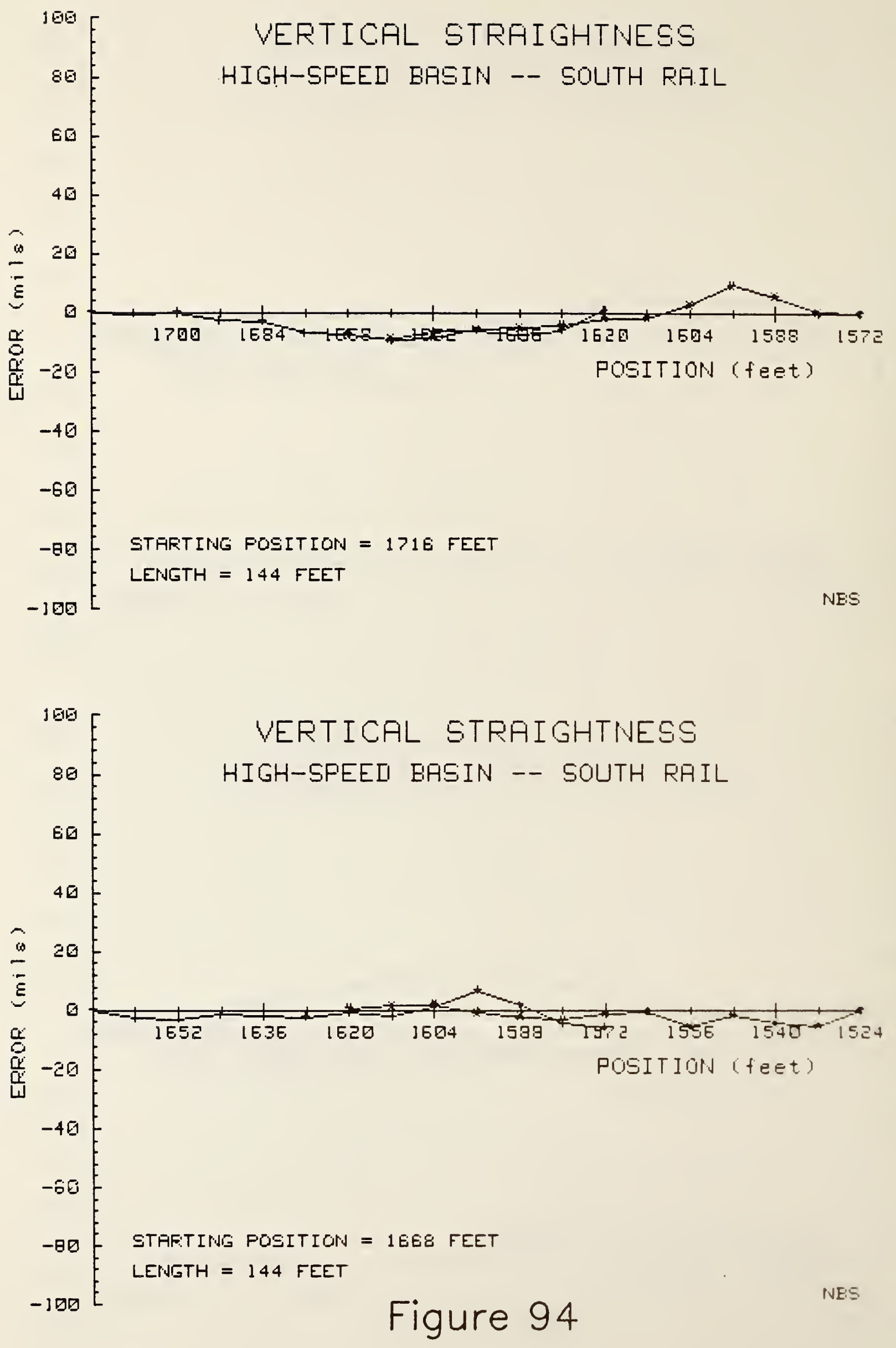

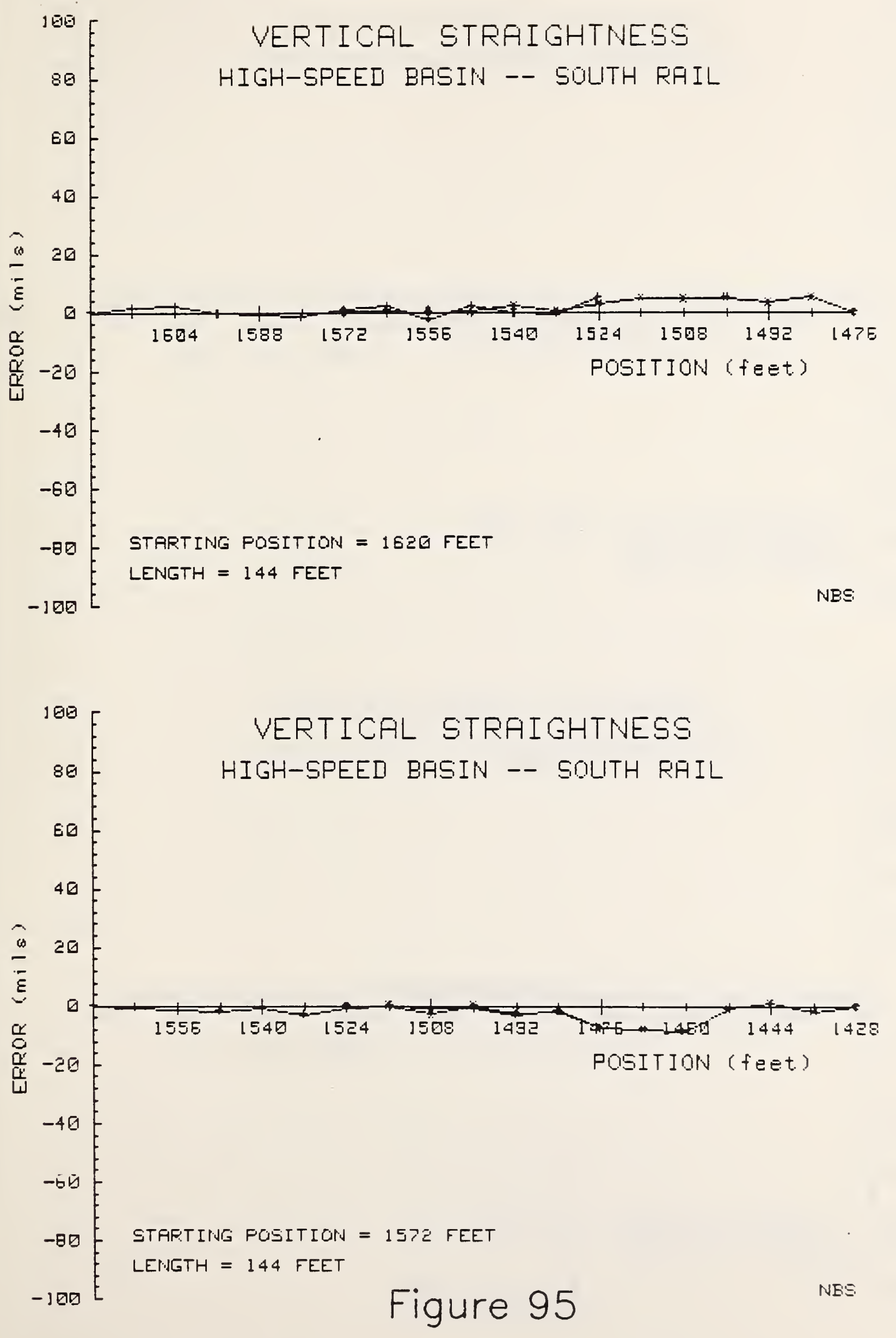

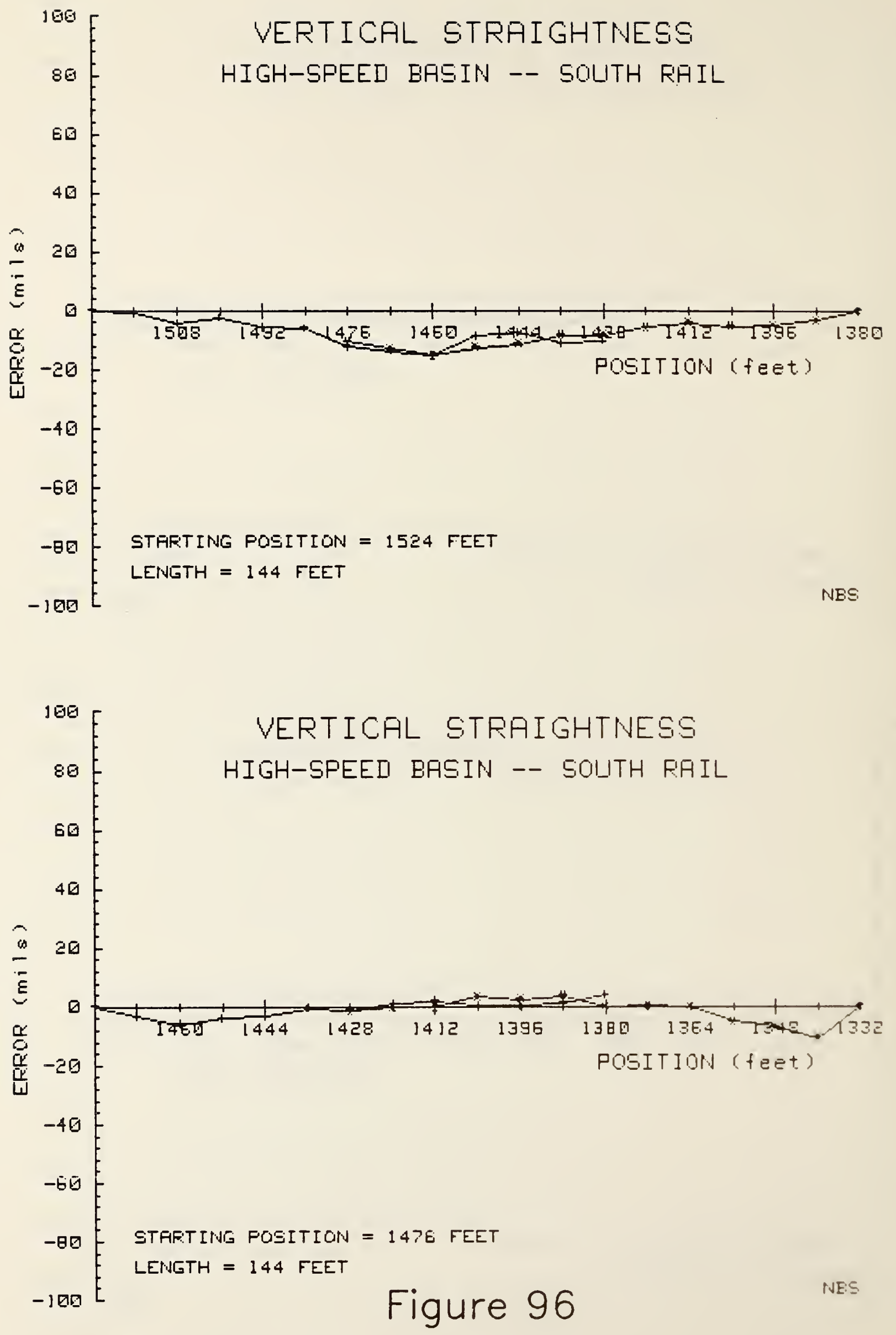

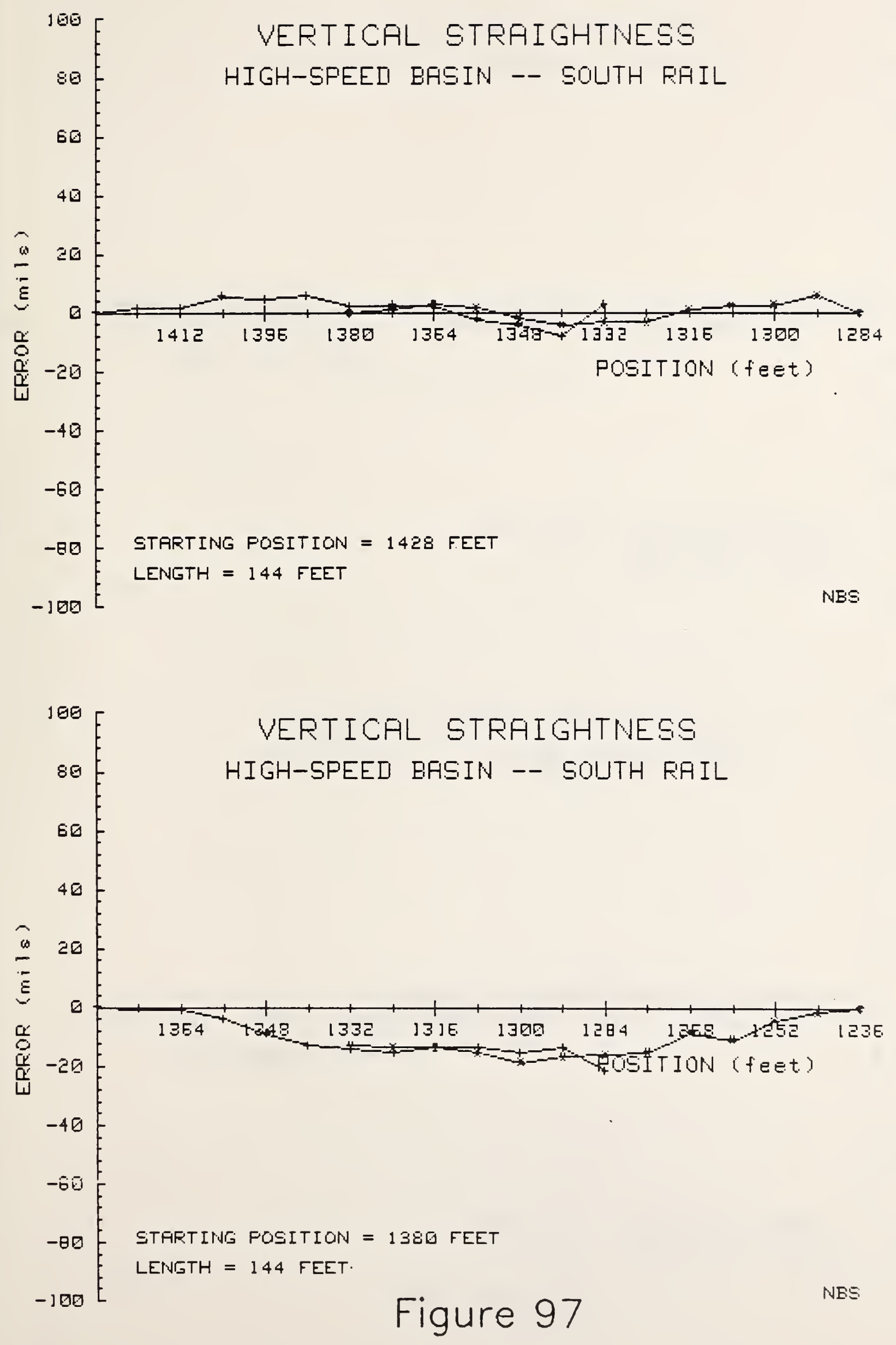

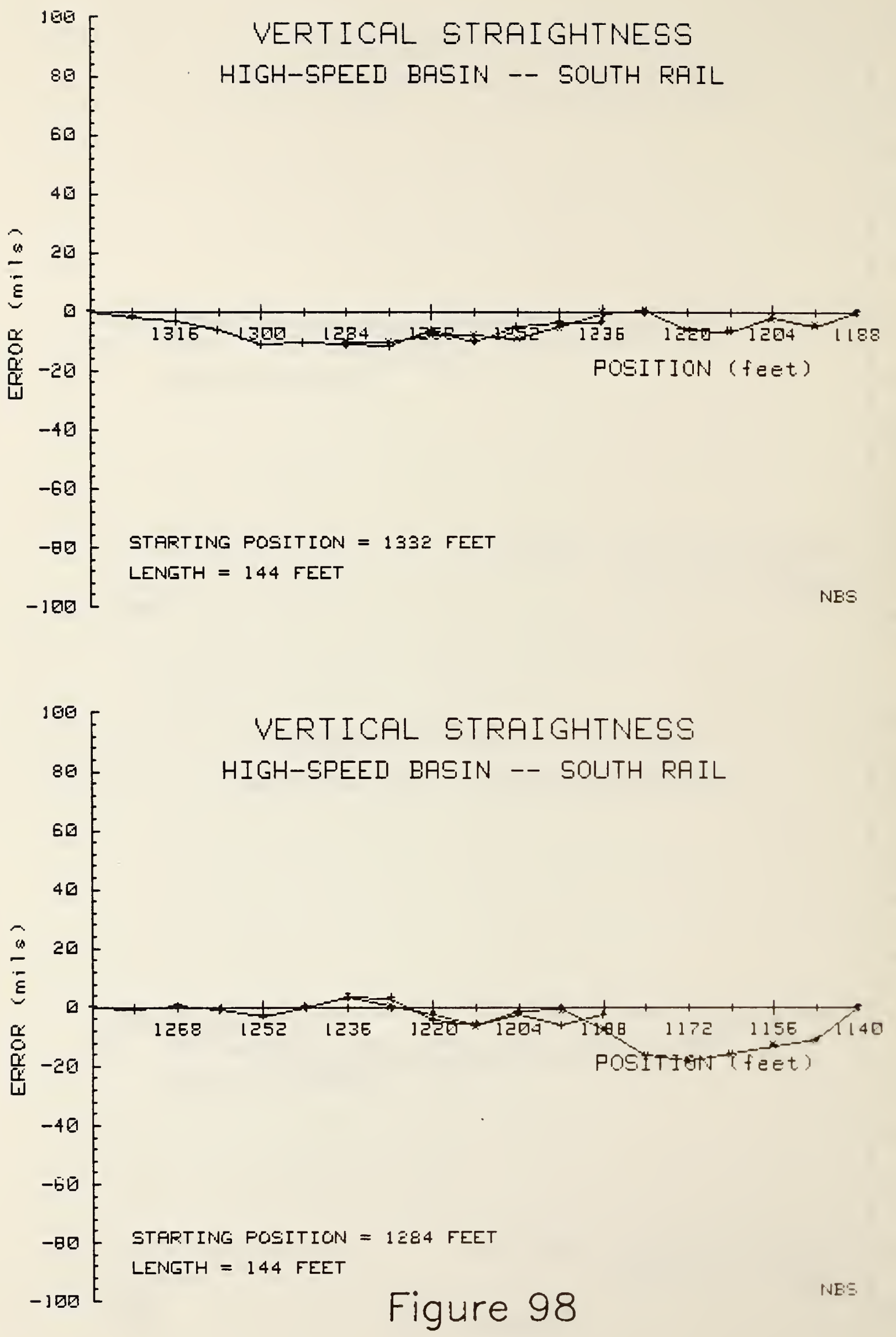

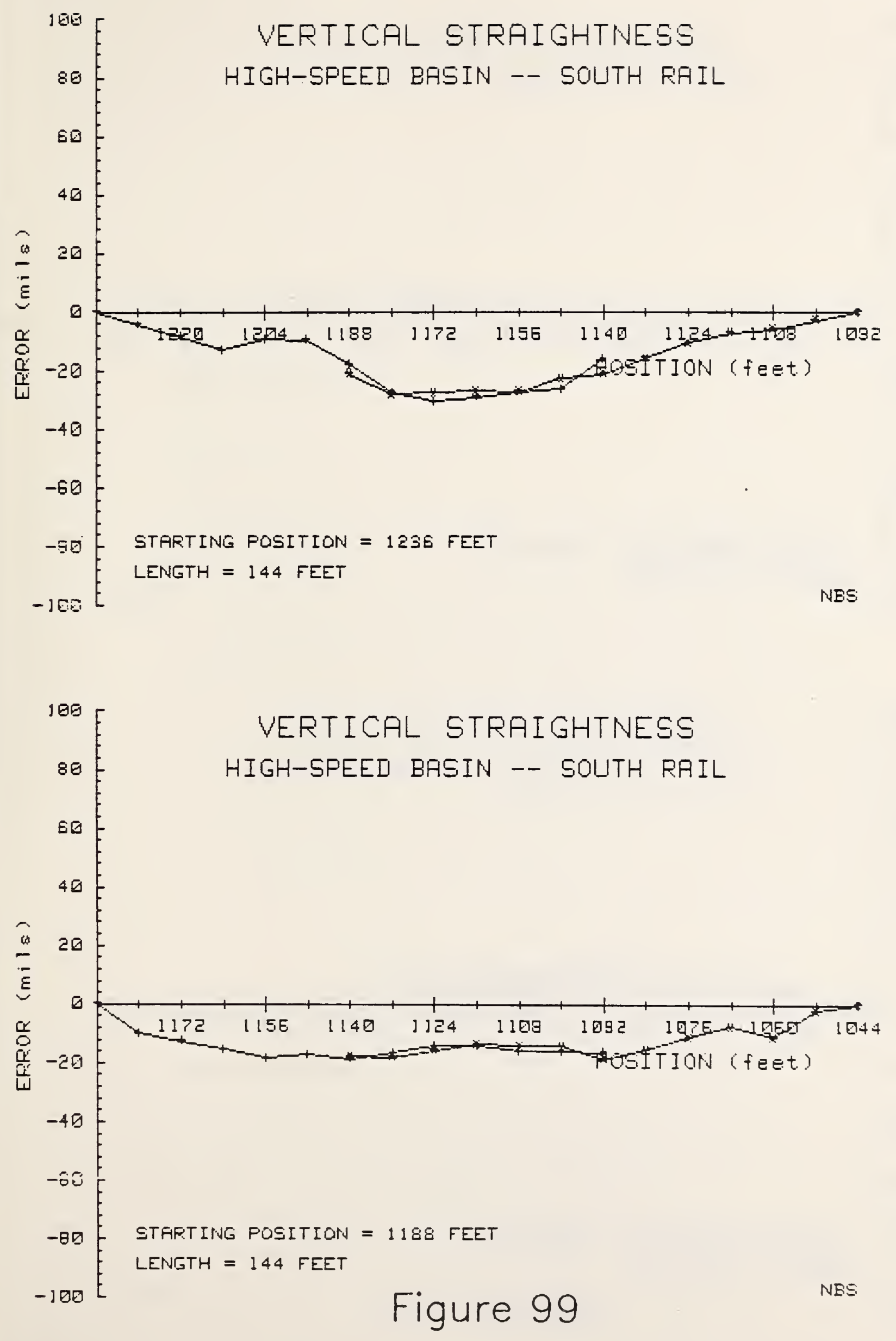

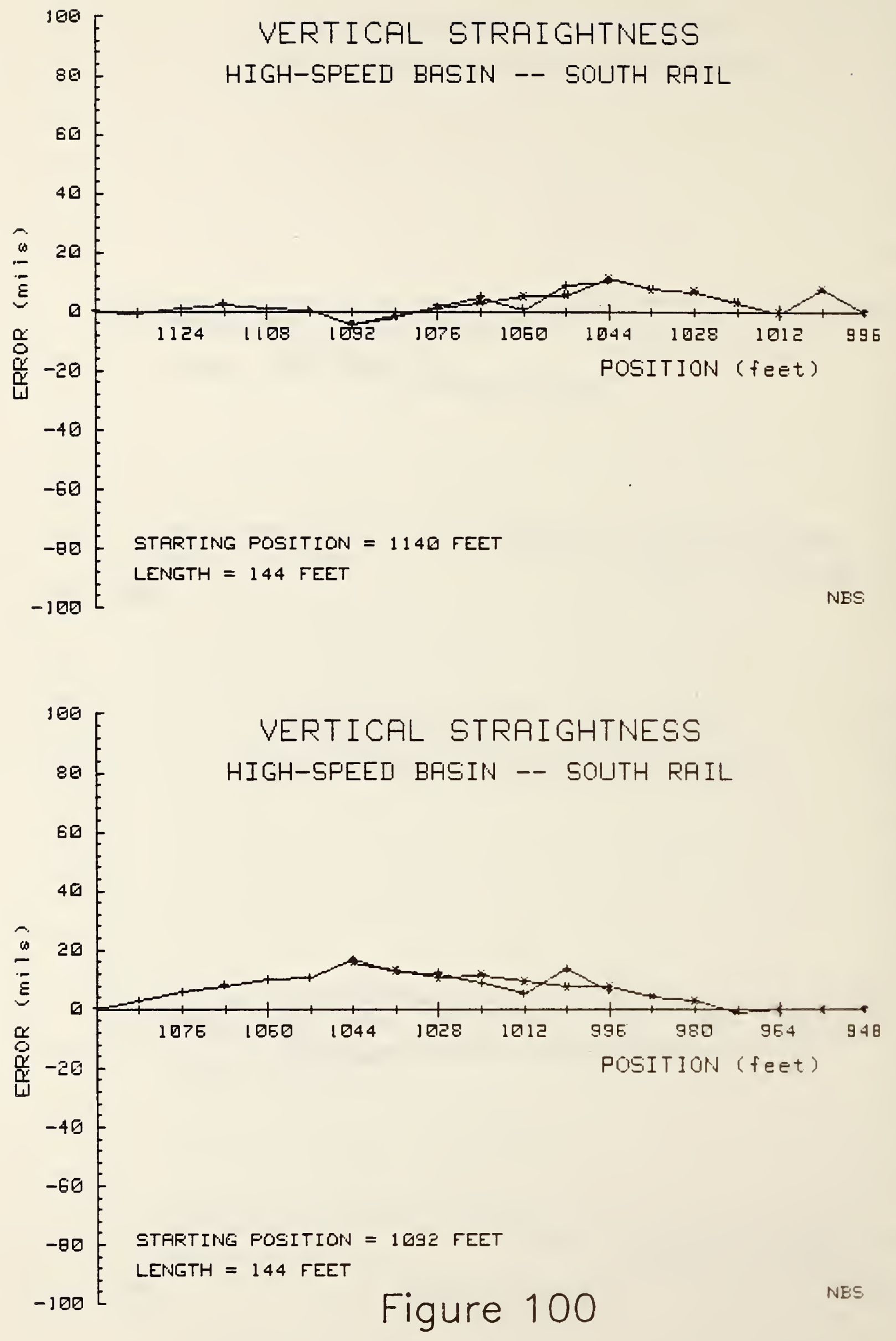

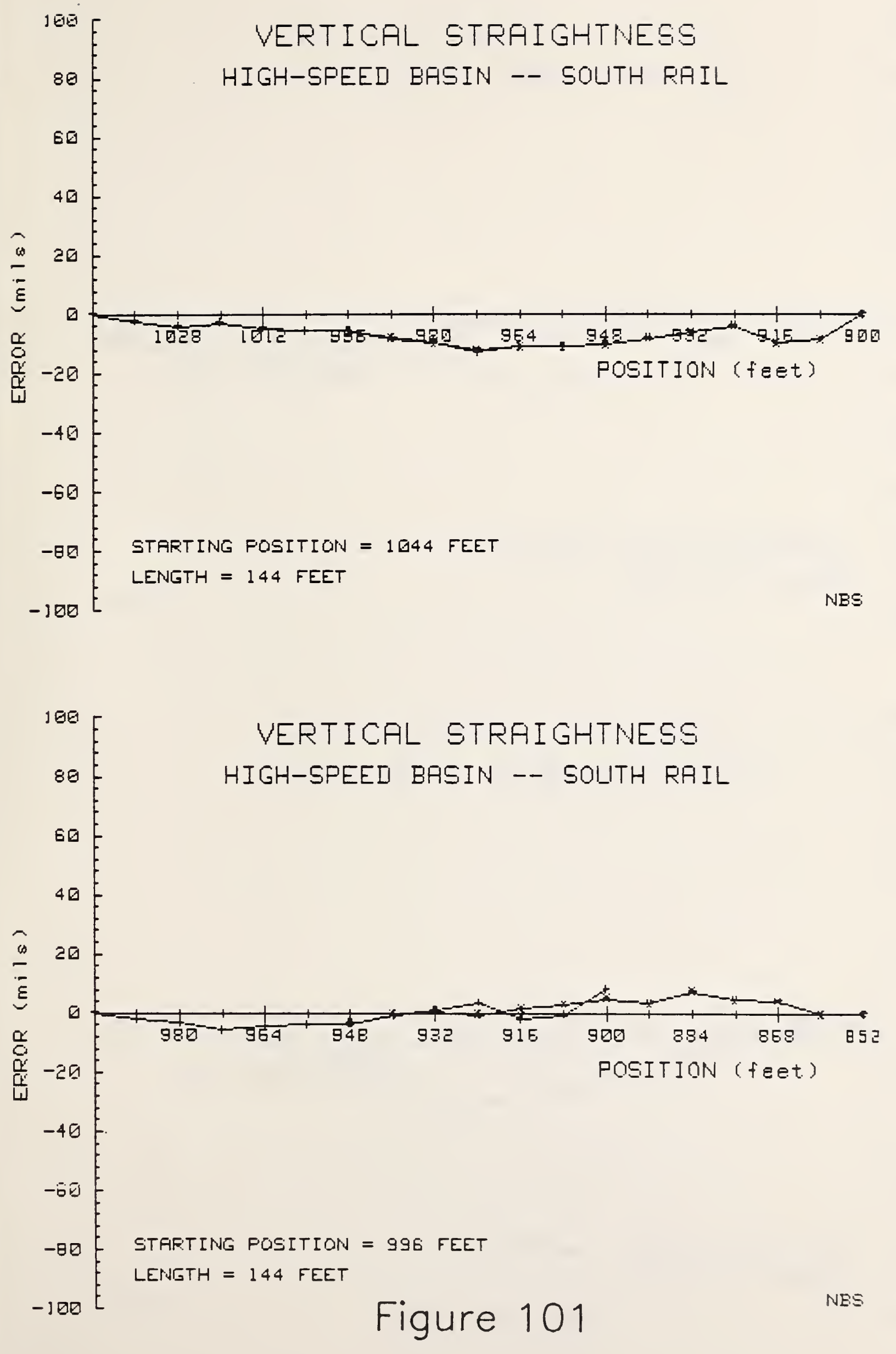

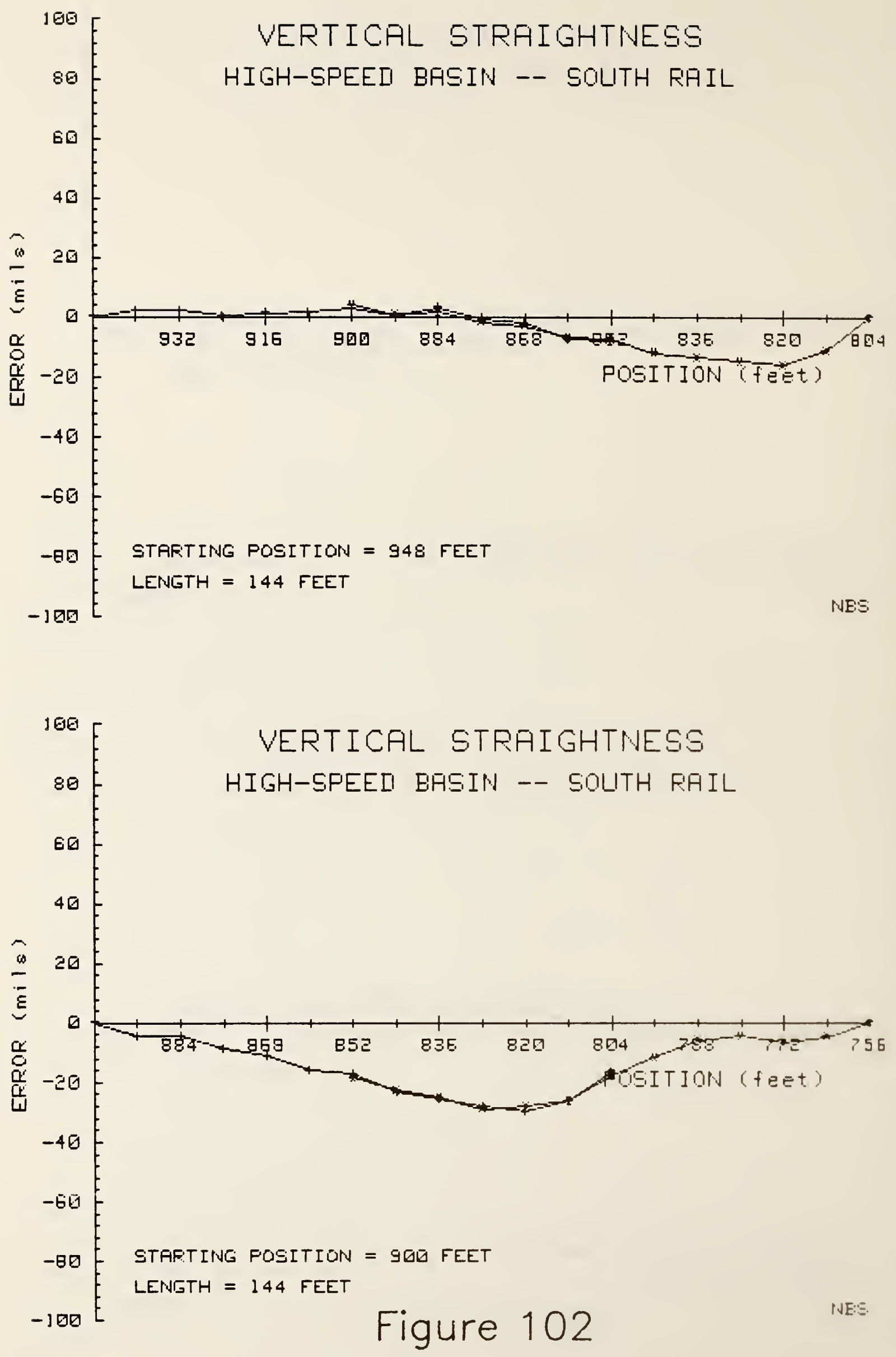

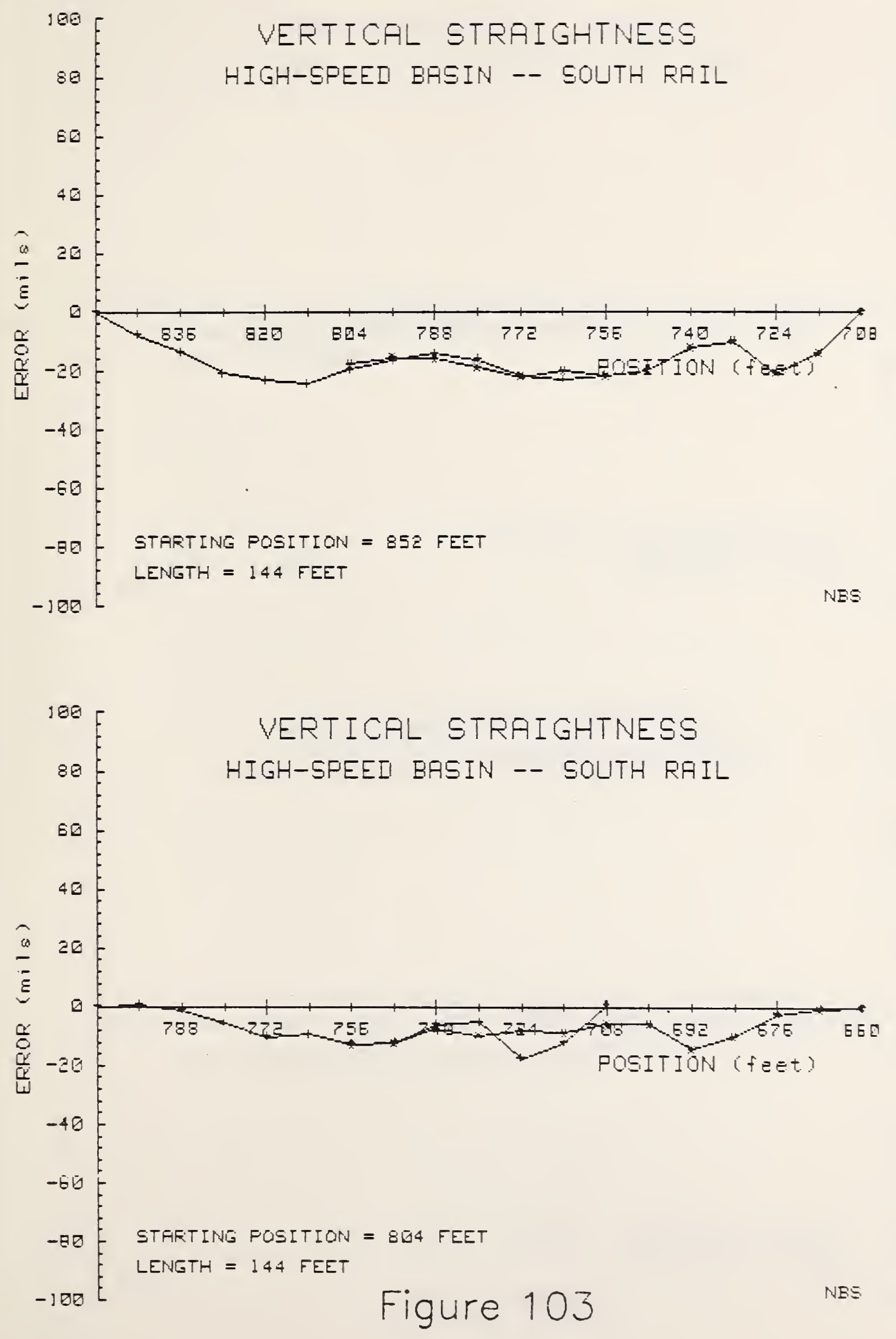

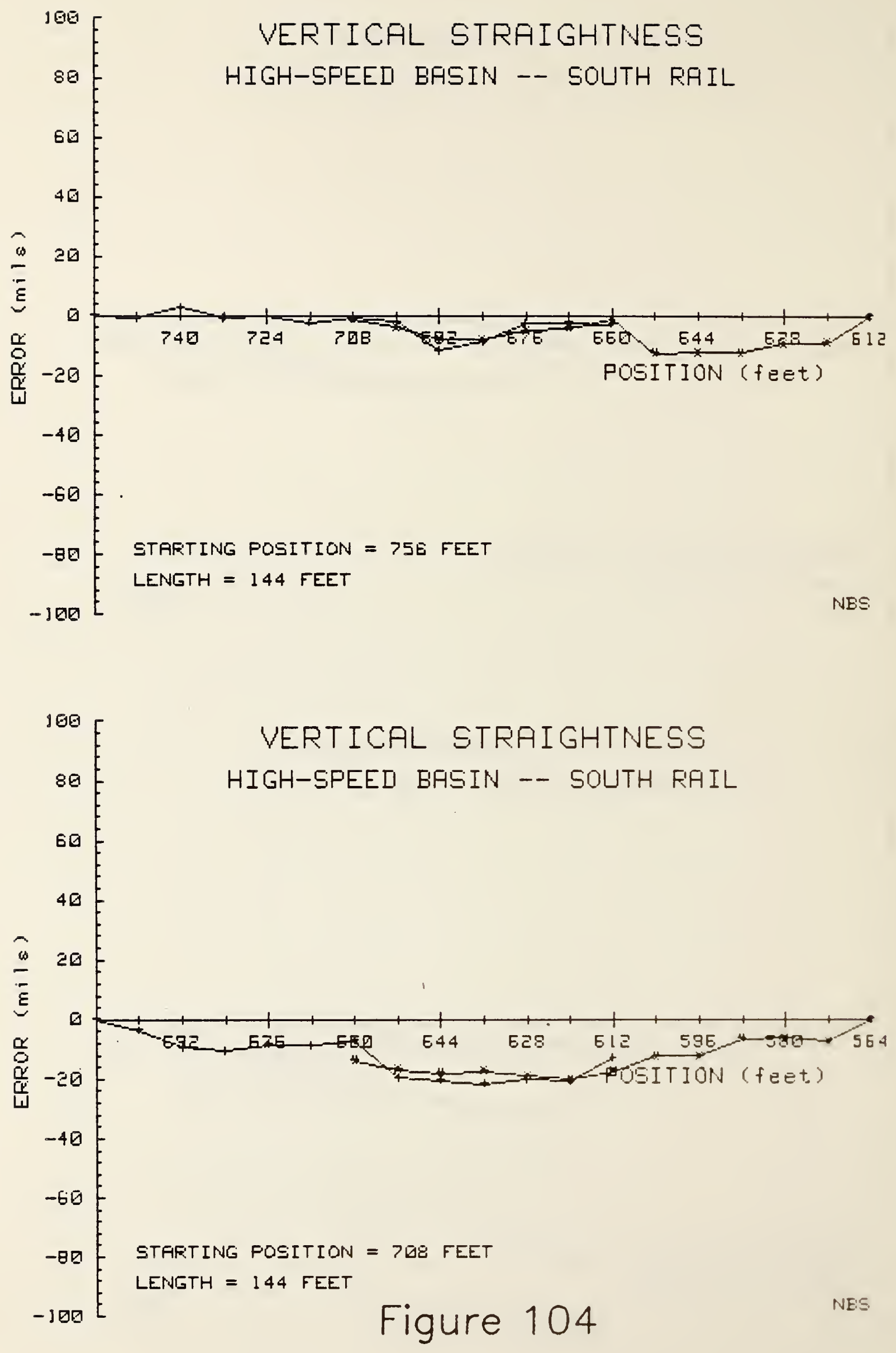

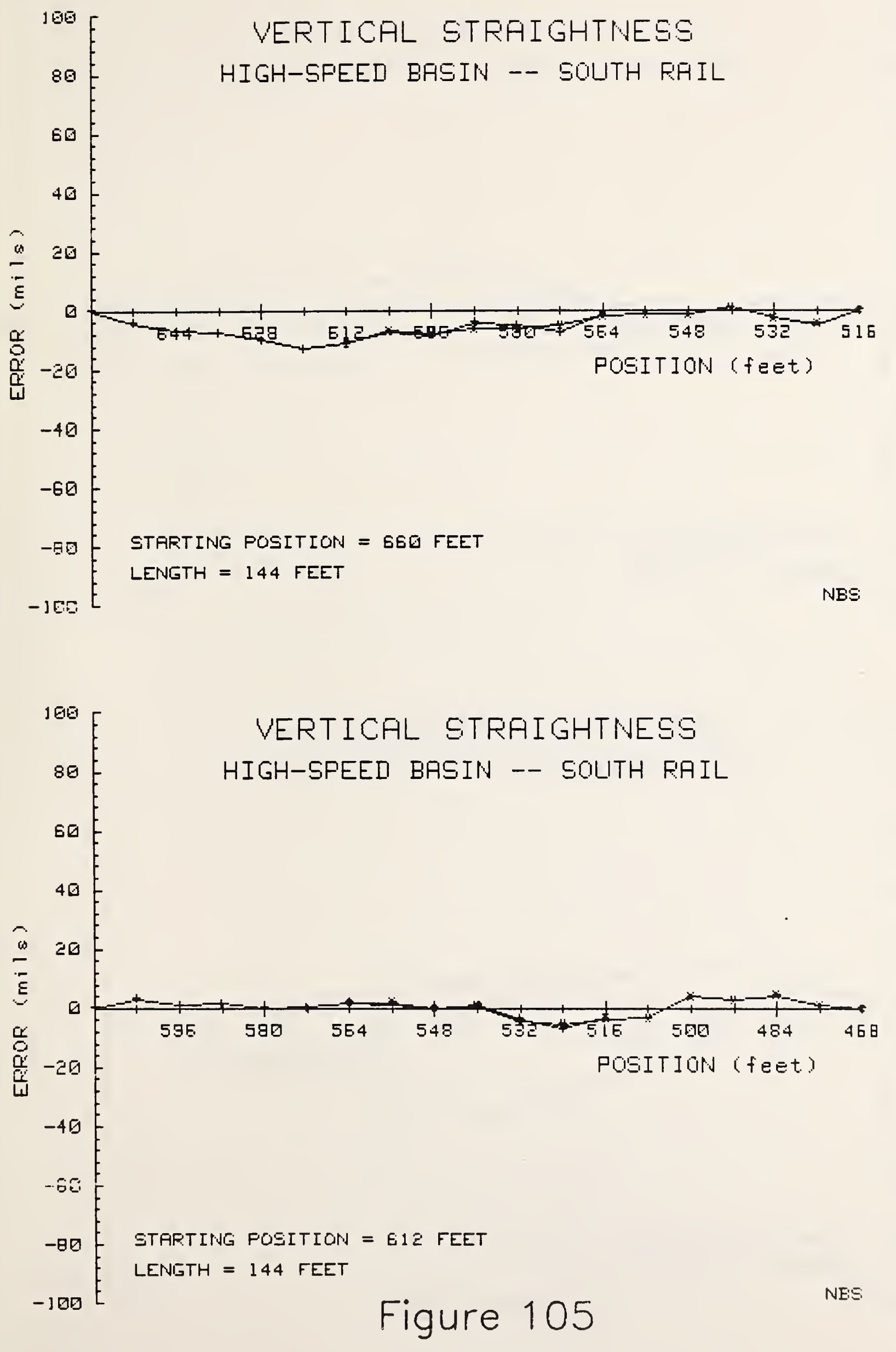

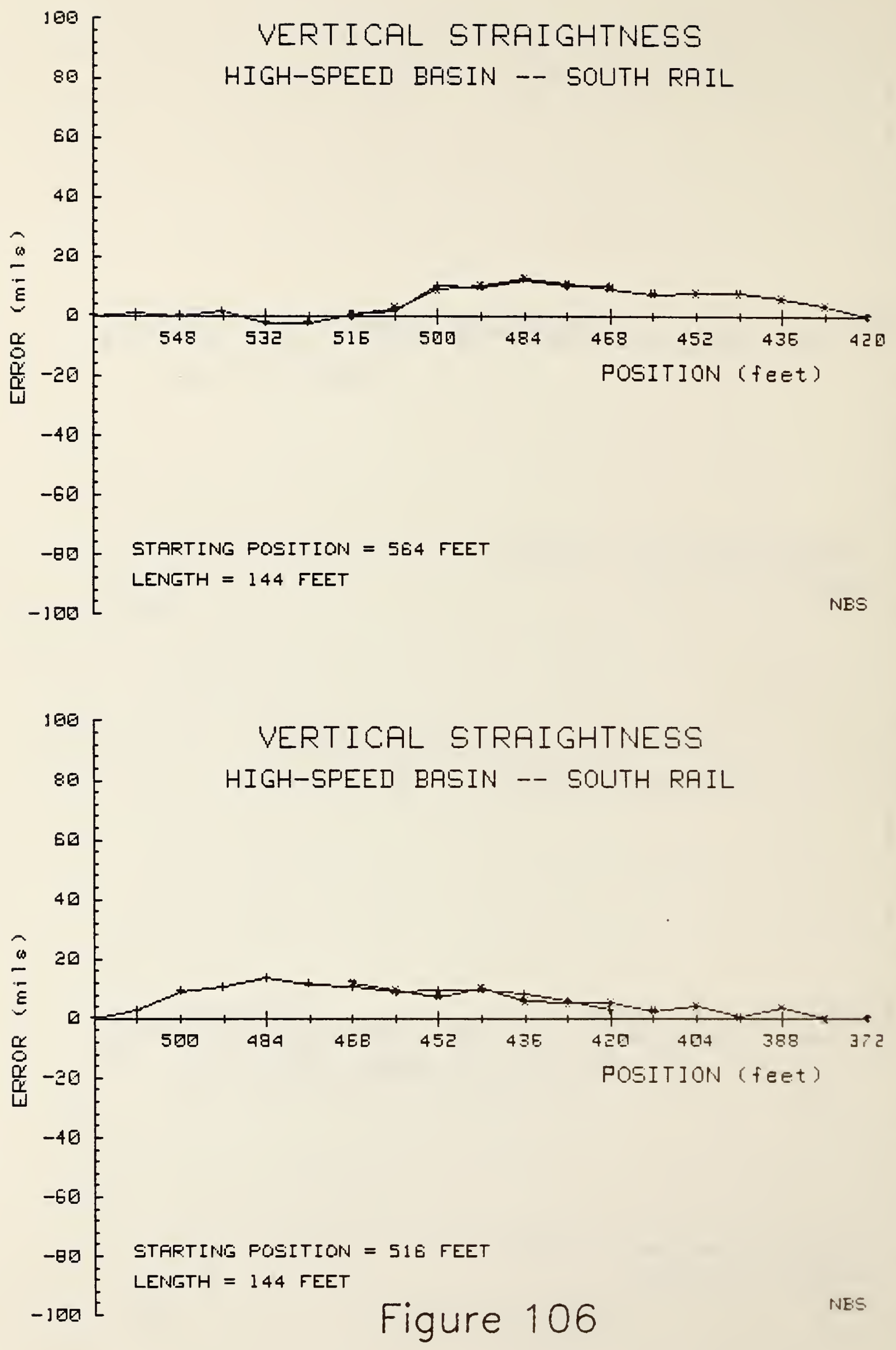

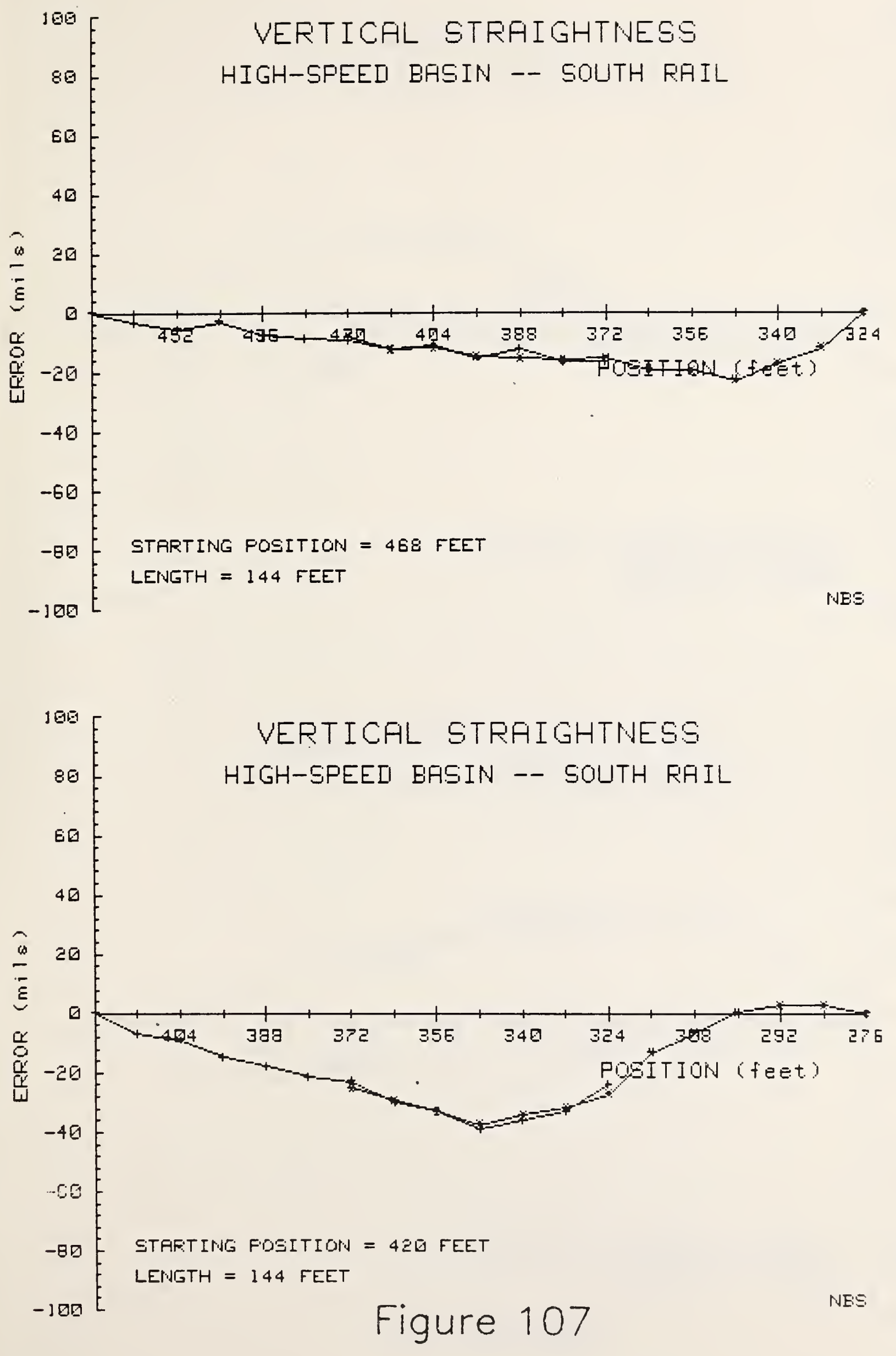

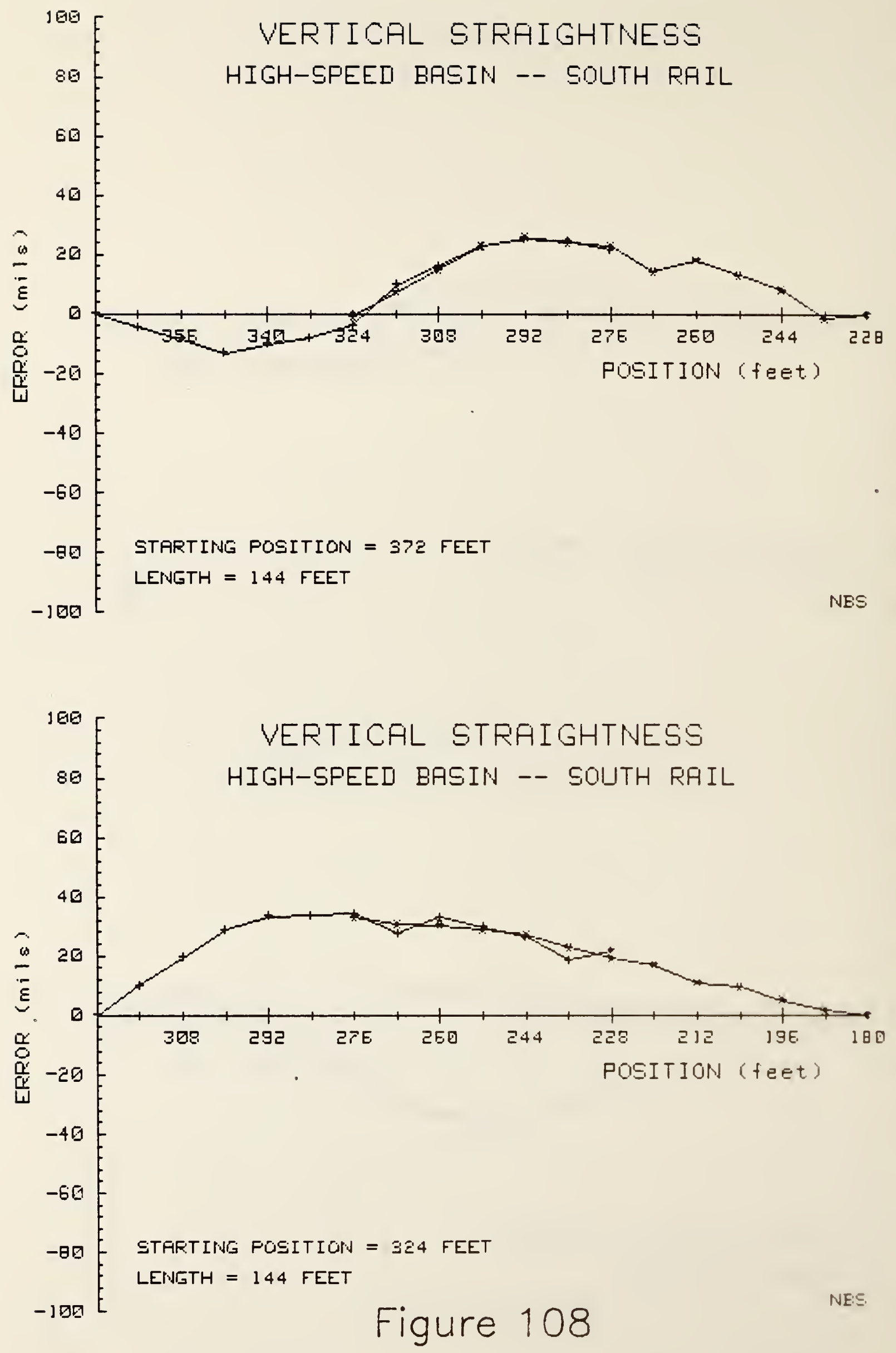

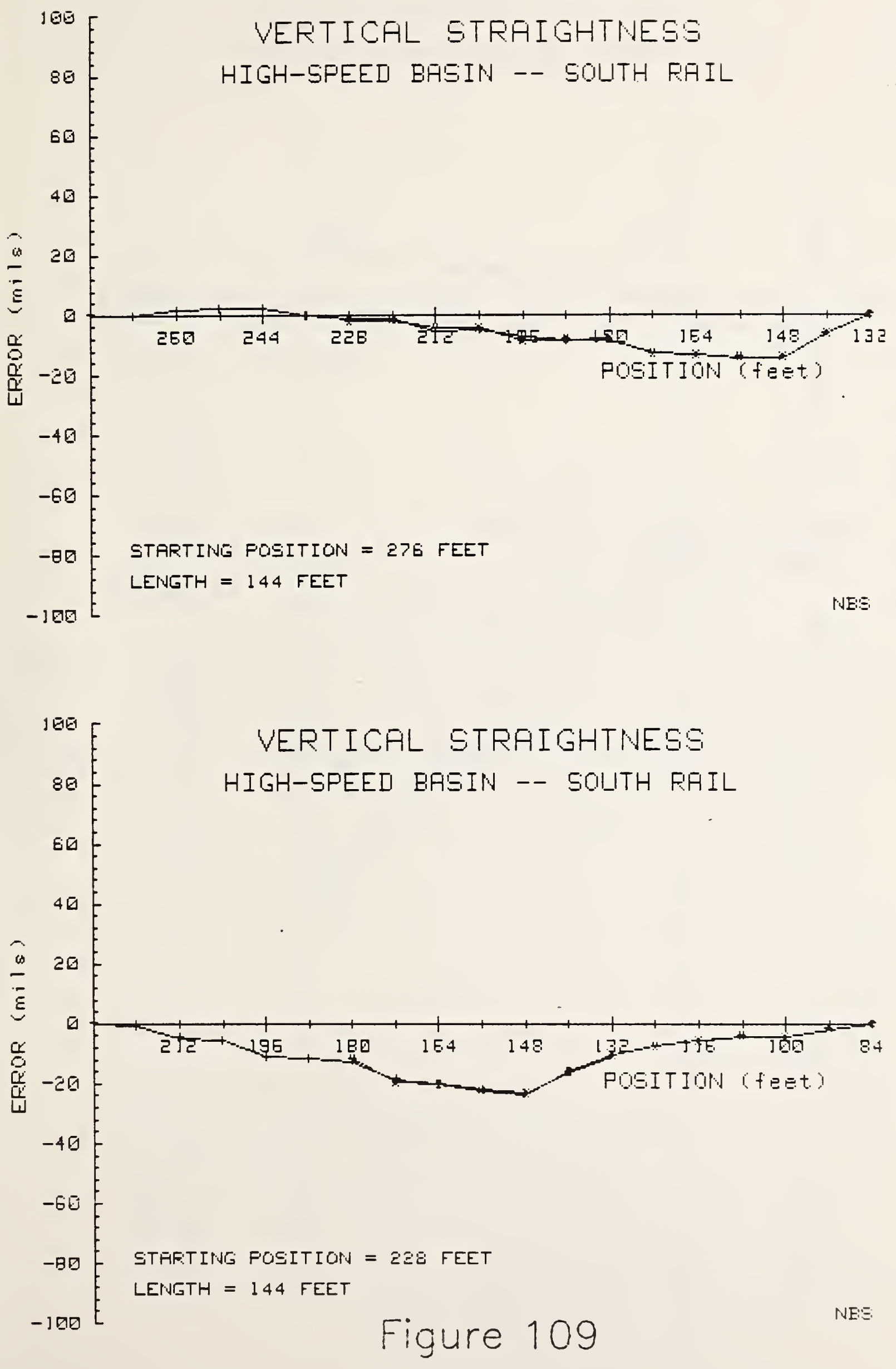


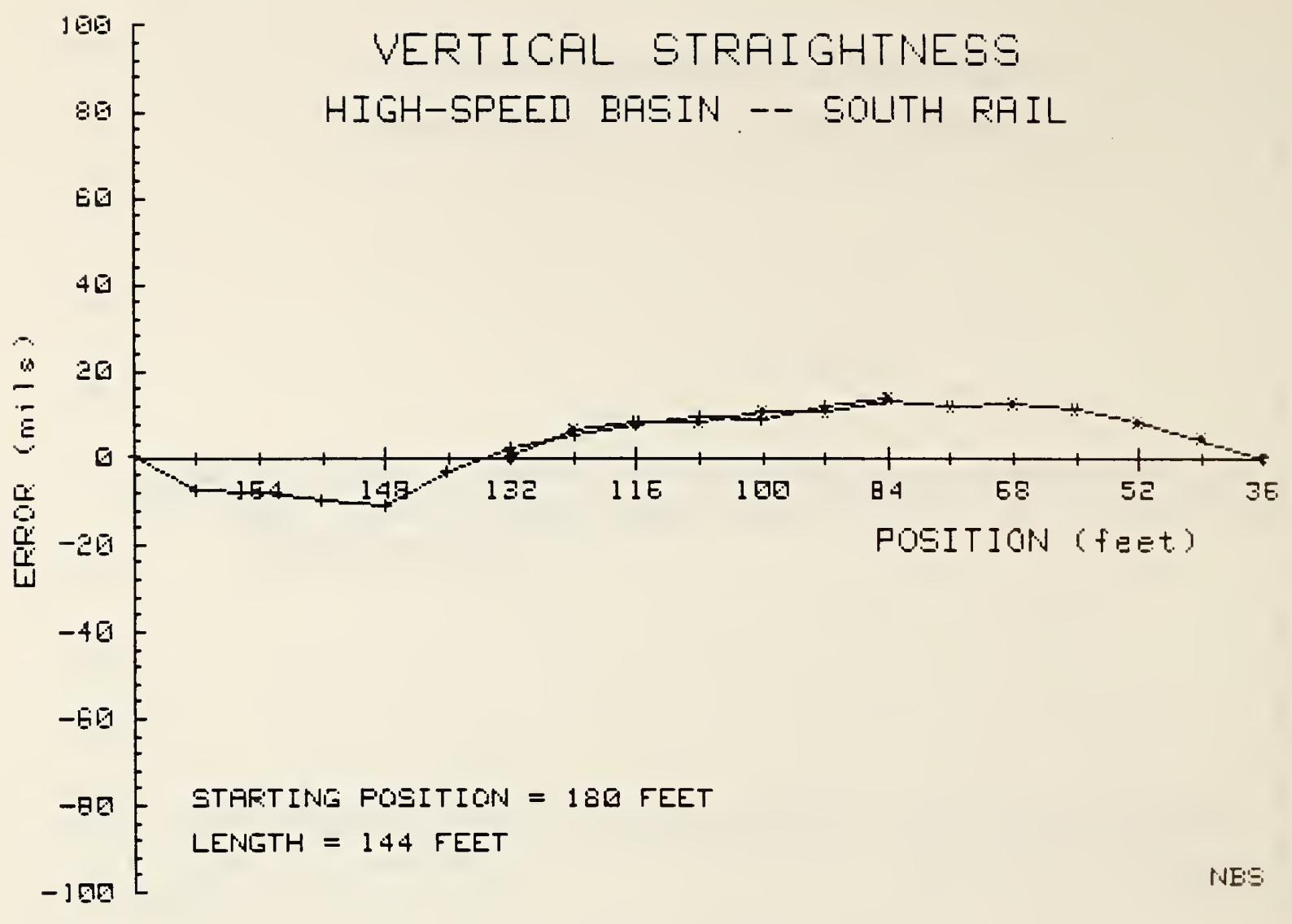

Figure 110 


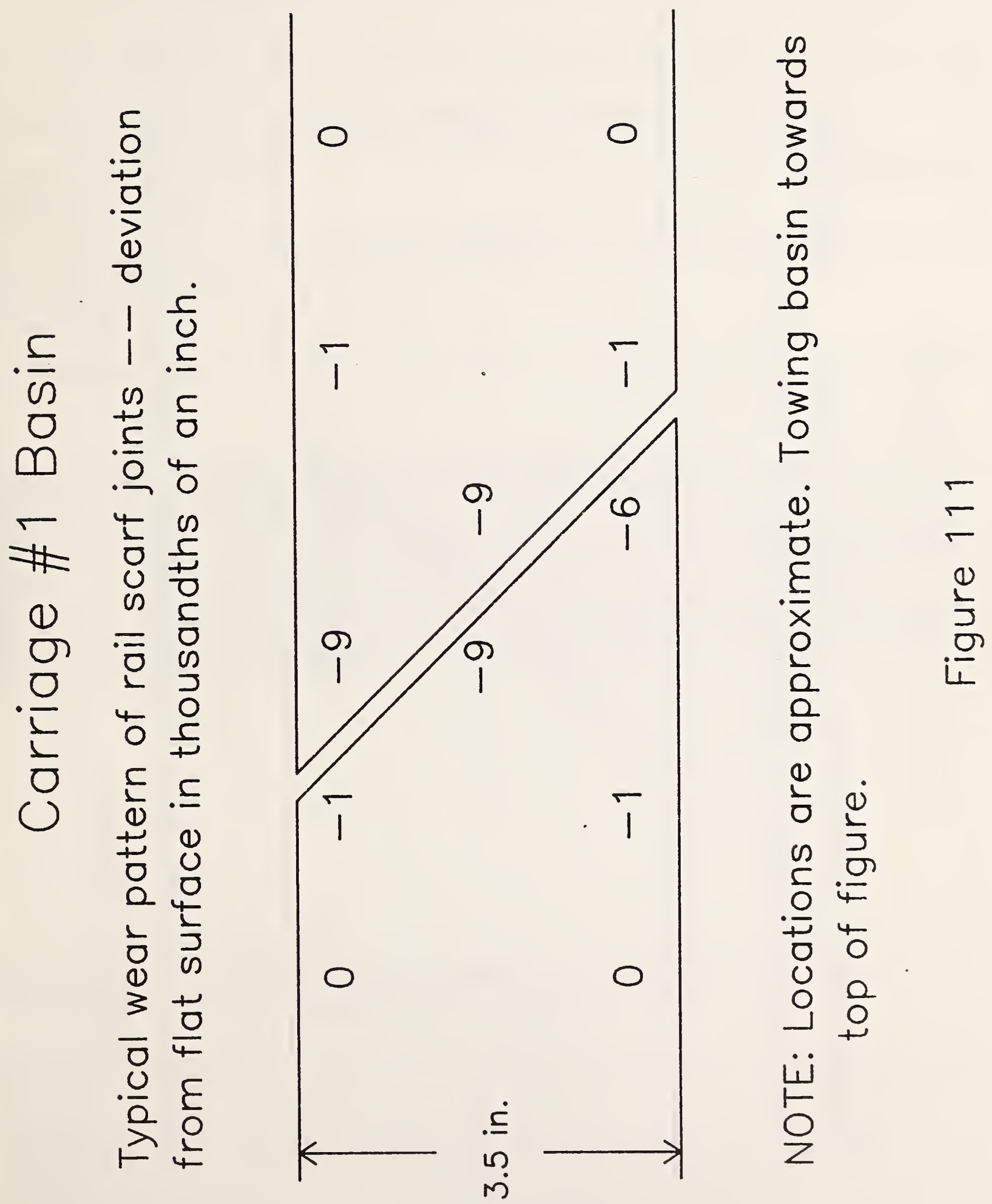




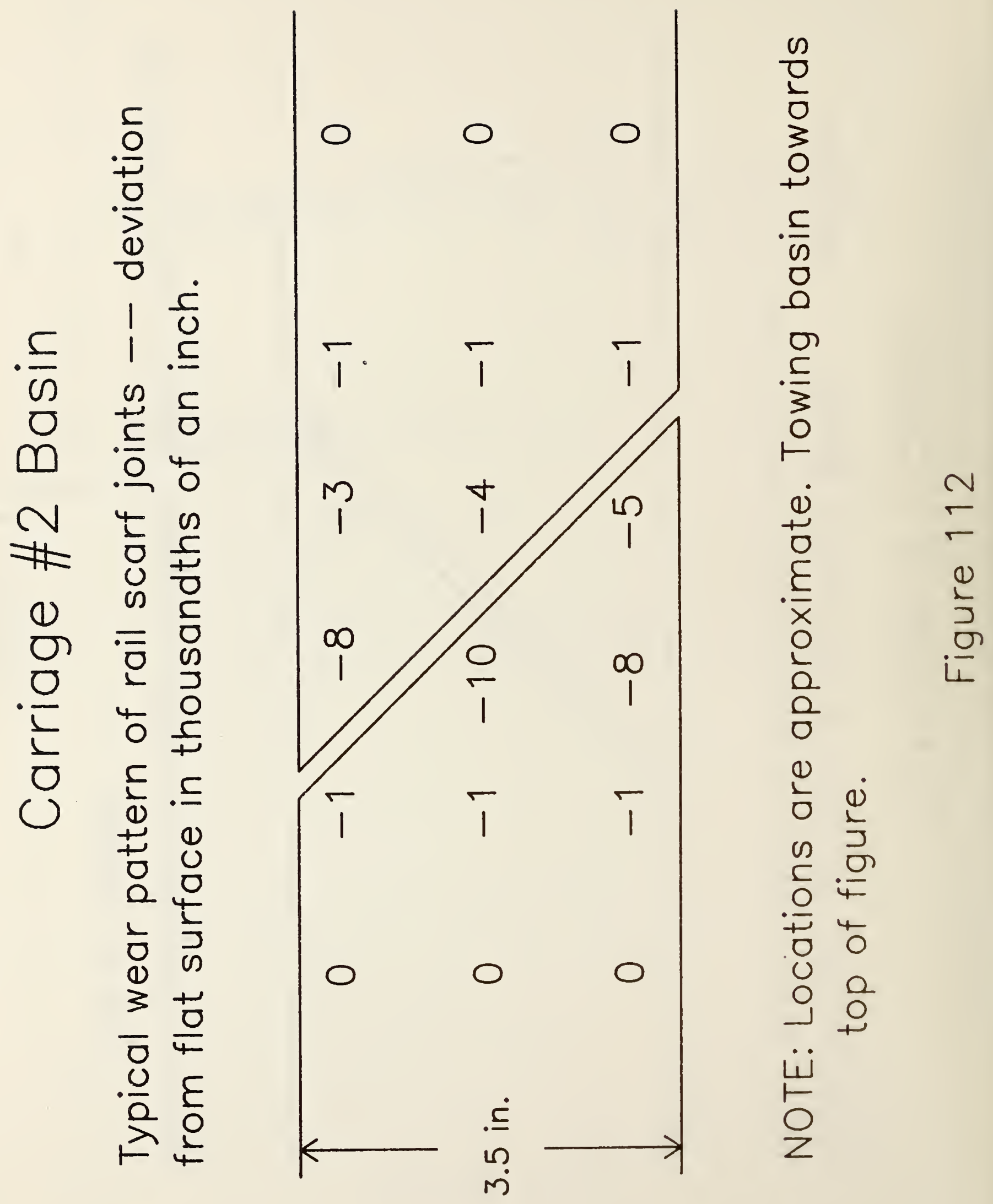


4. TITLE AND SUBTITLE

Rail Straightness Metrology at the David W. Taylor Model Basin

\section{5. $A \cup T H O R(S)$}

W. Tyler Estler, Bruce R. Borchardt, Charles J. Fronczek, Ralph C. Veale

6. PERFORMING ORGANIZATION (If joint or other than NBS, see instructions)

7. ContracUGrant No.

NATIONAL BUREAU OF STANDARDS

DEPARTMENT OF COMMERCE

8. Type of Report \& Period Covered

WASHINGTON, D.C. 20234

9. SPONSORING ORGANIZATION NAME AND COMPLETE ADDRESS (Street. City. State, ZIP)

Department of the Navy

David W. Taylor Naval Ship $R$ \& D Center

Bethesda, MD 20084

10. SUPPLEMENTARY NOTES

Document describes a computer program; SF-185, FIPS Software Summary, is attached.

11. ABSTRACT (A 200-word or less foctual summary of most significant information. If document includes a significant bibliography or literature survey, mention it here)

We present results of field measurements of the horizontal and vertical straightness errors of three drive rails at the David Taylor Naval Ship Research and Development Center. The three measured rails are the main rails of Basin No. 1 ( 1008 feet) and Basin No. 2 (1296 feet), and the South rail of the High-Speed Basin (2640 feet). In addition to the straightness measurements, we also conducted a brief series of local flatness measurements near the scarf joints on Basins 1 and 2 . These joints show a very systematic pattern of wear.

12. KEY WORDS (Six to twelve entries: alphabetical order: capitalize only proper names; and separate key words by semicolons) alignment, metrology, straightness, towing basins

\section{AVAILABILITY}

[X] Unlimited

$\square$ For Official Distribution. Do Not Release to NTIS

$\square$ Order From Superintendent of Documents, U.S. Government Printing Office, Washington, D.C. 20402.

[X] Order From National Technical Information Service (NTIS), Springfield, VA. 22I6I
14. NO. OF

PRINTED PAGES

$$
125
$$

15. Price 


